\title{
Repression of PHLPP by miR-190 Contributes to Arsenic-Induced Akt Activation and Carcinogenesis
}

\author{
Kevin John Beezhold \\ West Virginia University
}

Follow this and additional works at: https://researchrepository.wvu.edu/etd

\section{Recommended Citation}

Beezhold, Kevin John, "Repression of PHLPP by miR-190 Contributes to Arsenic-Induced Akt Activation and Carcinogenesis" (2011). Graduate Theses, Dissertations, and Problem Reports. 3421.

https://researchrepository.wvu.edu/etd/3421

This Dissertation is protected by copyright and/or related rights. It has been brought to you by the The Research Repository @ WVU with permission from the rights-holder(s). You are free to use this Dissertation in any way that is permitted by the copyright and related rights legislation that applies to your use. For other uses you must obtain permission from the rights-holder(s) directly, unless additional rights are indicated by a Creative Commons license in the record and/ or on the work itself. This Dissertation has been accepted for inclusion in WVU Graduate Theses, Dissertations, and Problem Reports collection by an authorized administrator of The Research Repository @ WVU.

For more information, please contact researchrepository@mail.wvu.edu. 


\title{
Repression of PHLPP by miR-190 Contributes to Arsenic-Induced Akt Activation and Carcinogenesis
}

\author{
Kevin John Beezhold \\ Dissertation submitted to the School of Medicine at West Virginia University in partial \\ fulfillment of the requirements for the degree of \\ Doctor of Philosophy \\ In \\ Cancer Cell Biology
}

Michael Ruppert, PhD, Chair

Yehenew Agazie, PhD

Vincent Castranova, PhD

Karen Martin, PhD

Fred Minnear, $\mathrm{PhD}$

Fei Chen, PhD, Mentor

Cancer Cell Biology Program

Morgantown, West Virginia

2011

Keywords: Akt, arsenic, microRNA, miR-190, PHLPP, carcinogenesis, lung cancer, epithelial cells. 


\begin{abstract}
Arsenic-Induced miR-190 Enhances Akt Activation and Carcinogenesis through DownRegulation of PHLPP Expression
\end{abstract}

\title{
Kevin John Beezhold
}

Arsenic is a well-studied human carcinogen. The mechanism by which arsenic induces cancer, however, is not fully understood. It is known that as a general stress inducer, arsenic can activate kinases, such as mitogen-activated protein kinases, leading to over activation of transcription factors. These transcription factors, including AP-1, NF- $\mathrm{kB}$ and Myc, are known to regulate the expression of early response genes, and likely to regulate miRNAs. The expression of miRNAs is often altered in cancer and other proliferative disorders. It is highly probable that miRNAs whose expressions are altered by arsenic will play a significant role in carcinogenesis. To test this hypothesis, we investigated: (1) the role of arsenic in the generation of miRNAs in the human bronchial epithelial cell line, BEAS-2B, using a microRNA array; (2) detailed the concentration-dependent regulation of the selected individual miRNA, such as miR-190, by arsenic using real-time PCR; (3) co-transcription of the intronic miRNA, miR-190, and its host gene, talin2, by a dual luciferase reporter gene assay and real-time PCR; (4) the potential target genes of miR-190 using in silico analysis, western blot, and 3'UTR reporter assays, and (5) the overall carcinogenic potential or cellular responses to arsenic-induced miR-190 through transient and stable overexpression of miR-190, followed by analytical tests such as western blot, proliferation assay and soft agar assay. The data obtained from this study show that arsenic is capable of inducing expression of several miRNAs, most remarkably miRNA-190 whose expression correlated with that of its host gene talin 2. In silico analysis of possible miR-190 targets indicated that this miRNA may be involved in tumor formation by targeting multiple proteins including PHLPP, an Akt phosphatase, and TP53INP1, a key cell apoptosis regulator. PHLPP is a known tumor suppressor that inactivates Akt by dephosphorylating serine 473, leading to decreased cell growth and enhanced apoptosis. PHLPP reporter assays indicate that miR-190 is a genuine PHLPP repressor that binds to the 3'UTR of the PHLPP mRNA. Kinase activation analysis demonstrated that miR-190 is able to mediate arsenic-induced Akt activation in a PHLPP dependant manner. Furthermore, overexpression of a miR-190 precursor could enhance the expression of VEGF, a growth factor downstream of Akt signaling responsible for enhancing tumor growth through neoangiogenesis and epithelial cell proliferation. Stable over expression of miR-190 led to an increase in colony number and size in a soft agar assay. This increase in colonies was accompanied by an increase in basal Akt phosphorylation and VEGF expression.

Taken together, these data suggest that arsenic is capable of inducing expression of miRNAs that may play critical roles in arsenic-induced carcinogenesis. Specifically, arsenicinduced miR-190 expression led to increased Akt activation and overall proliferation through repression of PHLPP. Accordingly, these findings not only revealed a novel mechanism of arsenic-induced carcinogenesis but also highlight a pathway which may be a good target for therapeutic intervention. Inhibiting miR-190 would lead to an elevated expression of PHLPP 
which inactivates Akt, and consequently, reduces potential for the malignant transformation of cells or the tumorigenesis of the transformed cells. 


\section{TABLE OF CONTENTS}

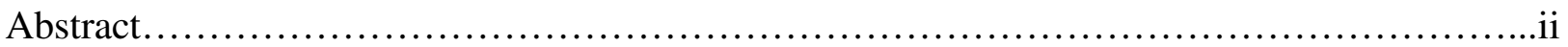

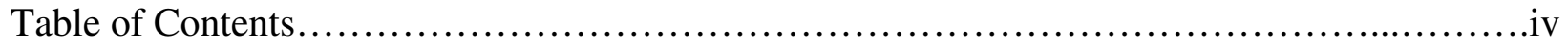

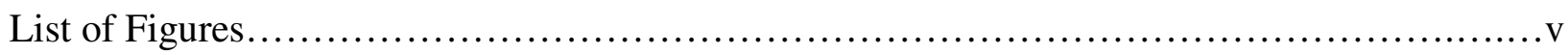

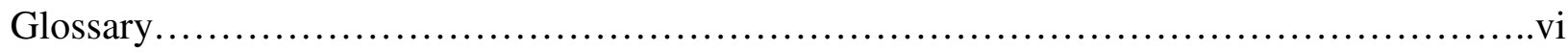

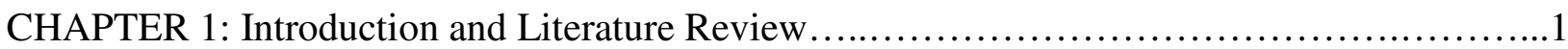

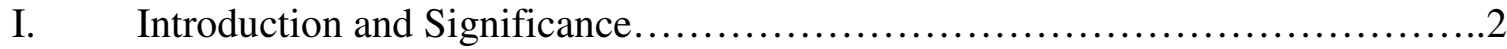

II. Arsenic Exposure and Functions........................................2

III. MicroRNA Expression, Regulation and Function............................

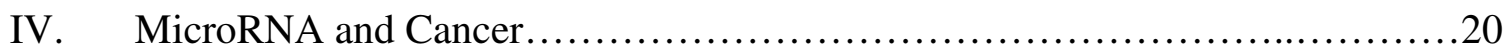

V. A Case for MicroRNA-190 in Arsenic-Induced Cancer.......................24

VI. PHLPP Expression and Regulation.......................................27

VII. Akt Activation and Cancer............................................. 30

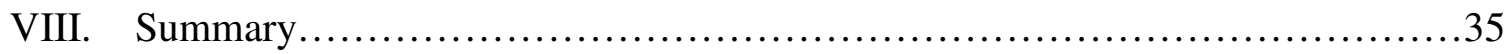

CHAPTER 2: miR-190-Mediated Downregulation of PHLPP Contributes to Arsenic-Induced Akt Activation and Carcinogenesis......................................52

CHAPTER 3: RT-PCR for miRNA Target Identification: A Preliminary Study................92

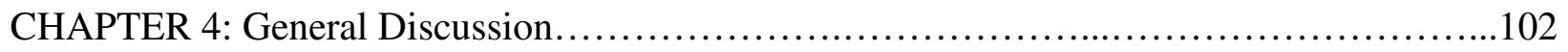

APPENDIX A.................................................................... 117

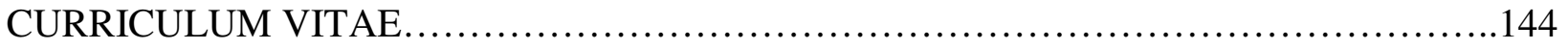




\section{LIST OF FIGURES}

\section{Introduction and Literature Review}

1. Biotransformation of inorganic arsenic in mammalian systems

2. Schematic representation of miRNA biogenesis and function

3. Modulation of microprocessor function.

\section{miR-190-mediated downregulation of PHLPP contributes to arsenic-induced Akt activation and carcinogenesis}

1. Exposure to arsenite does not alter miR-155 expression in BEAS-2B cells

2. MicroRNA-155/BIC promoter activity

3. $\mathrm{As}^{3+}$ regulates the expression of miRNAs

4. Talin 2 expression in response to $\mathrm{As}^{3+}$

5. miR-190 targets PHLPP

6. Overexpression of miR-190 enhances $\mathrm{As}^{3+}$-induced Akt phosphorylation and VEGF generation

7. Stable expression of miR-190 enhances cell proliferation and carcinogenic transformation.

Table S1. As3+ exposure changes miRNA expression

S1. As3+ induces miR-190 expression in human primary SAEC cells.

S2. miR-190 targets TP53INP1

S3. miR-190 has no effect on the control of the p-MIR REPORT vector.

\section{General Discussion}

1. Reverse-transcriptase PCR for miRNA target identification

2. Sequence alignment of the sequencing results for PCR product 4 (priming site 2) with the MT-CO1 mRNA sequence 


\section{GLOSSARY}

AC6 Adenylyl cyclase 6

Acr3p Yeast plasma membrane anti-porter

Ago

Argonaute protein

AGO2

Argonaute protein 2

AGO3

Argonaute protein 3

Akt

Protein kinase B

AMP

Adenosine monophosphate

AP-1

Activator protein-1

AQP7

Aquaporin 7

AQP9

Aquaporin 9

ARE

AU-rich element

Ars2

Arsenate resistance protein 2

ATP

Adenosine triphosphate

BAD

BCL-2 associated death promoter

BCL2

B-cell lymphoma protein 2

BDNF Brain derived neurotrophic factor

BIC B-cell integration cluster

BMP4 Bone morphogenic protein 4

CAF1 Chromatin assembly factor 1

CAT-1 Cool-associated tyrosine phosphorylated 1

CCR4 C-C chemokine receptor type 4

ChIP Chromatin immunoprecipitation

CLL Chronic lymphocytic leukemia

c-MYC Cellular-myelocytomatosis oncogene

c-SRC Cellular Src tyrosine kinase

CXCR4 C-X-C chemokine receptor type 4

Cys Cysteine

DCP1:DCP2 Decapping1:Decapping2

DGCR8 DiGeorge syndrome critical region 8

DMA(III) Dimethyl arsinous acid

DMA(V) Dimethylarsinic acid

DNA Deoxyribonucleic acid

Dnd1 Dead end 1

Drosha A Class 2 RNase III enzyme

E2F2 E2F transcription factor 2

EGF Epidermal growth factor

EGFR Epidermal growth factor receptor

eIF Eukaryotic initiation factor

eIF4E Eukaryotic initiation factor 4E 


\begin{tabular}{ll} 
eIF4F & Eukaryotic initation factor 4F \\
eIF6 & Eukaryotic initation factor 6 \\
ELISA & Enzyme linked immunosorbent assay \\
eNOS & Endothelial nitric oxide synthase \\
ERK & Extracellular signal-related kinase \\
Erk2 & Extracellular signal-related kinase 2 \\
ER $\alpha$ & Estrogen receptor alpha \\
FBS & Fetal bovine serum \\
FERM & 4.1 protein exrin radixin and moesin \\
FKBP51 & FK506-binding protein 51 \\
FOXO3A & Forkhead box O3a transcription factor \\
FPS1 & Yeast aquaporin \\
FXR1 & Fragile X mental retardation-related protein 1 \\
GADD45 & Growth arrest and DNA damage protein 45 alpha \\
GDP & Guanosine diphosphate \\
GlpF & Glycerol facilitator \\
Grb2 & Growth factor receptor-bound protein 2 \\
GSH & Glutathione \\
GSK-3 $\alpha$ & Glycogen synthase kinase 3 alpha \\
GSTP1-1 & Glutathione S-transferase P1-1 \\
GTP & Guanosine-5'-triphosphate \\
GW182 & Glycine-tryptophan repeat protein with molecular mass of 182 kD \\
HCV & Hepatitis C virus \\
HDM2 & Human MDM2 \\
HER-2 & Human epidermal growth factor receptor 2 \\
HER-3 & Human epidermal growth factor receptor 3 \\
HIF1alpha & Hypoxia inducible factor 1 alpha \\
HMGA2 & High mobility group AT- hook 2 \\
HuR protein & AU-rich element RNA binding protein \\
IARC & International Agency of Research on Cancer \\
IGF-1 & Insulin-like growth factor 1 \\
IKKalpha & Inhibitor of kappaB kinase alpha \\
IRES & Internal ribosome entry site \\
JNK & Jun N-terminal kinase \\
Limk1 & Lim domain kinase 1 \\
LNA & Locked nucleic acid \\
MAP & Mitogen activated protein \\
MDM2 & Murine double minute 2 \\
MeCP2 & Methyl-CpG binding protein 2 \\
MEK & Mitogen activate protein kinase \\
\hline &
\end{tabular}




\begin{tabular}{|c|c|}
\hline miRNA & MicroRNA \\
\hline $\operatorname{miRNP}$ & miRNA ribonucleoprotein complex \\
\hline MMA(III) & Monomethy arsonous acid \\
\hline MMA(V) & Monomethyl arsonate \\
\hline MRE & MicroRNA recognition element \\
\hline MRP1 & Multidrug resistance protein 1 \\
\hline MRP2 & Multidrug resistance protein 2 \\
\hline Mst1 & Mammailan sterile 20-like kinase 1 \\
\hline mTOR & Mammalian target of rapamycin \\
\hline MYC & Myelocytomatosis oncogene \\
\hline MYCN & Myelocytomatosis viral related oncogene neuroblastoma derived \\
\hline NADPH & Nicotinamide adenine dinucleotide phosphate \\
\hline NeuroD & Neurogenic differentiation 1 \\
\hline $\mathrm{NF}-\kappa \mathrm{B}$ & Nuclear factor- kappa B \\
\hline NO & Nitric oxide \\
\hline NT & Nucleotide \\
\hline OSHA & Occupational Safety and Health Administration \\
\hline p27Kip1 & Cyclin-dependant kinase inhibitor 1B \\
\hline p53 & Tumor protein 53 \\
\hline p68 & DEAD box protein p68 \\
\hline p72 & DEAD box protein p 72 \\
\hline PACT & PKR activating protein \\
\hline PARP-1 & Poly (ADP)-ribose polymerase 1 \\
\hline PAZ & Piwi/Argonaute/Zwille \\
\hline PCR & Polymerase chain reaction \\
\hline PDCD4 & Programmed cell death 4 \\
\hline PDGF & Platelet derived growth factor \\
\hline PDK1 & Pyruvate dehydrogenase kinase isozyme 1 \\
\hline PHLPP & PH-domain and leucine rich repeat protein phosphatase \\
\hline PIP3 & Phosphatidylinositol $(3,4,5)$-triphosphate \\
\hline PIP5KI & Phosphatidylinositol-4-phosphate-5-kinase I \\
\hline PKA & Protein kinase $\mathrm{A}$ \\
\hline PKB & Protein kinase B (Akt) \\
\hline $\mathrm{PKC}$ & Protein kinase $\mathrm{C}$ \\
\hline PML & Promyelocytic leukemia \\
\hline PPARgamma & Peroxisome proliferator-activator receptor gamma \\
\hline Pre-miRNA & Precursor miRNA \\
\hline Pri-miRNA & Primary miRNA \\
\hline PTEN & Phosphatase and tensin homolog \\
\hline PTP & Protein tyrosine phosphatase \\
\hline
\end{tabular}




\begin{tabular}{ll} 
PUMA & p53 upregulated modulator of apoptosis \\
Ran & RAs-related nuclear protein \\
Ras & Rat sarcoma protein \\
RhoA & Ras homolog gene family, member A \\
RISC & RNA-induced silencing complex \\
RNA & Ribonucleic acid \\
RNA pol II & RNA polymerase-II \\
RNase & Ribonuclease \\
ROS & Reactive oxygen species \\
RRM & RNA recognition motif \\
rRNA & Ribosomal ribonucleic acid \\
R-SBE & RNA Smad binding element \\
RTK & Receptor tyrosine kinase \\
RT-PCR & Real-time PCR \\
SAEC & Small airway epithelial cells \\
SBE & Smad binding element \\
SCOP & Suprachiasmatic nucleus circadian oscillatory protein \\
Shc & Src homology 2 domain-containing protein \\
Smad & Intracellular protein responsive to transforming growth factor beta signaling \\
SOCS1 & Suppressor of cytokine signaling 1 \\
Src & Src tyrosine kinase \\
STAT3 & Signal transducer and activator of transcription 3 \\
TGF- $\beta$ & Transforming growth factor beta \\
TNRC6C & Trinucleotide repeat containing 6C \\
TP53INP1 & Tumor protein 53 induced nuclear protein 1 \\
TPM1 & Tropomyosin alpha \\
TRBP & TAR RNA-binding protein \\
TRIM32 & Tripartite motif-containing protein 32 \\
TRIM-NHL & Tripartite motif containing protein family \\
TSS & Transcriptional start site \\
UTR & Untranslated region \\
UV & Ultraviolet \\
VEGF & Vascular endothelial growth factor \\
WHO & World Health Organization \\
XIAP & X-linked inhibitor of apoptosis \\
XRN1 & 5 '-3' exoribonuclease 1 \\
Ycf1p & Yeast ABC transporter \\
YY1 & Yin Yang 1 \\
ß-TrCP & Beta-transducing repeat containing protein \\
& \\
\hline
\end{tabular}




\section{CHAPTER 1}

\section{Introduction and Literature review}




\section{Introduction and Significance:}

The development of human cancers following environmental or occupational exposure to arsenic is an issue of significant concern. Residing or working in environments in which there are high concentrations of arsenic is significantly associated with increased cancer risk. Understanding how these malignancies develop is necessary for proper treatment after development of the disease and potentially may lead to prophylactic mechanisms where arsenic exposure cannot realistically be limited. Arsenic-induced cancers are thought to be mediated by activation of biological pathways involved in tumorigenesis. The discovery of a class of small RNAs known as microRNAs (miRNA) introduced a new paradigm in thinking about protein synthesis and expression. miRNA are small cellular regulators which can either drastically or subtly alter the expression of proteins in biologically relevant ways. They have been identified as key regulators of cell differentiation as well as cancer initiation and progression. Understanding how the expression of miRNAs are altered by arsenic exposure will provide important insights to how arsenic induces carcinogenesis and may provide clues as to how these malignancies may be treated.

\section{Arsenic Exposure and Functions:}

\section{Epidemiology:}

Arsenic is a common element found in nature including soil, rocks, water, air, etc. While high dose exposure to arsenic is lethal, low dose exposure over a long period of time has proved to be carcinogenic in humans. The International Agency for Research on Cancer (IARC) and the World Health Organization (WHO) have classified arsenic as a group I human carcinogen. People who live in areas with high levels of arsenic in the drinking water or work where arsenic 
exposure is common are more prone to develop cancers of the skin, lung, liver, kidney, and bladder [1]. While the carcinogenicity of arsenic in laboratory animals was once controversial [2], a growing body of evidence supports this concept in experimental models using multiple rodents and multiple routes of exposure [3]. The route of entry for arsenic would appear to be related with the origin of the malignancy; e.g., frequent foot contact with arsenic-containing soil causes skin cancer, inhalation of air or dusts mixed with arsenic induces lung cancer or bladder cancer, and ingestion of arsenic-contaminated drinking water may result in liver or kidney cancers. This may not always be the case. Some work has shown that the increased risk of lung cancer is largely independent of route of entry, with the mortality rate ratio estimate being comparable between inhalation and ingestion [4]. Additionally, if arsenic is acting as a cocarcinogen, with UV radiation for example, ingested arsenic could lead to increased skin cancer risk [5]. In lung cancer, relatively low levels have been observed to increase risk to lung cancer. In a study of populations living near smelting plants in Japan, concentrations of arsenic in the air as low as $1.77 \mathrm{ng} / \mathrm{m}^{3}$ produced a significant increase in the standard mortality rate of lung cancer [6]. This concentration is considerably lower than the OSHA permitted exposure level of 10 $\mu \mathrm{g} / \mathrm{m}^{3}$ over an 8-hour time weighted average (OSHA occupational safety and health standards). All of these observations support the notion that environmental or occupational exposure to arsenic poses a significant risk for developing cancer. Understanding how this occurs is crucial to treating arsenic-induced disease and may provide insights into the development and treatment of other diseases associated with environmental exposure.

\section{Arsenic Biochemistry; Uptake:}

The major environmental arsenic species include arsenate (arsenic pentoxide, $\mathrm{H}_{3} \mathrm{AsO}_{4}$ ) and arsenite (arsenite trioxide, $\left.\mathrm{As}_{3}(\mathrm{OH})_{3}\right)$. At physiological $\mathrm{pH}$, arsenate can be reduced to 
arsenite which is credited with most of the intracellular and pathological effects. The uptake of arsenite into both prokaryotic and eukaryotic cells has been shown to be achieved by aquaglyceroporin proteins, which are members of the aquaporin family. Aquaporin proteins are responsible for the flow of water in and out of cells and some of which are capable of transporting additional molecules in concert with water. In E. coli, the protein likely to be responsible for arsenite transport is GlpF. GlpF is a glycerol facilitator that is capable of transporting antimonite, a metalloid with properties similar to arsenite [7]. The mammalian aquaglycerporin proteins responsible for arsenite uptake into cells are AQP7 and AQP9. Liu Z. et al. showed the functionality of these proteins to transport arsenite by cloning of AQP9 and microinjection of AQP7 [8]. AQP9 was cloned into strains of S. cerevisiae that had FPS1 (Arsenite uptake) and Acr3p and Ycf1p (Arsenite efflux) deleted or mutated. AQP9 was then capable of making the mutated strains more sensitive to arsenite exposure. Expression of AQP7 was unable to be achieved in the $S$. cerevisiae system. Instead, capped cRNA of AQP7 was microinjected into Xenopus oocytes and enabled dramatic uptake of arsenite. This finding suggests that mutation or loss of these transporters in human cells could make an individual more susceptible or resistant to arsenic exposure, increasing cancer risk or reducing treatment efficacy in the case of acute promyelocytic leukemia.

\section{Arsenic Metabolism:}

After arsenic is taken up, it is metabolized by the cell which includes methylation, reduction, oxidation, sequestration and efflux. Following these steps, as many as six different arsenic species can exist including arsenate, arsenite, monomethylarsonate (MMA(V)), monomethylarsonous acid (MMA(III)), dimethylarsinic acid (DMA(V)), and dimethylarsinous 
acid (DMA(III)) [9] (Fig. 1). Arsenate is reduced to arsenite before it can be sequestered or eliminated, which is achieved by arsenate reductase enzymes. While reduction of arsenate in mammalian organisms is not as well understood as bacterial or yeast systems, recent research has identified the reductases responsible for metabolism and subsequent elimination in human cells. One such protein is the enzyme purine nucleotide phosphorylase, also called arsenate reductase, which was isolated from human liver extract and was capable of reducing arsenate [10]. This reduction occurs in the presence of an inosine and a thiol compound.

\section{Arsenic Export:}

The export of arsenic from mammalian cells is achieved by human multidrug resistance protein 1 (MRP1/ABCC1) and 2 (MRP2/ABCC2). They are members of a superfamily of transport proteins known as the ATP binding cassette superfamily. The MRP proteins export many different substrates, which are usually stimulated by the presence of glutathione (GSH) that is co-transported with or conjugated to the substrate. The ability to export arsenic was originally described by Cole et al. while demonstrating the ability of MRP to confer resistance to multiple drugs [11]. The efflux of drugs by MRP was later shown to be catalyzed by the presence of GSH within cells [12]. Depletion of GSH from cells was able to reverse the resistance conferred by MRP overexpression in cell lines. Additionally, arsenite was observed to cause an MRP-mediated release of GSH from cells. The MRP1-mediated arsenite efflux from cells mediated via MRP1 was later shown to be dependent upon the presence of GSH $S$-transferase P1-1 (GSTP1-1) [13]. This protein catalyzed the formation of arsenic triglutathione $\left(\mathrm{As}(\mathrm{GS})_{3}\right)$ which was efficiently eliminated from cells. Cells without GSTP1-1 could not transport arsenite out of the cell regardless of the presence of GSH. Arsenite is then filtered by the kidneys and 
stored in the bladder before elimination. As arsenite is more bioactive than arsenate, the bladder is a common site of arsenic-induced carcinogenesis.

\section{Carcinogenic Functions:}

There are three main mechanisms by which the various arsenic species are capable of interacting with biological systems to induce carcinogenesis. Arsenic species are known to generate reactive oxygen species but not reactive nitrogen species [14]. They can also change the methylation state of DNA, leading to either hypermethylation or hypomethylation. Finally trivalent arsenic species are able to bind to sites on peptides and proteins, commonly sulfhydryl groups [15].

One of the more recently discovered mechanisms of carcinogenesis for arsenic within cells is its ability to bind to zinc finger domains. Arsenic competitively binds to cysteine residues within the zinc fingers inhibiting functions that would normally be active when zinc is bound. This has been demonstrated by analysis of the inhibition of arsenite on poly (ADP-ribose) polymerase 1(PARP-1)-mediated DNA damage repair [16]. Arsenite was shown to compete with zinc for binding to the cysteine residues of the zinc finger domain of PARP-1. This competitive binding leads to the inhibition of PARP-1 activity, and an increase in the amount of ultraviolet radiation-induced 8-hydroxyl-2'-deoxyguanine DNA lesions. This resulted in an increase in carcinogenesis of skin cell lines indicating a mechanism for the co-carcinogenesis of arsenic with ultraviolet radiation. This is an important discovery that indicates additional roles for arsenic as a zinc finger domain binder, and it will be interesting to see what additional zinc finger proteins arsenic may bind. 
One signaling protein indicated to be involved in arsenic induced carcinogenesis is ERK. A crucial study that indicated this activity was performed by Huang et al.[17]. They showed that doses of arsenite from $0.8 \mu \mathrm{M}$ to $200 \mu \mathrm{M}$ were capable of activating ERK in mouse epidermal cells. They further showed that it was this ERK activation that was critical for the induction of cell transformation. When dominant negative ERK2 was expressed, there was a dramatic reduction in cell transformation in response to arsenic exposure [17]. The mechanism by which arsenic activates ERK appears to be through the Epidermal Growth Factor Receptor (EGFR) and associated pathways. Arsenite does not activate EGFR through ligand binding, but through the alternate mechanism of c-Src activation [18]. This activation of Src may be due to the sulfhydryl binding activity of arsenite, binding to an inhibitory phosphotyrosine residue causing oxidation, and consequent activation of Src. Active Src can then bind to EGFR promoting phosphorylation and activation of the receptor [18]. Downstream of EGFR activation is the activation of the adaptor proteins Grb2 and Shc. Activation of these proteins by arsenic has also been observed and are directly responsible for the activation of the MAP kinase cascade upstream of ERK [19]. Active ERK is also known to activate several transcription factors involved in cell survival and proliferation including the proto-oncogene c-myc.

A second kinase that has been studied as having a relationship to arsenic-induced carcinogenesis is JNK and its downstream transcription factor AP-1. Early studies examining arsenic-induced JNK expression used high doses of arsenic over either short or long time points which induced apoptosis [20-22]. Studies using lower doses showed arsenic-induced JNK activation leads to an increase in GADD45 $\alpha$ expression inducing cell cycle arrest [23, 24]. However, additional studies showed that low dose exposures performed over mid to long term time points (24 hrs-months) was shown to induce activation of JNK and AP-1 and cause 
proliferation and transformation of cells [25]. Additionally, inhibition of JNK in arsenic-trioxide treated human keratinocyte cell line led to an increase in apoptosis, suggesting an anti-apoptotic role of arsenic-induced JNK activation [26].

Arsenic has also been shown to be involved in the activation of Akt. Activation of Akt is one of the most well known anti-apoptotic and proliferative signals within the cell. Akt is activated by phosphorylation on two residues, serine 473 and threonine 308. Elevated expression of the PI3K/Akt pathway is often observed in various cancers including non-small cell lung cancer, breast cancer, and pancreatic cancer [27]. Downstream effectors of Akt have roles in apoptosis inhibition, cell cycle regulation, metabolism, stress response, and protein translation [28]. Negative regulators of the Akt pathway include PTEN and PHLPP. PTEN dephosphorylates PIP3 upstream of Akt, inhibiting recruitment of Akt and PDK1 to the membrane and PHLPP directly dephosphorylates Akt at serine 473 [29]. Phosphorylation of serine 473 by arsenic has been observed in mouse epidermal cells [30] and human bronchial epithelial cells [31]. Activation of Akt by arsenic trioxide has also been observed in leukemic cells where arsenic is used as a therapeutic agent. Inhibition of this activity greatly enhances the sensitivity of the leukemic cells to arsenic-induced apoptosis, enhancing its therapeutic effect [32]. Additionally, long term low dose arsenic exposure $(0.5-2.0 \mu \mathrm{M}$ for 3 mo-1yr) of human small airway epithelial cells showed an increase in phosphorylation of Akt and ERK. While colony number and plating efficiency for these cells were greatly increased, the proliferation rate stayed largely the same compared to control cells [33].

Occupational or environmental exposure to arsenic poses a significant health risk due to its carcinogenic activity. Although arsenic is an established carcinogen, the mechanisms by which tumorigenesis takes place is not fully understood. Further research is required to 
understand the biological activity of arsenic so that diseases caused by arsenic may be more effectively treated.

\section{MicroRNA Expression, Function and Regulation}

The discovery of microRNA (miRNA) revealed a new mechanism for the regulation of gene expression. MiRNAs are short, approximately 22 nucleotide long, RNA molecules which are capable of targeting partially or fully complementary sequences in the 3'UTR of mRNA transcripts. The pairing of miRNA with target mRNA represses the expression of the mRNA leading to reduced protein expression, through various mechanisms. Since their discovery, miRNA have been observed to be involved in nearly every biological process including embryonic development, self renewal of stem cells, immune response, neurological function, and cancer development and progression.

MicroRNA were first discovered in 1993 through the close collaboration of Ambros [34] and Ruvkun [35]. While studying the developmental regulation of LIN-14 protein expression in C. elegans, they found that the lin-4 gene which was known to repress LIN-14 did not encode a protein but a very short RNA sequence. Together they observed within the LIN-14 3'UTR, a sequence partially complementary to the short lin-4 sequence. This observation suggested a mechanism by which repression could occur through antisense binding thereby reducing protein levels. The next miRNA to be discovered was let-7 in early 2000 [36]. Also in C. elegans, this miRNA was observed to have complementary sites in a number of genes including lin- 41 whose repression by let-7 was experimentally validated. Since these two discoveries much work has been done to determine how these short RNAs are produced and processed and how they function. 


\section{Mammalian MicroRNA Biogenesis:}

The biogenesis of miRNA involves three distinct processes including transcription followed by processing in the nucleus and further processing in the cytoplasm. Transcription of miRNA is usually performed by RNA polymerase II creating long RNA transcripts which contain hairpin structure(s) known as primary miRNA (pri-miRNA). The hairpin structures are cleaved from the pri-miRNA to form precursor miRNA (pre-miRNA). This pre-miRNA is exported to the cytoplasm and further processed to form the single stranded mature miRNA (Fig. 2). Each of these steps is highly controlled by multiple regulatory proteins indicating the importance of miRNA expression and function within the cell.

\section{Genomic Organization and Transcription:}

The genes encoding miRNA are characterized into three major categories; intergenic, intronic and exonic [37]. Most miRNAs are considered to be intergenic, meaning they have their own promoter regions. Many of intergenic miRNA can be clustered together forming polycistronic transcription units, encoding multiple miRNAs [38]. Some miRNAs are intronic, that is they are located within the introns of host genes, and are subject to transcriptional control of the host's promoter. The miRNA-containing introns are spliced from the larger RNA before the miRNA is processed further. Exonic miRNAs are the rarest, accounting for approximately $10 \%$, and they must be processed out of the exons of transcripts which likely become non functional [39].

Generation of new mature miRNA molecules begins with transcription of pri-miRNAs

that are typically transcribed by RNA pol II. These transcripts are normally several kilobases in length and contain stem loop structures characterized by a $\sim 33$ nt stem, terminal loop and 
flanking single stranded sequences (Fig.2). The activation of transcription is controlled by pol II associated transcription factors allowing for highly variable miRNA expression depending upon the cellular context [40].

Processing by the Microprocessor and Nuclear Export.

After transcription the stem-loop structures must be cleaved from the RNA transcript, creating the $\sim 70 \mathrm{nt}$ pre-miRNA. This cleavage is performed by the Drosha microprocessor, a complex of proteins including the RNase III enzyme Drosha and DiGeorge syndrome critical region 8 (DGCR8) (Fig. 3). This complex binds to the stem of the pri-miRNA to define the appropriate cleavage site for formation of the pre-miRNA. DGCR8 is believed to bind to the base of the pri-miRNA stem, recognizing the single stranded RNA on both sides, and act as a molecular ruler directing Drosha to cleave 11 base pairs up the stem from the single stranded sequences $[41,42]$. The resulting pri-miRNA stem loop contains a 2 nt $3^{\prime}$ overhang that is typical for RNase III mediated cleavage [43].

After cleavage by the microprocessor the pre-miRNAs are bound to Exportin 5 and are shuttled out of the nucleus in a Ran-GTP dependant manner [44]. The proper length stem, and 3' overhang of the pre-miRNAs are required for Exportin 5 binding and transport [45]. This requirement may ensure that pre-miRNAs with the proper sequence are exported to the cytoplasm. Exportin-5 may also play a role in protecting pre-miRNAs from degradation before export. Reduction in the amount of Exportin 5 results in reduced mature miRNA in the cytoplasm without a buildup of pre-miRNA within the nucleus, suggesting degradation. Once in the cytoplasm Ran-GTP is hydrolyzed to GDP, and the miRNA is released for further processing. 
In some cases miRNAs can avoid the processing step from pri-miRNA to pre-miRNA when the miRNA sequence comprises the entire intron. In this case splicing of the intron from the larger RNA transcript creates the pre-miRNA molecule ready to be transported to the cytoplasm. These miRNAs are referred to as mirtrons [46]. Mirtrons can bypass the Drosha processing step by being processed by the mRNA splicing machinery [46, 47]. These specialized pri-miRNAs are characterized by having $\mathrm{G}$ and $\mathrm{C}$ rich regions at the 5' and 3' end of the intron for mammalian genes, and $U$ rich regions at both ends for invertebrate genes [48]. It is unclear whether this is a type of primitive miRNA and whether there is an evolutional reason for these types of miRNAs [48].

\section{Processing by Dicer and RISC Incorporation.}

In the cytosol, miRNAs are further processed by the RNase III enzyme Dicer by removing the loop to create a double stranded RNA about 22 nucleotides long [49-51]. One strand is removed and degraded, while the mature miRNA is incorporated into an RNA-induced silencing complex (RISC). Cleavage of the pre-miRNA by Dicer is directed by its domain structure. The PAZ domain of Dicer recognizes the 3'overhang left behind by Drosha processing. The rest of the protein then acts as a molecular ruler guiding the cleavage of premiRNA loop structure [52]. Dicer is known to interact with two proteins; TAR RNA-binding protein (TRBP) [53] and PACT [54]. It is not known whether either of these proteins is involved in modulating Dicer's processing function. They do however aid in loading of the miRNA into the RISC. Depletion of TRBP and PACT causes reduced miRNA activity, and reduced mature miRNA accumulation respectively. After cleavage by Dicer, the mature miRNA is loaded onto an Argonaute protein (Ago) of the RISC complex. One strand of the miRNA duplex is selected 
for degradation while the mature miRNA remains bound to the RISC. This selection is based upon the thermodynamic stability of the individual strands. The strand with the most thermodynamically stable 5' end is usually selected for degradation [55]. The Argonaute protein makes up the core of the RISC of which there are four family members in humans AGO1-4. All of these family members are capable of binding miRNAs, however AGO2 and to a lesser extent AGO3 appear to be the predominantly active family members $[56,57]$. The mature miRNA then guides the miRISC to target sites in the 3'UTRs of mRNAs.

\section{Regulation of Biogenesis:}

The biogenesis of miRNAs occurs in a multi-step process with many regulatory proteins that give rise to control of abundance at several levels. This possibility was first suggested by an observation of post-transcriptional repression during cell development [58]. Indeed, the Drosha cleavage event is subject to regulation by several proteins including p68, p72, Smad, p53, Ars2, and Estrogen receptor alpha (ER $\alpha)($ Fig. 3). The topic of regulation at the Drosha processing step is reviewed elsewhere [59] and supplied in the appendix.

The two DEAD-box RNA helicases p68 and p72 have both been shown to be involved in modulating Drosha processing. The first association of the DEAD-box helicases with Drosha was observed by Gregory et al. when they isolated two multi-protein Drosha-containing complexes. The smaller one, termed the microprocessor contained Drosha and DGCR8, while the larger complex contained nearly twenty additional proteins. The smaller complex was deemed sufficient for miRNA processing, while a role for the larger complex which contained the helicases, was not yet determined [60]. Further research showed that p68 and p72 were critical for the expression of a subset of miRNAs as well as 5.8s rRNA. Knock down of these 
two proteins also resulted in either embryonic lethality or neonatal lethality [61]. The exact roles of these proteins within the complex have still not been determined. One possibility is as helicases they may be involved in unwinding the long pri-miRNA stems so Drosha may more efficiently cleave off the pre-miRNA, or expose binding elements for additional proteins to bind and modulate processing.

Association of R-Smad proteins with the microprocessor has been shown to enhance the expression of several miRNAs including miR-21 and miR-199a in response to TGF- $\beta$ or BMP4 [62]. Smad proteins with the exception of Smad4 are capable of binding directly to p68, which help to facilitate an accumulation of pre-miRNA. Furthermore upregulation of miR-21 leads to a decrease in PDCD4 and PTEN, the well known targets of miR-21, indicating a new mechanism for TGF- $\beta$ in cancer pathology [62]. An additional study identified a conserved sequence similar to a Smad binding element (SBE) in the miRNAs regulated by Smads. This sequence is located within the stem of regulated miRNAs and is termed an RNA Smad binding element (R-SBE). Smad-bound pri-miRNAs efficiently recruit Drosha for processing which enhances the formation of pre-miRNA and increases expression of the mature miRNAs [63]. The presence of this element within the stem of pre-miRNAs easily identifies the subset of miRNAs that are regulated by TGF- $\beta$ and BMP4.

The tumor suppressor protein p53 is also capable of binding to the microprocessor and modifying the expression of multiple miRNAs. It was observed that exposure to DNA damaging agents increased the abundance of specific pre- and mature miRNAs without increasing primiRNA abundance, suggesting a post-transcriptional regulatory mechanism. Capable of binding to p68 as well as p72, association of p53 with pri-miRNA enhances recruitment of Drosha, leading to an enhanced processing of pri-miRNA and increased generation of pre-miRNA [64]. 
While no consensus sequence or other identifying characteristic has been found to easily identify those miRNA post-transcriptionally regulated by $\mathrm{p} 53$, the miRNA whose abundance are regulated have functions within the cell that are consistent with the pro-apoptotic activities of p53. In addition to post-transcriptional regulation, p53 has also been shown to activate transcription of miRNA. The transcriptional activation of miR-34a by p53 has been confirmed, and miR-34a has been shown to be involved in mediating the apoptotic activity of p53 [65].

Association of these proteins with the microprocessor appears to enhance the regulation of some but not all miRNAs. The complete identification of all members of these subsets will confirm whether or not the miRNAs with enhanced processing and expression regulate similar biological processes to that of their modulators.

miRISC Functions:

The mechanisms by which miRNA repress protein expression have yet to be fully delineated. The miRISC complex containing Ago, the miRNA, and Dicer is associated with several additional proteins forming the miRNP or micro-ribonucleoprotein that is responsible for directing the downstream function. To date, there appear to be two main mechanisms for miRNA-mediated repression following target recognition; first, mRNA deadenylation and degradation and second, inhibition of translation.

\section{Target Recognition:}

Repression of mRNA by miRNAs is achieved by sufficient recognition and binding of the miRNA to a miRNA recognition element (MRE) within the 3'UTR of a target mRNA. For most miRNAs the region that appears to be most important for recognition of a target mRNA 
from an evolutionary standpoint is bases $2-8$ on the 5 ' end of the miRNA [66]. This region is the most highly conserved across species within the miRNA as well as the MRE. It has been shown however that many miRNAs can violate this seed sequence rule. Examples of this include miR10a which targets the 5'UTR using a non-seed site [67]. Additionally, miR-24 inhibits expression of cell cycle genes including E2F2 by binding unpredicted "seedless" MREs [68]. While no seed region was identified, a high degree of complementarity was sufficient for target recognition.

\section{Deadenylation and Degradation of Target $m R N A$ :}

While the mechanisms for miRNA induced repression of protein expression are still being studied and are of some debate, target mRNA deadenylation and degradation have been well established [69]. The protein or protein family most critically involved in this process is GW182 or TNRC6C in humans. This protein has been demonstrated to be necessary for the assembled miRISC to repress gene expression. In humans GW128 physically associates with Ago proteins and is involved in mediating miRNA-induced repression [70], and it appears that the c-terminus and an RRM domain both contribute to this activity [71, 72]. Knock down of GW182 expression within cells decreases both miRNA function and the presence of p-bodies which are cytoplasmic foci of mRNA silencing and degradation [70]. GW182 is responsible for recruitment of the CAF1 and NOT1 deadenylases to the miRNP-bound mRNA target [73, 74]. Additionally it has been shown that Ago proteins interact directly with CAF1 and CCR4 deadenylases, and that GW182 interacts with poly-A binding protein (PABP) which acts as a coactivator for miRNA-mediated repression [75]. Deadenylation occurs by recruitment of the DCP1:DCP2 complex followed by decapping. Finally, XRN1 mediates exonucleolytic cleavage 
and degradation of the target mRNA. While the deadenylase complex, decapping complex and XRN1 are all p-body components, the formation of p-bodies does not appear to be necessary for the repressive activity of miRNA [76]. Some results have shown that repression is mainly an effect of translation inhibition, and not mRNA degradation. GW182 may also function in this regard as it is also capable of repressing protein expression when the deadenylase complex is not present in Drosophila cells [77].

\section{Inhibition of Translation:}

The inhibition of translation by miRNA has been observed, and this mechanism of repression is widely accepted. There is, however, little agreement concerning whether the inhibition occurs at the onset of translation or at post-initiation steps. Multiple laboratories have presented data suggesting that repression occurs at initation $[78,79]$. Inhibition of initiation has been observed as an effect of the miRNP binding to translation initation factors, such as the eukaryotic initation factors or eIFs. Observations have been made of miRNA complexes inhibiting the function of eIF4E, [79] eIF4F, of which eIF4E is a component, [80] and promoting the effect of eIF6, a factor which inhibits the binding of $40 \mathrm{~S}$ and $60 \mathrm{~S}$ ribosomal subunits to the mRNA[81]. In most cases, utilization of a reporter including an internal ribosome entry site or IRES, abolishes the repressive effect of the miRNA, indicating that proper $\mathrm{m}^{7} \mathrm{GpppN}$-cap mediated translation is necessary for repression [78-80].

While many studies indicate a role for inhibition at initiation, several other studies provide evidence that repression may occur at post-initiation steps. These studies are highlighted by reports that miRNPs can associate with polysomes, and that repression is not affected by the introduction of an internal ribosome entry site or IRES. A model was used where siRNA for 
CXCR4 was used to knock down a luciferase reporter with 6 binding sites in its 3'UTR with or without an IRES. The presence of the IRES had no effect on the ability of the siRNA to repress luciferase expression. Repressed RNA was associated with polysomes indicating that initation had already taken place, but full length mRNAs were not synthesized indicating pre-mature ribosome drop-off as the mechanism of repression [82]. Similarly when miRNA binding sites were inserted into a 5'UTR in which an IRES was present or when Ago2 was tethered to either the 5'or 3'UTR, repression was still observed indicating a mechanism at post-initiation steps [83]. A few additional studies suggest other post-initation mechanisms such as miRNA-mediated recruitment of proteases to degrade nacent polypeptides [84], however much work needs to be done before this repressive mechanism can be fully elucidated.

\section{Regulation of Repression:}

Similar to miRNA biogenesis, miRNA-mediated repression is also regulated by multiple factors including RNA-binding proteins that interact with the miRNP complex and alter its function to either increase or decrease repression. The TRIM-NHL family of proteins, TRIM32 specifically in humans, has been shown to interact with miRNPs associated with several miRNAs including let-7a, miR-214, and miR-134. TRIM32 was also shown to enhance the repressive activity of let-7a as indicated by a luciferase reporter [85]. Modulating proteins have also been shown to inhibit miRNA-based repression. Examples of this regulation include translocation of HuR to the cytoplasm after cellular stress. HuR protein binds to AU-rich elements within the 3'UTR of CAT-1 mRNA and releases it from miR-122-mediated repression [86]. Additional examples of protein-induced alleviation of repression include: expression of Dnd1 in humans alleviates miR-221 repression of p27 [87]; the Apolipoprotein B mRNA-editing 
enzyme polypeptide-like 3G causes exit of miRNA reporters from P-bodies [88]; and the inhibition of miR-134-mediated repression on Limk1 mRNA in rat neurons by brain derived neurotrophic factor (BDNF) [89].

miRNA-mediated upregulation of protein expression:

Expression of miRNAs is normally associated with the repression of protein expression. There are a few reports however of circumstances in which miRNAs have been observed to increase protein levels. One of these cases is miR-10a. When binding to the 5'UTR of mRNAs that encode ribosomal proteins, translation is enhanced. This enhancement is capable of overcoming the repression of expression experienced during amino acid starvation, and is required for translation initiation after Ras overexpression [67]. A second example reported by Vasudevan et al. suggests two mechanisms by which miRNA might enhance protein expression. They observed AU-rich elements (ARE), conserved regions within 3'UTRs, acting as an activation signal by recruiting Fragile $\mathrm{X}$ mental retardation-related protein 1 (FXR1) and AGO associated with miRNPs containing miRNAs. The miRNA in this case was responsible for directing the association of these proteins with the ARE and causing enhanced protein expression [90]. The second mechanism they reported acted as a switch from repression to expression. The miRNA let-7 was shown to repress translation of target mRNAs during cell proliferation, and switch to up-regulation upon cell cycle arrest. These observations indicate that the cellular role of miRNAs may be much broader than initially observed, being involved in repression, upregulation, and binding to other areas than just the 3'UTR.

\section{MicroRNA and Cancer:}


Since the discovery of miRNA there have been implications for a role of this small but potentially powerful cellular regulator in cancer development and progression. The first miRNAs lin-4 and let-7 were discovered as having a role in C. elegans development. Later, miRNAs such as miR-21 and miR-155 emerged as having significant influence on the development and progression of cancer, targeting tumor suppressor genes, and enhancing tumorigenesis.

\section{Oncosuppressive miRNAs:}

The first study that directly linked expression of miRNA with the pathogenesis of human cancers revealed that miR-15a and miR-16-1 were lost as a consequence of deletion of chromosome 13q14 during development of chronic lymphocytic leukemia [91]. A follow up study on these miRNAs showed that miR-15a and miR-16-1 targeted the oncogene BCL2. Loss of 13q14 then causes an overexpression of BCL2, protecting cells from apoptosis and enhancing leukemogenesis [92]. Other tumor suppressive miRNAs exist such as let-7. This miRNA, aside from its roles in C. elegans, targets oncogenes such as RAS [93], HMGA2 [94], and MYC [95]. Experssion of the let-7 miRNA family in breast cancer initiating cells represses proliferation, mammosphere formation, and tumor formation in mouse models [96]. Additionally, in small-cell lung cancer, the let-7 family represses tumor growth and enhances apoptosis [97]. Another miRNA commonly repressed in cancer, miR-145 [98, 99], has significant tumor suppressive functions. Activation of the p53 pathway increases expression of miR-145 which directly represses expression of c-MYC, inhibiting tumor growth [100]. The regulation of receptor tyrosine kinases by miRNA has also been observed, and loss of this regulation enhances cancer cell proliferation. One example of this is the EGF receptor family. Expression of both HER-2 and HER-3 can be repressed by miR-125a and miR-125b [101]. HER-3 can also be regulated by 
miR-205 in breast cancer. Forced expression of miR-205 reduces breast cancer cell growth and enhances sensitivity to tyrosine kinase inhibitors [102].

\section{Tumor promoting miRNAs:}

While many miRNAs which can function as as tumor suppressors, there are equally many that act as tumor promoters. These miRNAs that have roles in promoting tumorigenesis or cancer progression have been termed oncomirs. A commonly overexpressed miRNA, miR-21 has been observed in many solid tumors including lung, breast, ovary and others. This miRNA has been shown to directly target tumor suppressor genes PDCD4 [103], PTEN [104, 105], and TPM1 [106]. Originally miR-155 was shown to be upregulated in multiple lymphoma subtypes [107]. Since then, overexpression of miR-155 has been observed in many different malignancies including cancers of the lung, breast, colon, cervix, pancreas and thyroid [108]. Expression of miR-155 is achieved by transcription of the BIC gene, the retroviral integration site for avian leukosis virus which induces B-cell lymphomas [109]. Targets of miR-155 indicating its oncomir status include FOXO3a [110], SOCS1 [111], SMAD5 [112], TP53INP1 [113], and other additional tumor suppressor proteins. Another common oncomir or set of oncomirs is miR221/222. These two miRNAs which are coordinately expressed are involved in multiple cancers including breast cancer where they target p27Kip1 [114] and gastric cancer by targeting PTEN [115]. The pair of miRNAs has also been identified as targeting the pro-apoptotic protein PUMA [116] and estrogen receptor alpha [117]. Thus far, most of the miRNA targets mentioned have roles in proliferation or apoptosis avoidance. However, miRNAs have also been shown to be involved in cancer cell invasion and metastasis. 
miRNA expression profiling:

The purpose of profiling of miRNA expression in various cancers, cancer cell lines or patient samples, is to identify whether a specific miRNA expression signature exists for tumors or tumors of a specific background. Identification of such a signature could help in various ways from diagnosis to therapeutic intervention. The first such signature was identified in chronic lymphocytic leukemia (CLL). A 13 gene signature was defined that identified prognostic factors, and expression was independent of disease progression [118]. Expression signatures for many different malignancies have since been identified including lung [119], pancreatic [120], liver [121] and others. Expression profiling for miRNA has also been used to differentiate tumor subtypes for the potential use as a diagnostic or prognostic tool [122].

miRNAs in cancer therapeutics:

The ability of miRNAs to be involved in multiple stages of cancer development and progression where individual miRNAs targeting several proteins within the same or similar pathways indicates that they may be good targets or tools for therapeutic intervention. As mentioned above, when miRNAs are manipulated in vitro or in vivo, they have the ability to induce or reverse cancer phenotypes. However, the hope of miRNA in cancer therapeutics has yet to be realized. Clinical trials for miRNA in cancer and other diseases have however been started, with some promising results. One example of this is miR-122 in hepatitis C infection. The hepatitis $\mathrm{C}$ virus uses miR-122 to activate the transcription of its genome. As miR-122 is largely liver specific, repression of its expression using a locked nucleic acid (LNA) antagonist, SPC3649 that is also liver specific represses HCV replication and viremia [123]. Phase 1 clinical trials for this therapeutic are underway and phase 2 trials are in planning stages [124]. Several 
additional clinical or preclinical trials are also being performed on multiple malignancies and diseases [124]. Several approaches are being taken in an attempt to alter miRNA levels within cells, to reduce or increase the expression or activity of miRNAs. This change in miRNA activity will hopefully reverse the disease phenotype by decreasing tumor growth and spread, or make resistant cancer cells more susceptible to chemotherapy.

Since the role of miRNA within cells is to act as regulators of protein expression, they have great potential to cause phenotypic changes in cells whether they are directing normal cellular differentiation or tumorigenesis. The expression of a single miRNA or group of miRNAs can be either oncogenic or oncosupressive, indicating that miRNAs can be involved in cancer diagnosis, prognostic prediction, and cancer therapeutics.

Alteration of miRNA expression could greatly enhance the understanding of mechanisms by which arsenic induces cancer formation. Therapeutics using miRNA and miRNA pathways are being developed which may make miRNAs a 'double-edged sword' for arsenic induced malignancies. It is important then to study how arsenic might control the expression of miRNAs, understand which miRNAs are regulated and if they might be manipulated to prevent or treat arsenic induced disease.

\section{A Case for microRNA-190 in Arsenic-Induced Cancer:}

\section{Genomic Context:}

It is well known that cytoskeletal control is important in tumorigenesis. miRNA-190 is derived from an intronic region of the talin 2 gene on chromosome 15. The proteins of the talin family include talin 1 and talin 2 . They share several highly conserved domains, such as the rod domain and the FERM domain, that are important for interaction with F-actin, integrin, PIP5KI isoforms, and focal adhesion molecules $[125,126]$. Talin 2 , while not as well studied as talin 1 , 
plays a role within the cell cytoskeleton. It is not known however, whether miR-190 and talin 2 are involved in similar processes. miR-190 is located within an intronic region between exons 51 and 52 of talin 2 that is approximately 12,800 base pairs long [127]. This location for miR-190 has been described as an intronic exaptation, or a situation in which miRNAs arise within an intron of a previously existing gene where the host gene and miRNA have differing selective pressures [127]. In this case miR-190 is specific to bilaterian lineage, and is found within the intron of a gene which is much older. Evolution of miRNAs within pre-existing genes circumvents the need for the miRNA to evolve a promoter, perhaps speeding up and simplifying the process. The expression of miR-190 and talin2 has been linked at least in a correlative manner. The presence of miR-190 within an intron of the talin2 transcript suggests that expression of talin 2 would also express miR-190. This relationship between the two genes appears to be genuine as evidenced by one study thus far [128]. An additional study has shown a correlation between miR-190 and talin 2 expression using microarray technologies. A correlation coefficient of 0.662 was found to exist between these two genes, suggesting that the expression of both genes coincide with one another at least in part [129]. Using bioinformatic means as well as ChIP-chip experiments targeting RNA polymerase II, it has been indicated that miR-190 may have its own promoter [130]. The predicted transcriptional start site (TSS) is located 41,530 bp upstream of the miR-190 transcript, within the region encompassed by the talin2 gene, and it will be of interest to determine what activates the expression of miR-190 independent of talin2. Sufficient evidence exists suggesting that miR-190 is under the control of two promoters, and activation of either will produce the mature miR-190 sequence.

\section{Function and Regulation:}


Early data indicating a role for miR-190 suggested that its inhibition decreased growth of HeLa cells. When miR-190 and several other miRNAs were individually inhibited with an antisense oligonucleotide, growth was inhibited without an overall change in the apoptotic caspase activity [131]. An additional study shows that the level of miR-190 was increased in granulocytes from patients with primary myelofibrosis [132]. These results suggest a role for miR-190 in regulating cell cycle or proliferation rate. In a study profiling the expression of miRNAs in pancreatic cell lines and tumor tissues, miR-190 was one of several miRNAs found to be significantly overexpressed. In tumor samples, miR-190 expression was increased $88 \%$ of the time with an average of a 21 fold increase. Also, in comparison to normal human pancreatic ductal epithelium, Panc-1 as well as multiple other cell lines exhibited a greater than 5 fold increase in miR-190 expression [133]. MiR-190 has also been indicated to play a role in breast cancer. In a study identifying miRNA signatures which might predict the expression of the receptors for estrogen, progesterone and HER2/neu, miR-190 was predictive of estrogen receptor expression [134]. While ER positive breast cancers are more susceptible to endocrine-based therapy, miR-190 may not play a tumor suppressive or tumorigenic role in this contex.

The expression of miR-190 has recently been studied in neurons. In response to exposure to the $\mu$-opioid receptor agonist fentanyl, miR-190 levels were found to decrease. This decrease is caused by an increase in ERK phosphorylation via a $\beta$-arrestin 2 dependant mechanism [135]. ERK, when phosphorylated through $\beta$-arrestin 2 , translocates to the nucleus where it can phosphorylate the transcription factor Yin Yang 1 (YY1). Phosphorylated YY1 has a decreased binding affinity for a binding site within the talin2/miR-190 promoter, reducing gene transcription [128]. The role of miR-190 in this context is to reduce the expression levels of NeuroD by binding to its 3'UTR and repressing translation through mRNA degradation. NeuroD 
is an important neuronal protein, involved in many neuronal processes including the development and maintenance of dendrites. Chronic use or misuse of substances such as fentanyl may lead to a lasting reduction of miR-190 expression and an increase in NeuroD levels, possibly having pathogenic consequences [128].

Two other studies indicate that miR-190 may play a role in the survival of neuronal cells. One such study examined the role of miRNA in neuroblastomas with amplification of the MYCN oncogene. They found that miR-190 along with miR-572 (of the survival signature miRNAs) were differentially expressed in tumors with MYCN amplification. A set of miRNAs which closely associated with event free and overall survival were compiled. Of these 15 miRNAs only miR-190 and miR-572 were also associated with amplification of MYCN [136]. These observations indicate that low miR-190 expression is associated with MYCN amplification. Interestingly patients with low miR-190 expressing neuroblastomas have better event free and overall survival. These results are similar with the previous study on fentanyl in that the ERK/MEK/MYC pathway is involved in repressing miR-190 expression in neurons. The other study examined the expression of miRNA in the mouse cortex in response to ischemic preconditioning in order to understand the nature of the resulting neuroprotection. While the focus of the study was miRNAs which targeted methyl-CpG binding protein 2 (MeCP2), the miRNA array analysis revealed an increase in the expression of miR-190 [137]. This result could indicate that miR-190 expression is increased in response to cellular stress within the brain, and thus may be involved in cell survival. While these two studies along with the previous study may potentially indicate an anti-tumorigenic role for miR-190, it should be noted that all studies are performed on neuronal cells and this may represent a cell type specific phenomenon. 
The expression of miR-190 has been linked with survival and proliferation of cells since its discovery. Its regulation by ERK indicates that it could be regulated by arsenic exposure. Potential downstream targets of miR-190 include pro-apoptotic proteins such as PHLPP and Tumor protein 53 induced nuclear protein 1 (TP53INP1). While previous evidence suggests that miR-190 is negatively regulated by ERK, it is possible that this effect is cell context specific, and positive regulation by ERK activation is still likely. This sets up a potential pathway where ERK activation by arsenic exposure might increase expression of miR-190, repressing PHLPP, prolonging or enhancing Akt activity, and enhancing growth, survival or tumorigenicity.

\section{PHLPP Expression and Regulation:}

\section{Discovery:}

One of the potential targets of miR-190 predicted by multiple algorithms freely available online is $\mathrm{PH}$-domain and leucine rich repeat protein phosphatase (PHLPP), also known as suprachiasmatic circadian oscillatory protein (SCOP). SCOP was discovered in the rat suprachiasmatic nucleus and is expressed with a circadian rhythm [138]. The domain structure of SCOP was determined to contain a plekstrin homology $(\mathrm{PH})$ domain, as well as a leucine rich repeat region, a leucine zipper, a protein phosphatase $2 \mathrm{C}(\mathrm{PP} 2 \mathrm{C})-$ like domain and a glutaminerich region. This domain structure indicates that SCOP may have important signaling functions in the cytoplasm as the $\mathrm{PH}$ domain is important for membrane localization and the phosphatase domain may terminate or activate certain signals. The leucine zipper however indicates that this protein may also have roles within the nucleus, suggesting that this protein may play a number of different roles [138]. SCOP (hereon referred to as PHLPP) was then identified as a protein capable of dephosphorylating Akt and given the name PHLPP. It was shown that the PP2C domain was responsible for the dephosphorylation at serine 473, and not at threonine 308 the 
other activating signal for Akt [29]. Reduced expression of PHLPP was observed in several cancer cell lines, correlating with an increase in Akt phosphorylation. Addition of PHLPP into cancer cells which had low levels of the protein, showed a marked reduction in tumor growth, solidifying its role as a tumor suppressor [29]. Since its discovery, multiple members of the PHLPP family have been identified. These include PHLPP1 $\alpha$ [138], PHLPP1 $\beta$ (SCOP [29]), and PHLPP2. PHLPP1 $\alpha$ and $\beta$ differ in that PHLP1 $\beta$ is spliced such that it contains an additional 5' sequence, however differing roles for these two splice variants have yet to be determined [139]. PHLPP2 was discovered as having the same domain structure as PHLPP1 but is transcribed from chromosome 16q22.3, and has 50\% amino acid identity [139]. PHLPP2 and PHLPP1 are also different in their modulation of Akt. While both isoforms target Akt1, they target Akt2 and 3 differently. PHLPP1 dephosphorylates Akt2, leading to a decreased activation of downstream targets HDM2 and GSK-3 $\alpha$, whereas PHLPP2 dephosphorylates Akt3, decreasing downstream phosphorylation of p27 [139]. These roles for the different isoforms allow for a more robust and specific termination of Akt and its downstream signaling pathways.

\section{Function:}

Additional roles for PHLPP in signaling pathways include an interaction with Ras, dephosphorylation of protein kinase $\mathrm{C}$ (PKC), and interaction and activation of Mst1. PHLPP1 $\beta$ was characterized as having an interaction with Ras that is mediated by its leucine rich repeat region. This region only binds to the subset of K-Ras that is free of guanine nucleotides and inhibits the downstream activation of ERK1/ERK2 [140]. Both PHLPP1 and PHLPP2 are capable of dephosphorylating PKC $\beta$ II on its hydrophobic motif. This event causes PKC to be transferred to a detergent insoluble fraction, which ends PKC cycling and degrades the protein 
[141]. Mst1 or Mammalian sterile 20-like kinase 1 is a protein involved in the apoptotic response and its overexpression is capable of inducing apoptosis in cells. Mst1 is capable of being bound by the PHLPP family members, and subsequently dephosphorylated on an inhibitory site (T387), activating the protein [142]. Downstream effector proteins of Mst1 include p38 and JNK which are responsible for mediating its apoptotic properties [143, 144]. The interaction between PHLPPs and Mst1 delineates a pathway by which PHLPP family members can actively induce apoptosis, rather than passively terminate Akt signaling.

\section{Regulation:}

Expression and activation of the PHLPP family of phosphatases, may be achieved by multiple mechanisms. Recent research has shown that PHLPP expression is controlled by mammalian target of rapamycin (mTOR). Inhibition of mTOR with rapamycin resulted in a significant decrease in PHLPP expression [145]. While it has yet to be determined if the PHLPPs require phosphorylation to carry out the function of the phosphatase domain, it has been shown that PHLPP1 can be phosphorylated on a tyrosine residue by activated insulin receptor. It is not known however if this phosphorylation catalytically activates the PHLPPs, provides a docking site for binding with other proteins, or has some other function that enhances its activity [146]. Additional research has shown that FKBP51 plays a role as a scaffolding protein for PHLPP, allowing it to dephosphorylate Akt. Loss of FKBP51 as observed in pancreatic cancers, allows for increased Akt phosphorylation and subsequent tumorigenesis [147]. The inactivation or inhibition of the PHLPP family members may also occur by additional mechanisms. The PHLPPs have been shown to be held inactive by being bound to other proteins. Adenylyl cyclase 6 (AC6) is an enzyme involved in the cyclic AMP pathway which is capable of binding to PHLPP2. When PHLPP2 is bound by AC6, it is inhibited and Akt phosphorylation is enhanced. 
This inhibition is removed by stimulation with isoproterenol or forskolin, allowing PHLPP2 to dephosphorylate Akt [148]. Repression of PHLPP activity has also been observed to be mediated by elimination via ubiquitination and degradation. This degradation is mediated by $\beta$-TrCP containing E3 ubiquitin ligase that requires PHLPP1 to be phosphorylated. The necessary phosphorylation occurs on a serine or threonine residue mediated by casein kinase 1 or GSK$3 \beta$. Because GSK-3 $\beta$ is inhibited downstream of activated Akt, this regulation reveals a pathway in which active Akt represses PHLPP degradation and forms a negative feedback loop [149].

The phosphatases PHLPP1 and PHLPP2 are relatively 'new' proteins whose regulation and function are not yet fully understood. Thus far, as a regulator of Akt, the expression and activity of PHLPP is evidenced to be tightly regulated by multiple mechanisms. Abberations in this regulation leading to decreases in PHLPP activity could lead to a hyperactivation of Akt, allowing cells to proliferate more rapidly and perhaps undergo tumorigenesis. Negative regulation of these PHLPP proteins by various mechanisms including repression by miRNA could represent a route through which arsenic exposure enhances Akt phosphorylation.

\section{Akt Activation and Cancer}

Akt kinase:

The serine/threonine kinase Akt was first discovered in early 1990s by three independent groups through screening cDNA libraries from human cell lines MCF-7, WI38 and HeLa, [150, 151] or isolating AKT8 retrovirus from rodent $T$ cell lymphoma [152]. Since the similarity in the kinase domain to protein kinases $\mathrm{A}(\mathrm{PKA})$ and $\mathrm{C}(\mathrm{PKC})$, it was also named as protein kinase B (PKB). Further studies revealed that three human gene loci encode three highly homologous Akt isoforms, Akt1, Akt2 and Akt3. It is believed that each Akt isoform might have preferential 
activating signaling pathways and distinctive functions in cell growth, metabolism and cancer development [153]. Akt1 is ubiquitously expressed in a majority of tissues, whereas Akt2 is detected mostly in insulin-sensitive tissues, including liver, pancreas, skeletal muscle, and adipose tissue. In contrast, the expression of Akt3 is largely restricted to brain and testis. All Akt isoforms contain an N'-terminal pleckstrin domain (PH domain), a central kinase domail and a C'-terminal hydrophobic motif. In response to extracellular stimuli, Akt1 was phosphorylated at the threonine 308 in the kinase domain (309 in Akt2, 305 in Akt3) and serine 473 (474 in Akt2 and 472 in Akt3) by PI3K-phosphoinositide-dependent protein kinase (PDK1) and mTORC2, respectively. Activated Akt can phosphorylate a number of downstream targets important for cell proliferation, apoptosis, metabolism, malignant transformation, and neoangiogenesis, such as FoxO3a, FoxO4, TSC2, DSK3a/b, MDM2, BAD, eNOS, IKK $\alpha$, etc., some of which may contain Akt recognition motif R-X-R-X-X-S/T-B [154].

\section{Activation of Akt Signaling:}

Several reports indicated that arsenic is able to activate Akt in a number of cell lines, which was considered as one of the key mechanisms of arsenic-induced carcinogenesis. For example, a study by Zhang et al. [31] showed that arsenic activated Akt in BEAS-2B cells in a time dependent manner. The Activation of Akt by arsenic peaked at 4 to 8 hours, which possibly contributes to arsenic-induced phosphorylation of FoxO3a, but not GADD45 $\alpha$ expression. An earlier study by Souza et al. [155] suggested that arsenic induced Akt phosphorylation at both ser473 and thr308 in keratinocytes. It was speculated that arsenic-induced activation of MAP kinase, p38, might be responsible for such an Akt phosphorylation. In 3T3L1 cells, Akt activation by arsenic inhibited differentiation of these cells to fat cells by interfering with the 
PPAR $\gamma$ signaling on the expression of adipogenic genes [156]. Even in some types of leukemic cells that are sensitive to arsenic-induced cell apoptosis, activation of Akt and the downstream mammalian target of rapamycin (mTOR) by arsenic were observed, which could explain the resistance of some patients with leukemia to arsenic treatment [32]. In addition, data from phosphoproteomic profiling suggested activation of Akt as well as receptor tyrosine kinases and MAP kinases in human small airway epithelial cells treated with either short-term or long-term arsenic exposure [33]. Furthermore, most recent study indicated that arsenic-activated Akt signal is pivotal for the release of angiogenic factors from human bronchial epithelia cell line, BEAS2B, and lung tumor cell line, A549 cells [157].

It remains to be fully elucidated how arsenic activates Akt. Overwhelming evidence suggested that Akt kinases are downstream targets of several receptor tyrosine kinases (RTK) that are regulated by growth factors, cytokines, and insulin [154]. In general, engagement of RTK with growth factors, such as EGF, PDGF, IGF-1, etc., causes tyrosine phosphorylation of the receptor and/or adaptor proteins, which in turn attracts binding of the p85 regulator subunit of the class I phosphatidylinositol 3-kinase (PI3K) to the receptor or adaptor protein through the Src homology 2 (SH2) domains in p85, followed by activation of the p110 $\alpha$ kinase subunit of the PI3K. Activated PI3K phosphorylates phosphatidylineositol-4,5-bisphosphate (PIP2) to generate phosphatidylinositol-3,4,5-trisphosphate (PIP3), a second messenger that is capable of recruiting effector proteins containing a PH domain, such as PDK1 and Akt to the proximity of the cell membrane, enabling PDK1 to phosphorylate Thr308 of the Akt kinase. RTK and/or additional intracellular signaling pathways can also activate mTORC2 complex that phosphorylates Ser473 of Akt, resulting in full activation of the Akt kinases. The conversion of PIP2 to PIP3 catalyzed by PI3K can be negatively regulated by a tumor suppressor, phosphatase and tensin homolog 
(PTEN). In addition, the activated Akt can be inactivated by PHLPP that is able to dephosphorylate Ser473 of the Akt kinases.

As previously mentioned, exposure of cells to arsenite can activate RTK, such as the csrc/EGFR signaling pathways [18], which very likely contributes to the activation of PI3K and Akt. One possibility of arsenic-induced RTK activation is the oxidative inactivation of protein tyrosine phosphatases (PTPs) by the reactive oxygen species (ROS) induced by arsenic. Several studies demonstrated that arsenic is able to activate NADPH oxidases to generate ROS that can inactivate PTPs by direct oxidizing the invariant cysteine (Cys) residue in the signature motif of PTPs [158, 159]. It was shown that arsenic not only enhances expression of some NADPH oxidase subunits, such as p47phox and p22phox, but also induces phosphorylation and membrane translocation of these subunits to activate the NADPH oxidase. Biochemical evidence indicates that transient activation of the NADPH oxidase causes mild and reversible oxidation of the PTPs by a modification of Cys with sulfenic acid. In contrast, sustained activation of the NADPH oxidase will result in irreversible oxidation of the PTPs due to the addition of two (sulfinic acid) or three (sulfonic acid) oxygens to the Cys residue in the signature motif of PTPs. In addition to the classic activating signaling, arsenic-induced Akt activation might also be achieved by other signaling pathways, such as MAPK and STAT3 [160, 161].

\section{Akt Activation and Activity in Cancers:}

Accumulating evidence suggests that Akt activation or activity is altered in a number of human cancers or cancer cell lines. Amplified expression of Akt1, Akt2 or Akt3 mRNA has been documented in various human malignancies, such as colon cancer, breast cancer, ovarian

cancer, prostate cancer, glioblastoma, hepatocellular carcinoma, and pancreatic cancer. In 
addition, activating point mutations at Akt1 or the p110 $\alpha$ subunit of PI3K had been noted in some cancers. Furthermore, some cancers exhibited functional deficiency of PTEN or PHLPP, the negative regulators of the PI3K and Akt signaling pathway, due to mutations, deletions or promoter methylation [162].

The cancer promoting activities of Akt family kinases are largely based on their regulatory roles on cell growth, cell cycle, cell survival, metabolism, migration, and angiogenesis. One of the first identified functions of Akt is its role in inducing cell growth by increasing cell mass, which is possibly through activating mTOR complex 1 (mTORC1). In response to nutrients or growth factors, Akt dependent phosphorylation of Ser939 and Thr1462 on tuberous sclerosis complex 2 (TSC2), a tumor suppressor and inhibitor of mTORC1, suppresses the inhibitory function of TSC1-TSC2 complex, leading to activation of mTORC1 and the subsequent activation of protein translational machinery for cellular protein synthesis [163]. The survival function of Akt in cellular responses to apoptotic stimuli is achieved by Aktdependent phosphorylation and inactivation of several pro-apoptotic factors, including BH3-only protein BAD, FoxO3a, FoxO4, caspase-9, etc. The pro-survival or anti-apoptotic function of Akt might also be made through crosstalk with other signaling pathways that are important for cell proliferation or metabolism, such as NF-kB and MAP kinases. It has been well-known that Akt or its activating signaling is critical for cell proliferation or cell cycle regulation. A number of studies revealed that Akt is capable of phosphorylating Thr157 on p27kip1, an endogenous inhibitor of cyclin-dependent kinase inhibitor [164]. This phosphorylation prevented p27 nuclear translocation due to cytosolic sequestration via 14-3-3 binding of the p27 protein, leading to a sustained activation of the cyclin-dependent kinases and cell proliferation. During the pathogenesis of tumorigenesis, formation of the new blood vessels through neoangiogenesis is 
the key for the blood supply of the growing tumors. In this regard, Akt dependent expression of hypoxia-inducible factor- $\alpha$ (HIF1 $\alpha$ and HIF2 $\alpha$ ) might be pivotal for the expression and secretion of VEGF from the endothelial cells [165]. In addition, phosphorylation of endothelial nitric oxide (NO) synthase (eNOS) by Akt can promote NO production, which causes vasodilation and vascular remodeling during angiogenesis [166]. Taken together, it is clear that Akt activation by arsenic or other environmental hazards is one of the central mechanisms of carcinogenesis associated with environmental exposure.

\section{Summary:}

The expression of miRNA has been linked to several diseases as well as normal cellular development and function. MiRNA expression has been intensely studied in relationship to cancer development and progression with the hope that miRNAs will provide insights into better and faster diagnosis, accurate prognosis, as well as more efficient and effective therapeutic strategies. Arsenic is a well known human carcinogen that, while extensively studied, its carcinogenic mechanisms are not fully understood. On the cell and molecular level arsenic is known to cause formation of reactive oxygen species, alter DNA methylation and interact with proteins causing aberrant kinase activation and altered gene expression. The kinases activated by arsenic are commonly found to be activated in cancers as well including ERK, JNK and Akt. While it is likely that arsenic exposure might regulate miRNA expression, it has not been well studied to this point. We hypothesize that arsenic exposure can influence miRNA expression resulting in specific miRNA changes that can control critical downstream pathways associated with arsenic carcinogenesis. 


\section{References:}

1. Some drinking-water disinfectants and contaminants, including arsenic. IARC Monogr Eval Carcinog Risks Hum 2004, 84:1-477.

2. Huff $\mathrm{J}$, Chan $\mathrm{P}$, Nyska $\mathrm{A}$ : Is the human carcinogen arsenic carcinogenic to laboratory animals? Toxicol Sci 2000, 55:17-23.

3. Tokar EJ, Benbrahim-Tallaa L, Ward JM, Lunn R, Sams RL, 2nd, Waalkes MP: Cancer in experimental animals exposed to arsenic and arsenic compounds. Crit Rev Toxicol 2010, 40:912-927.

4. Smith AH, Ercumen A, Yuan Y, Steinmaus CM: Increased lung cancer risks are similar whether arsenic is ingested or inhaled. J Expo Sci Environ Epidemiol 2009, 19:343-348.

5. Burns FJ, Uddin AN, Wu F, Nadas A, Rossman TG: Arsenic-induced enhancement of ultraviolet radiation carcinogenesis in mouse skin: a dose-response study. Environ Health Perspect 2004, 112:599-603.

6. Yoshikawa M, Aoki K, Ebine N, Kusunoki M, Okamoto A: Correlation between the arsenic concentrations in the air and the SMR of lung cancer. Environ Health Prev Med 2008, 13:207-218.

7. Sanders OI, Rensing C, Kuroda M, Mitra B, Rosen BP: Antimonite is accumulated by the glycerol facilitator GlpF in Escherichia coli. J Bacteriol 1997, 179:3365-3367.

8. Liu Z, Shen J, Carbrey JM, Mukhopadhyay R, Agre P, Rosen BP: Arsenite transport by mammalian aquaglyceroporins AQP7 and AQP9. Proc Natl Acad Sci U S A 2002, 99:6053-6058.

9. Aposhian HV, Zakharyan RA, Avram MD, Sampayo-Reyes A, Wollenberg ML: A review of the enzymology of arsenic metabolism and a new potential role of hydrogen peroxide in the detoxication of the trivalent arsenic species. Toxicol Appl Pharmacol 2004, 198:327-335.

10. Radabaugh TR, Sampayo-Reyes A, Zakharyan RA, Aposhian HV: Arsenate reductase II. Purine nucleoside phosphorylase in the presence of dihydrolipoic acid is a route for reduction of arsenate to arsenite in mammalian systems. Chem Res Toxicol 2002, 15:692-698.

11. Cole SP, Sparks KE, Fraser K, Loe DW, Grant CE, Wilson GM, Deeley RG: Pharmacological characterization of multidrug resistant MRP-transfected human tumor cells. Cancer Res 1994, 54:5902-5910.

12. Zaman GJ, Lankelma J, van Tellingen O, Beijnen J, Dekker H, Paulusma C, Oude Elferink RP, Baas F, Borst P: Role of glutathione in the export of compounds from cells by the multidrug-resistance-associated protein. Proc Natl Acad Sci U S A 1995, 92:7690-7694. 
13. Leslie EM, Haimeur A, Waalkes MP: Arsenic transport by the human multidrug resistance protein 1 (MRP1/ABCC1). Evidence that a tri-glutathione conjugate is required. J Biol Chem 2004, 279:32700-32708.

14. Barchowsky A, Klei LR, Dudek EJ, Swartz HM, James PE: Stimulation of reactive oxygen, but not reactive nitrogen species, in vascular endothelial cells exposed to low levels of arsenite. Free Radic Biol Med 1999, 27:1405-1412.

15. Kitchin KT, Wallace K: The role of protein binding of trivalent arsenicals in arsenic carcinogenesis and toxicity. $J$ Inorg Biochem 2008, 102:532-539.

16. Ding W, Liu W, Cooper KL, Qin XJ, de Souza Bergo PL, Hudson LG, Liu KJ: Inhibition of poly(ADP-ribose) polymerase-1 by arsenite interferes with repair of oxidative DNA damage. $J$ Biol Chem 2009, 284:6809-6817.

17. Huang C, Ma WY, Li J, Goranson A, Dong Z: Requirement of Erk, but not JNK, for arsenite-induced cell transformation. J Biol Chem 1999, 274:14595-14601.

18. Simeonova PP, Wang S, Hulderman T, Luster MI: c-Src-dependent activation of the epidermal growth factor receptor and mitogen-activated protein kinase pathway by arsenic. Role in carcinogenesis. J Biol Chem 2002, 277:2945-2950.

19. Chen W, Martindale JL, Holbrook NJ, Liu Y: Tumor promoter arsenite activates extracellular signal-regulated kinase through a signaling pathway mediated by epidermal growth factor receptor and Shc. Mol Cell Biol 1998, 18:5178-5188.

20. Cavigelli M, Li WW, Lin A, Su B, Yoshioka K, Karin M: The tumor promoter arsenite stimulates AP-1 activity by inhibiting a JNK phosphatase. EMBO J 1996, 15:62696279 .

21. Huang C, Ma WY, Li J, Dong Z: Arsenic induces apoptosis through a c-Jun NH2terminal kinase-dependent, p53-independent pathway. Cancer Res 1999, 59:30533058 .

22. Muscarella DE, Bloom SE: Differential activation of the c-Jun $\mathbf{N}$-terminal kinase pathway in arsenite-induced apoptosis and sensitization of chemically resistant compared to susceptible B-lymphoma cell lines. Toxicol Sci 2002, 68:82-92.

23. Chen F, Lu Y, Zhang Z, Vallyathan V, Ding M, Castranova V, Shi X: Opposite effect of NF-kappa $B$ and c-Jun N-terminal kinase on p53-independent GADD45 induction by arsenite. J Biol Chem 2001, 276:11414-11419.

24. Chang Q, Bhatia D, Zhang Y, Meighan T, Castranova V, Shi X, Chen F: Incorporation of an internal ribosome entry site-dependent mechanism in arsenic-induced GADD45 alpha expression. Cancer Res 2007, 67:6146-6154.

25. Zhang D, Li J, Gao J, Huang C: c-Jun/AP-1 pathway-mediated cyclin D1 expression participates in low dose arsenite-induced transformation in mouse epidermal JB6 Cl41 cells. Toxicol Appl Pharmacol 2009, 235:18-24. 
26. Huang HS, Liu ZM, Hong DY: Blockage of JNK pathway enhances arsenic trioxideinduced apoptosis in human keratinocytes. Toxicol Appl Pharmacol 2010, 244:234241.

27. Steelman LS, Stadelman KM, Chappell WH, Horn S, Basecke J, Cervello M, Nicoletti F, Libra M, Stivala F, Martelli AM, McCubrey JA: Akt as a therapeutic target in cancer. Expert Opin Ther Targets 2008, 12:1139-1165.

28. Franke TF: PI3K/Akt: getting it right matters. Oncogene 2008, 27:6473-6488.

29. Gao T, Furnari F, Newton AC: PHLPP: a phosphatase that directly dephosphorylates Akt, promotes apoptosis, and suppresses tumor growth. Mol Cell 2005, 18:13-24.

30. Ouyang W, Li J, Ma Q, Huang C: Essential roles of PI-3K/Akt/IKKbeta/NFkappaB pathway in cyclin D1 induction by arsenite in JB6 Cl41 cells. Carcinogenesis 2006, 27:864-873.

31. Zhang Y, Bhatia D, Xia H, Castranova V, Shi X, Chen F: Nucleolin links to arsenicinduced stabilization of GADD45alpha mRNA. Nucleic Acids Res 2006, 34:485-495.

32. Altman JK, Yoon P, Katsoulidis E, Kroczynska B, Sassano A, Redig AJ, Glaser H, Jordan A, Tallman MS, Hay N, Platanias LC: Regulatory effects of mammalian target of rapamycin-mediated signals in the generation of arsenic trioxide responses. $J$ Biol Chem 2008, 283:1992-2001.

33. Wen G, Hong M, Calaf GM, Roy D, Partridge MA, Li B, Hei TK: Phosphoproteomic profiling of arsenite-treated human small airway epithelial cells. Oncol Rep 2010, 23:405-412.

34. Lee RC, Feinbaum RL, Ambros V: The C. elegans heterochronic gene lin-4 encodes small RNAs with antisense complementarity to lin-14. Cell 1993, 75:843-854.

35. Wightman B, Ha I, Ruvkun G: Posttranscriptional regulation of the heterochronic gene lin-14 by lin-4 mediates temporal pattern formation in C. elegans. Cell 1993, 75:855-862.

36. Reinhart BJ, Slack FJ, Basson M, Pasquinelli AE, Bettinger JC, Rougvie AE, Horvitz HR, Ruvkun G: The 21-nucleotide let-7 RNA regulates developmental timing in Caenorhabditis elegans. Nature 2000, 403:901-906.

37. Olena AF, Patton JG: Genomic organization of microRNAs. J Cell Physiol 2010, 222:540-545.

38. Lee Y, Jeon K, Lee JT, Kim S, Kim VN: MicroRNA maturation: stepwise processing and subcellular localization. EMBO J 2002, 21:4663-4670.

39. Kim VN, Han J, Siomi MC: Biogenesis of small RNAs in animals. Nat Rev Mol Cell Biol 2009, 10:126-139.

40. Lee YS, Dutta A: MicroRNAs in cancer. Annu Rev Pathol 2009, 4:199-227. 
41. Han J, Lee Y, Yeom KH, Nam JW, Heo I, Rhee JK, Sohn SY, Cho Y, Zhang BT, Kim VN: Molecular basis for the recognition of primary microRNAs by the DroshaDGCR8 complex. Cell 2006, 125:887-901.

42. Cordes KR, Srivastava D, Ivey $\mathrm{KN}$ : MicroRNAs in cardiac development. Pediatr Cardiol 2010, 31:349-356.

43. Lee Y, Ahn C, Han J, Choi H, Kim J, Yim J, Lee J, Provost P, Radmark O, Kim S, Kim VN: The nuclear RNase III Drosha initiates microRNA processing. Nature 2003, 425:415-419.

44. Yi R, Qin Y, Macara IG, Cullen BR: Exportin-5 mediates the nuclear export of premicroRNAs and short hairpin RNAs. Genes Dev 2003, 17:3011-3016.

45. Zeng Y, Cullen BR: Structural requirements for pre-microRNA binding and nuclear export by Exportin 5. Nucleic Acids Res 2004, 32:4776-4785.

46. Ruby JG, Jan $\mathrm{CH}$, Bartel DP: Intronic microRNA precursors that bypass Drosha processing. Nature 2007, 448:83-86.

47. Okamura K, Hagen JW, Duan H, Tyler DM, Lai EC: The mirtron pathway generates microRNA-class regulatory RNAs in Drosophila. Cell 2007, 130:89-100.

48. Berezikov E, Chung WJ, Willis J, Cuppen E, Lai EC: Mammalian mirtron genes. Mol Cell 2007, 28:328-336.

49. Bernstein E, Caudy AA, Hammond SM, Hannon GJ: Role for a bidentate ribonuclease in the initiation step of RNA interference. Nature 2001, 409:363-366.

50. Ketting RF, Fischer SE, Bernstein E, Sijen T, Hannon GJ, Plasterk RH: Dicer functions in RNA interference and in synthesis of small RNA involved in developmental timing in C. elegans. Genes Dev 2001, 15:2654-2659.

51. Knight SW, Bass BL: A role for the RNase III enzyme DCR-1 in RNA interference and germ line development in Caenorhabditis elegans. Science 2001, 293:2269-2271.

52. MacRae IJ, Zhou K, Doudna JA: Structural determinants of RNA recognition and cleavage by Dicer. Nat Struct Mol Biol 2007, 14:934-940.

53. Chendrimada TP, Gregory RI, Kumaraswamy E, Norman J, Cooch N, Nishikura K, Shiekhattar R: TRBP recruits the Dicer complex to Ago2 for microRNA processing and gene silencing. Nature 2005, 436:740-744.

54. Lee Y, Hur I, Park SY, Kim YK, Suh MR, Kim VN: The role of PACT in the RNA silencing pathway. EMBO J 2006, 25:522-532.

55. Khvorova A, Reynolds A, Jayasena SD: Functional siRNAs and miRNAs exhibit strand bias. Cell 2003, 115:209-216. 
56. Meister G, Landthaler M, Patkaniowska A, Dorsett Y, Teng G, Tuschl T: Human Argonaute2 mediates RNA cleavage targeted by miRNAs and siRNAs. Mol Cell 2004, 15:185-197.

57. Azuma-Mukai A, Oguri H, Mituyama T, Qian ZR, Asai K, Siomi H, Siomi MC: Characterization of endogenous human Argonautes and their miRNA partners in RNA silencing. Proc Natl Acad Sci U S A 2008, 105:7964-7969.

58. Thomson JM, Newman M, Parker JS, Morin-Kensicki EM, Wright T, Hammond SM: Extensive post-transcriptional regulation of microRNAs and its implications for cancer. Genes Dev 2006, 20:2202-2207.

59. Beezhold KJ, Castranova V, Chen F: Microprocessor of microRNAs: regulation and potential for therapeutic intervention. Mol Cancer 2010, 9:134.

60. Gregory RI, Yan KP, Amuthan G, Chendrimada T, Doratotaj B, Cooch N, Shiekhattar R: The Microprocessor complex mediates the genesis of microRNAs. Nature 2004, 432:235-240.

61. Fukuda T, Yamagata K, Fujiyama S, Matsumoto T, Koshida I, Yoshimura K, Mihara M, Naitou M, Endoh H, Nakamura T, et al: DEAD-box RNA helicase subunits of the Drosha complex are required for processing of rRNA and a subset of microRNAs. Nat Cell Biol 2007, 9:604-611.

62. Davis BN, Hilyard AC, Lagna G, Hata A: SMAD proteins control DROSHA-mediated microRNA maturation. Nature 2008, 454:56-61.

63. Davis BN, Hilyard AC, Nguyen PH, Lagna G, Hata A: Smad proteins bind a conserved RNA sequence to promote microRNA maturation by Drosha. Mol Cell 2010, 39:373384.

64. Suzuki HI, Yamagata K, Sugimoto K, Iwamoto T, Kato S, Miyazono K: Modulation of microRNA processing by p53. Nature 2009, 460:529-533.

65. Raver-Shapira N, Marciano E, Meiri E, Spector Y, Rosenfeld N, Moskovits N, Bentwich $\mathrm{Z}$, Oren M: Transcriptional activation of miR-34a contributes to p53-mediated apoptosis. Mol Cell 2007, 26:731-743.

66. Lewis BP, Shih IH, Jones-Rhoades MW, Bartel DP, Burge CB: Prediction of mammalian microRNA targets. Cell 2003, 115:787-798.

67. Orom UA, Nielsen FC, Lund AH: MicroRNA-10a binds the 5'UTR of ribosomal protein mRNAs and enhances their translation. Mol Cell 2008, 30:460-471.

68. Lal A, Navarro F, Maher CA, Maliszewski LE, Yan N, O'Day E, Chowdhury D, Dykxhoorn DM, Tsai P, Hofmann O, et al: miR-24 Inhibits cell proliferation by targeting E2F2, MYC, and other cell-cycle genes via binding to "seedless" 3'UTR microRNA recognition elements. Mol Cell 2009, 35:610-625. 
69. Chekulaeva M, Filipowicz W: Mechanisms of miRNA-mediated post-transcriptional regulation in animal cells. Curr Opin Cell Biol 2009, 21:452-460.

70. Liu J, Rivas FV, Wohlschlegel J, Yates JR, 3rd, Parker R, Hannon GJ: A role for the Pbody component GW182 in microRNA function. Nat Cell Biol 2005, 7:1261-1266.

71. Eulalio A, Helms S, Fritzsch C, Fauser M, Izaurralde E: A C-terminal silencing domain in GW182 is essential for miRNA function. RNA 2009, 15:1067-1077.

72. Eulalio A, Tritschler F, Buttner R, Weichenrieder O, Izaurralde E, Truffault V: The RRM domain in GW182 proteins contributes to miRNA-mediated gene silencing. Nucleic Acids Res 2009, 37:2974-2983.

73. Behm-Ansmant I, Rehwinkel J, Doerks T, Stark A, Bork P, Izaurralde E: mRNA degradation by miRNAs and GW182 requires both CCR4:NOT deadenylase and DCP1:DCP2 decapping complexes. Genes Dev 2006, 20:1885-1898.

74. Eulalio A, Huntzinger E, Nishihara T, Rehwinkel J, Fauser M, Izaurralde E: Deadenylation is a widespread effect of miRNA regulation. $R N A 2009, \mathbf{1 5 : 2 1 - 3 2}$.

75. Fabian MR, Mathonnet G, Sundermeier T, Mathys H, Zipprich JT, Svitkin YV, Rivas F, Jinek M, Wohlschlegel J, Doudna JA, et al: Mammalian miRNA RISC recruits CAF1 and PABP to affect PABP-dependent deadenylation. Mol Cell 2009, 35:868-880.

76. Eulalio A, Behm-Ansmant I, Schweizer D, Izaurralde E: P-body formation is a consequence, not the cause, of RNA-mediated gene silencing. Mol Cell Biol 2007, 27:3970-3981.

77. Eulalio A, Huntzinger E, Izaurralde E: GW182 interaction with Argonaute is essential for miRNA-mediated translational repression and mRNA decay. Nat Struct Mol Biol 2008, 15:346-353.

78. Pillai RS, Bhattacharyya SN, Artus CG, Zoller T, Cougot N, Basyuk E, Bertrand E, Filipowicz W: Inhibition of translational initiation by Let-7 MicroRNA in human cells. Science 2005, 309:1573-1576.

79. Humphreys DT, Westman BJ, Martin DI, Preiss T: MicroRNAs control translation initiation by inhibiting eukaryotic initiation factor $4 \mathrm{E} / \mathrm{cap}$ and poly(A) tail function. Proc Natl Acad Sci U S A 2005, 102:16961-16966.

80. Mathonnet G, Fabian MR, Svitkin YV, Parsyan A, Huck L, Murata T, Biffo S, Merrick WC, Darzynkiewicz E, Pillai RS, et al: MicroRNA inhibition of translation initiation in vitro by targeting the cap-binding complex eIF4F. Science 2007, 317:1764-1767.

81. Chendrimada TP, Finn KJ, Ji X, Baillat D, Gregory RI, Liebhaber SA, Pasquinelli AE, Shiekhattar R: MicroRNA silencing through RISC recruitment of eIF6. Nature 2007, 447:823-828.

82. Petersen CP, Bordeleau ME, Pelletier J, Sharp PA: Short RNAs repress translation after initiation in mammalian cells. Mol Cell 2006, 21:533-542. 
83. Lytle JR, Yario TA, Steitz JA: Target mRNAs are repressed as efficiently by microRNA-binding sites in the 5' UTR as in the 3' UTR. Proc Natl Acad Sci U S A 2007, 104:9667-9672.

84. Nottrott S, Simard MJ, Richter JD: Human let-7a miRNA blocks protein production on actively translating polyribosomes. Nat Struct Mol Biol 2006, 13:1108-1114.

85. Schwamborn JC, Berezikov E, Knoblich JA: The TRIM-NHL protein TRIM32 activates microRNAs and prevents self-renewal in mouse neural progenitors. Cell 2009, 136:913-925.

86. Bhattacharyya SN, Habermacher R, Martine U, Closs EI, Filipowicz W: Relief of microRNA-mediated translational repression in human cells subjected to stress. Cell 2006, 125:1111-1124.

87. Kedde M, Strasser MJ, Boldajipour B, Oude Vrielink JA, Slanchev K, le Sage C, Nagel R, Voorhoeve PM, van Duijse J, Orom UA, et al: RNA-binding protein Dnd1 inhibits microRNA access to target mRNA. Cell 2007, 131:1273-1286.

88. Huang J, Liang Z, Yang B, Tian H, Ma J, Zhang H: Derepression of microRNAmediated protein translation inhibition by apolipoprotein B mRNA-editing enzyme catalytic polypeptide-like 3G (APOBEC3G) and its family members. $J$ Biol Chem 2007, 282:33632-33640.

89. Schratt GM, Tuebing F, Nigh EA, Kane CG, Sabatini ME, Kiebler M, Greenberg ME: A brain-specific microRNA regulates dendritic spine development. Nature 2006, 439:283-289.

90. Vasudevan S, Tong Y, Steitz JA: Switching from repression to activation: microRNAs can up-regulate translation. Science 2007, 318:1931-1934.

91. Calin GA, Dumitru CD, Shimizu M, Bichi R, Zupo S, Noch E, Aldler H, Rattan S, Keating M, Rai K, et al: Frequent deletions and down-regulation of micro- RNA genes miR15 and miR16 at 13q14 in chronic lymphocytic leukemia. Proc Natl Acad Sci U S A 2002, 99:15524-15529.

92. Cimmino A, Calin GA, Fabbri M, Iorio MV, Ferracin M, Shimizu M, Wojcik SE, Aqeilan RI, Zupo S, Dono M, et al: miR-15 and miR-16 induce apoptosis by targeting BCL2. Proc Natl Acad Sci U S A 2005, 102:13944-13949.

93. Johnson SM, Grosshans H, Shingara J, Byrom M, Jarvis R, Cheng A, Labourier E, Reinert KL, Brown D, Slack FJ: RAS is regulated by the let-7 microRNA family. Cell 2005, 120:635-647.

94. Lee YS, Dutta A: The tumor suppressor microRNA let-7 represses the HMGA2 oncogene. Genes Dev 2007, 21:1025-1030.

95. Sampson VB, Rong NH, Han J, Yang Q, Aris V, Soteropoulos P, Petrelli NJ, Dunn SP, Krueger LJ: MicroRNA let-7a down-regulates MYC and reverts MYC-induced growth in Burkitt lymphoma cells. Cancer Res 2007, 67:9762-9770. 
96. Yu F, Yao H, Zhu P, Zhang X, Pan Q, Gong C, Huang Y, Hu X, Su F, Lieberman J, Song E: let-7 regulates self renewal and tumorigenicity of breast cancer cells. Cell 2007, 131:1109-1123.

97. Kumar MS, Erkeland SJ, Pester RE, Chen CY, Ebert MS, Sharp PA, Jacks T: Suppression of non-small cell lung tumor development by the let-7 microRNA family. Proc Natl Acad Sci U S A 2008, 105:3903-3908.

98. Iorio MV, Ferracin M, Liu CG, Veronese A, Spizzo R, Sabbioni S, Magri E, Pedriali M, Fabbri M, Campiglio M, et al: MicroRNA gene expression deregulation in human breast cancer. Cancer Res 2005, 65:7065-7070.

99. Slaby O, Svoboda M, Fabian P, Smerdova T, Knoflickova D, Bednarikova M, Nenutil R, Vyzula R: Altered expression of miR-21, miR-31, miR-143 and miR-145 is related to clinicopathologic features of colorectal cancer. Oncology 2007, 72:397-402.

100. Sachdeva M, Zhu S, Wu F, Wu H, Walia V, Kumar S, Elble R, Watabe K, Mo YY: p53 represses c-Myc through induction of the tumor suppressor miR-145. Proc Natl Acad Sci U S A 2009, 106:3207-3212.

101. Scott GK, Goga A, Bhaumik D, Berger CE, Sullivan CS, Benz CC: Coordinate suppression of ERBB2 and ERBB3 by enforced expression of micro-RNA miR-125a or miR-125b. J Biol Chem 2007, 282:1479-1486.

102. Iorio MV, Casalini P, Piovan C, Di Leva G, Merlo A, Triulzi T, Menard S, Croce CM, Tagliabue E: microRNA-205 regulates HER3 in human breast cancer. Cancer Res 2009, 69:2195-2200.

103. Asangani IA, Rasheed SA, Nikolova DA, Leupold JH, Colburn NH, Post S, Allgayer H: MicroRNA-21 (miR-21) post-transcriptionally downregulates tumor suppressor Pded 4 and stimulates invasion, intravasation and metastasis in colorectal cancer. Oncogene 2008, 27:2128-2136.

104. Ji R, Cheng Y, Yue J, Yang J, Liu X, Chen H, Dean DB, Zhang C: MicroRNA expression signature and antisense-mediated depletion reveal an essential role of MicroRNA in vascular neointimal lesion formation. Circ Res 2007, 100:1579-1588.

105. Meng F, Henson R, Wehbe-Janek H, Ghoshal K, Jacob ST, Patel T: MicroRNA-21 regulates expression of the PTEN tumor suppressor gene in human hepatocellular cancer. Gastroenterology 2007, 133:647-658.

106. Zhu S, Si ML, Wu H, Mo YY: MicroRNA-21 targets the tumor suppressor gene tropomyosin 1 (TPM1). J Biol Chem 2007, 282:14328-14336.

107. Iorio MV, Croce CM: MicroRNAs in cancer: small molecules with a huge impact. $J$ Clin Oncol 2009, 27:5848-5856.

108. Faraoni I, Antonetti FR, Cardone J, Bonmassar E: miR-155 gene: a typical multifunctional microRNA. Biochim Biophys Acta 2009, 1792:497-505. 
109. Tam W, Hughes SH, Hayward WS, Besmer P: Avian bic, a gene isolated from a common retroviral site in avian leukosis virus-induced lymphomas that encodes a noncoding RNA, cooperates with c-myc in lymphomagenesis and erythroleukemogenesis. $J$ Virol 2002, 76:4275-4286.

110. Kong W, He L, Coppola M, Guo J, Esposito NN, Coppola D, Cheng JQ: MicroRNA-155 regulates cell survival, growth, and chemosensitivity by targeting FOXO3a in breast cancer. J Biol Chem 2010, 285:17869-17879.

111. Jiang S, Zhang HW, Lu MH, He XH, Li Y, Gu H, Liu MF, Wang ED: MicroRNA-155 functions as an OncomiR in breast cancer by targeting the suppressor of cytokine signaling 1 gene. Cancer Res 2010, 70:3119-3127.

112. Rai D, Kim SW, McKeller MR, Dahia PL, Aguiar RC: Targeting of SMAD5 links microRNA-155 to the TGF-beta pathway and lymphomagenesis. Proc Natl Acad Sci U S A 2010, 107:3111-3116.

113. Gironella M, Seux M, Xie MJ, Cano C, Tomasini R, Gommeaux J, Garcia S, Nowak J, Yeung ML, Jeang KT, et al: Tumor protein 53-induced nuclear protein 1 expression is repressed by miR-155, and its restoration inhibits pancreatic tumor development. Proc Natl Acad Sci U S A 2007, 104:16170-16175.

114. Miller TE, Ghoshal K, Ramaswamy B, Roy S, Datta J, Shapiro CL, Jacob S, Majumder S: MicroRNA-221/222 confers tamoxifen resistance in breast cancer by targeting p27Kip1. J Biol Chem 2008, 283:29897-29903.

115. Chun-Zhi Z, Lei H, An-Ling Z, Yan-Chao F, Xiao Y, Guang-Xiu W, Zhi-Fan J, Pei-Yu $\mathrm{P}$, Qing-Yu Z, Chun-Sheng K: MicroRNA-221 and microRNA-222 regulate gastric carcinoma cell proliferation and radioresistance by targeting PTEN. BMC Cancer 2010, 10:367.

116. Zhang CZ, Zhang JX, Zhang AL, Shi ZD, Han L, Jia ZF, Yang WD, Wang GX, Jiang T, You YP, et al: MiR-221 and miR-222 target PUMA to induce cell survival in glioblastoma. Mol Cancer 2010, 9:229.

117. Zhao JJ, Lin J, Yang H, Kong W, He L, Ma X, Coppola D, Cheng JQ: MicroRNA221/222 negatively regulates estrogen receptor alpha and is associated with tamoxifen resistance in breast cancer. J Biol Chem 2008, 283:31079-31086.

118. Calin GA, Ferracin M, Cimmino A, Di Leva G, Shimizu M, Wojcik SE, Iorio MV, Visone R, Sever NI, Fabbri M, et al: A MicroRNA signature associated with prognosis and progression in chronic lymphocytic leukemia. $N$ Engl J Med 2005, 353:17931801.

119. Yanaihara N, Caplen N, Bowman E, Seike M, Kumamoto K, Yi M, Stephens RM, Okamoto A, Yokota J, Tanaka T, et al: Unique microRNA molecular profiles in lung cancer diagnosis and prognosis. Cancer Cell 2006, 9:189-198. 
120. Lee EJ, Gusev Y, Jiang J, Nuovo GJ, Lerner MR, Frankel WL, Morgan DL, Postier RG, Brackett DJ, Schmittgen TD: Expression profiling identifies microRNA signature in pancreatic cancer. Int J Cancer 2007, 120:1046-1054.

121. Budhu A, Jia HL, Forgues M, Liu CG, Goldstein D, Lam A, Zanetti KA, Ye QH, Qin LX, Croce CM, et al: Identification of metastasis-related microRNAs in hepatocellular carcinoma. Hepatology 2008, 47:897-907.

122. Ratner ES, Tuck D, Richter C, Nallur S, Patel RM, Schultz V, Hui P, Schwartz PE, Rutherford TJ, Weidhaas JB: MicroRNA signatures differentiate uterine cancer tumor subtypes. Gynecol Oncol 2010, 118:251-257.

123. Lanford RE, Hildebrandt-Eriksen ES, Petri A, Persson R, Lindow M, Munk ME, Kauppinen S, Orum H: Therapeutic silencing of microRNA-122 in primates with chronic hepatitis C virus infection. Science 2010, 327:198-201.

124. Wahid F, Shehzad A, Khan T, Kim YY: MicroRNAs: synthesis, mechanism, function, and recent clinical trials. Biochim Biophys Acta 2010, 1803:1231-1243.

125. Monkley SJ, Pritchard CA, Critchley DR: Analysis of the mammalian talin2 gene TLN2. Biochem Biophys Res Commun 2001, 286:880-885.

126. Critchley DR, Gingras AR: Talin at a glance. J Cell Sci 2008, 121:1345-1347.

127. Campo-Paysaa F, Semon M, Cameron RA, Peterson KJ, Schubert M: microRNA complements in deuterostomes: origin and evolution of microRNAs. Evol Dev 2011, 13:15-27.

128. Zheng H, Chu J, Zeng Y, Loh HH, Law PY: Yin Yang 1 phosphorylation contributes to the differential effects of $\{$ micro\}-opioid receptor agonists on microRNA-190 expression. J Biol Chem 2010.

129. Baskerville S, Bartel DP: Microarray profiling of microRNAs reveals frequent coexpression with neighboring miRNAs and host genes. $R N A$ 2005, 11:241-247.

130. Corcoran DL, Pandit KV, Gordon B, Bhattacharjee A, Kaminski N, Benos PV: Features of mammalian microRNA promoters emerge from polymerase II chromatin immunoprecipitation data. PLoS One 2009, 4:e5279.

131. Cheng AM, Byrom MW, Shelton J, Ford LP: Antisense inhibition of human miRNAs and indications for an involvement of miRNA in cell growth and apoptosis. Nucleic Acids Res 2005, 33:1290-1297.

132. Guglielmelli P, Tozzi L, Pancrazzi A, Bogani C, Antonioli E, Ponziani V, Poli G, Zini R, Ferrari S, Manfredini R, et al: MicroRNA expression profile in granulocytes from primary myelofibrosis patients. Exp Hematol 2007, 35:1708-1718.

133. Zhang Y, Li M, Wang H, Fisher WE, Lin PH, Yao Q, Chen C: Profiling of 95 microRNAs in pancreatic cancer cell lines and surgical specimens by real-time PCR analysis. World J Surg 2009, 33:698-709. 
134. Lowery AJ, Miller N, Devaney A, McNeill RE, Davoren PA, Lemetre C, Benes V, Schmidt S, Blake J, Ball G, Kerin MJ: MicroRNA signatures predict oestrogen receptor, progesterone receptor and HER2/neu receptor status in breast cancer. Breast Cancer Res 2009, 11:R27.

135. Zheng $\mathrm{H}$, Zeng $\mathrm{Y}$, Zhang $\mathrm{X}$, Chu J, Loh HH, Law PY: mu-Opioid receptor agonists differentially regulate the expression of miR-190 and NeuroD. Mol Pharmacol 2010, 77:102-109.

136. Bray I, Bryan K, Prenter S, Buckley PG, Foley NH, Murphy DM, Alcock L, Mestdagh P, Vandesompele J, Speleman F, et al: Widespread dysregulation of MiRNAs by MYCN amplification and chromosomal imbalances in neuroblastoma: association of miRNA expression with survival. PLoS One 2009, 4:e7850.

137. Lusardi TA, Farr CD, Faulkner CL, Pignataro G, Yang T, Lan J, Simon RP, Saugstad JA: Ischemic preconditioning regulates expression of microRNAs and a predicted target, MeCP2, in mouse cortex. J Cereb Blood Flow Metab 2010, 30:744-756.

138. Shimizu K, Okada M, Takano A, Nagai K: SCOP, a novel gene product expressed in a circadian manner in rat suprachiasmatic nucleus. FEBS Lett 1999, 458:363-369.

139. Brognard J, Sierecki E, Gao T, Newton AC: PHLPP and a second isoform, PHLPP2, differentially attenuate the amplitude of Akt signaling by regulating distinct Akt isoforms. Mol Cell 2007, 25:917-931.

140. Shimizu K, Okada M, Nagai K, Fukada Y: Suprachiasmatic nucleus circadian oscillatory protein, a novel binding partner of $\mathrm{K}$-Ras in the membrane rafts, negatively regulates MAPK pathway. J Biol Chem 2003, 278:14920-14925.

141. Gao T, Brognard J, Newton AC: The phosphatase PHLPP controls the cellular levels of protein kinase C. J Biol Chem 2008, 283:6300-6311.

142. Qiao M, Wang Y, Xu X, Lu J, Dong Y, Tao W, Stein J, Stein GS, Iglehart JD, Shi Q, Pardee AB: Mst1 is an interacting protein that mediates PHLPPs' induced apoptosis. Mol Cell 2010, 38:512-523.

143. Lin Y, Khokhlatchev A, Figeys D, Avruch J: Death-associated protein 4 binds MST1 and augments MST1-induced apoptosis. J Biol Chem 2002, 277:47991-48001.

144. Graves JD, Gotoh Y, Draves KE, Ambrose D, Han DK, Wright M, Chernoff J, Clark EA, Krebs EG: Caspase-mediated activation and induction of apoptosis by the mammalian Ste20-like kinase Mst1. EMBO J 1998, 17:2224-2234.

145. Liu J, Stevens PD, Gao T: mTOR-Dependent Regulation of PHLPP Expression Controls the Rapamycin Sensitivity in Cancer Cells. J Biol Chem 2011, 286:65106520.

146. Zhang $\mathrm{M}$, Riedel $\mathrm{H}$ : Insulin receptor kinase-independent signaling via tyrosine phosphorylation of phosphatase PHLPP1. J Cell Biochem 2009, 107:65-75. 
147. Pei H, Li L, Fridley BL, Jenkins GD, Kalari KR, Lingle W, Petersen G, Lou Z, Wang L: FKBP51 affects cancer cell response to chemotherapy by negatively regulating Akt. Cancer Cell 2009, 16:259-266.

148. Gao MH, Miyanohara A, Feramisco JR, Tang T: Activation of PH-domain leucine-rich protein phosphatase 2 (PHLPP2) by agonist stimulation in cardiac myocytes expressing adenylyl cyclase type 6. Biochem Biophys Res Commun 2009, 384:193-198.

149. Li X, Liu J, Gao T: beta-TrCP-mediated ubiquitination and degradation of PHLPP1 are negatively regulated by Akt. Mol Cell Biol 2009, 29:6192-6205.

150. Jones PF, Jakubowicz T, Pitossi FJ, Maurer F, Hemmings BA: Molecular cloning and identification of a serine/threonine protein kinase of the second-messenger subfamily. Proc Natl Acad Sci U S A 1991, 88:4171-4175.

151. Coffer PJ, Woodgett JR: Molecular cloning and characterisation of a novel putative protein-serine kinase related to the cAMP-dependent and protein kinase $\mathbf{C}$ families. Eur J Biochem 1991, 201:475-481.

152. Bellacosa A, Testa JR, Staal SP, Tsichlis PN: A retroviral oncogene, akt, encoding a serine-threonine kinase containing an SH2-like region. Science 1991, 254:274-277.

153. Gonzalez E, McGraw TE: The Akt kinases: isoform specificity in metabolism and cancer. Cell Cycle 2009, 8:2502-2508.

154. Manning BD, Cantley LC: AKT/PKB signaling: navigating downstream. Cell 2007, 129:1261-1274.

155. Souza K, Maddock DA, Zhang Q, Chen J, Chiu C, Mehta S, Wan Y: Arsenite activation of P13K/AKT cell survival pathway is mediated by $\mathrm{p38}$ in cultured human keratinocytes. Mol Med 2001, 7:767-772.

156. Wang ZX, Jiang CS, Liu L, Wang XH, Jin HJ, Wu Q, Chen Q: The role of Akt on arsenic trioxide suppression of 3T3-L1 preadipocyte differentiation. Cell Res 2005, 15:379-386.

157. Liu LZ, Jiang Y, Carpenter RL, Jing Y, Peiper SC, Jiang BH: Role and mechanism of arsenic in regulating angiogenesis. PLoS One 2011, 6:e20858.

158. Chou WC, Jie C, Kenedy AA, Jones RJ, Trush MA, Dang CV: Role of NADPH oxidase in arsenic-induced reactive oxygen species formation and cytotoxicity in myeloid leukemia cells. Proc Natl Acad Sci U S A 2004, 101:4578-4583.

159. Meng TC, Fukada T, Tonks NK: Reversible oxidation and inactivation of protein tyrosine phosphatases in vivo. Mol Cell 2002, 9:387-399.

160. Miyazaki T, Bub JD, Iwamoto Y: c-Jun NH(2)-terminal kinase mediates leptinstimulated androgen-independent prostate cancer cell proliferation via signal transducer and activator of transcription 3 and Akt. Biochim Biophys Acta 2008, 1782:593-604. 
161. Takezawa K, Okamoto I, Nishio K, Janne PA, Nakagawa K: Role of ERK-BIM and STAT3-survivin signaling pathways in ALK inhibitor-induced apoptosis in EML4ALK-positive lung cancer. Clin Cancer Res 2011, 17:2140-2148.

162. Carnero A: The PKB/AKT pathway in cancer. Curr Pharm Des 2010, 16:34-44.

163. Huang J, Manning BD: A complex interplay between Akt, TSC2 and the two mTOR complexes. Biochem Soc Trans 2009, 37:217-222.

164. Liang J, Zubovitz J, Petrocelli T, Kotchetkov R, Connor MK, Han K, Lee JH, Ciarallo S, Catzavelos C, Beniston R, et al: PKB/Akt phosphorylates p27, impairs nuclear import of p27 and opposes p27-mediated G1 arrest. Nat Med 2002, 8:1153-1160.

165. Ackah E, Yu J, Zoellner S, Iwakiri Y, Skurk C, Shibata R, Ouchi N, Easton RM, Galasso G, Birnbaum MJ, et al: Akt1/protein kinase Balpha is critical for ischemic and VEGF-mediated angiogenesis. J Clin Invest 2005, 115:2119-2127.

166. Fulton D, Gratton JP, McCabe TJ, Fontana J, Fujio Y, Walsh K, Franke TF, Papapetropoulos A, Sessa WC: Regulation of endothelium-derived nitric oxide production by the protein kinase Akt. Nature 1999, 399:597-601. 


\section{Figures:}

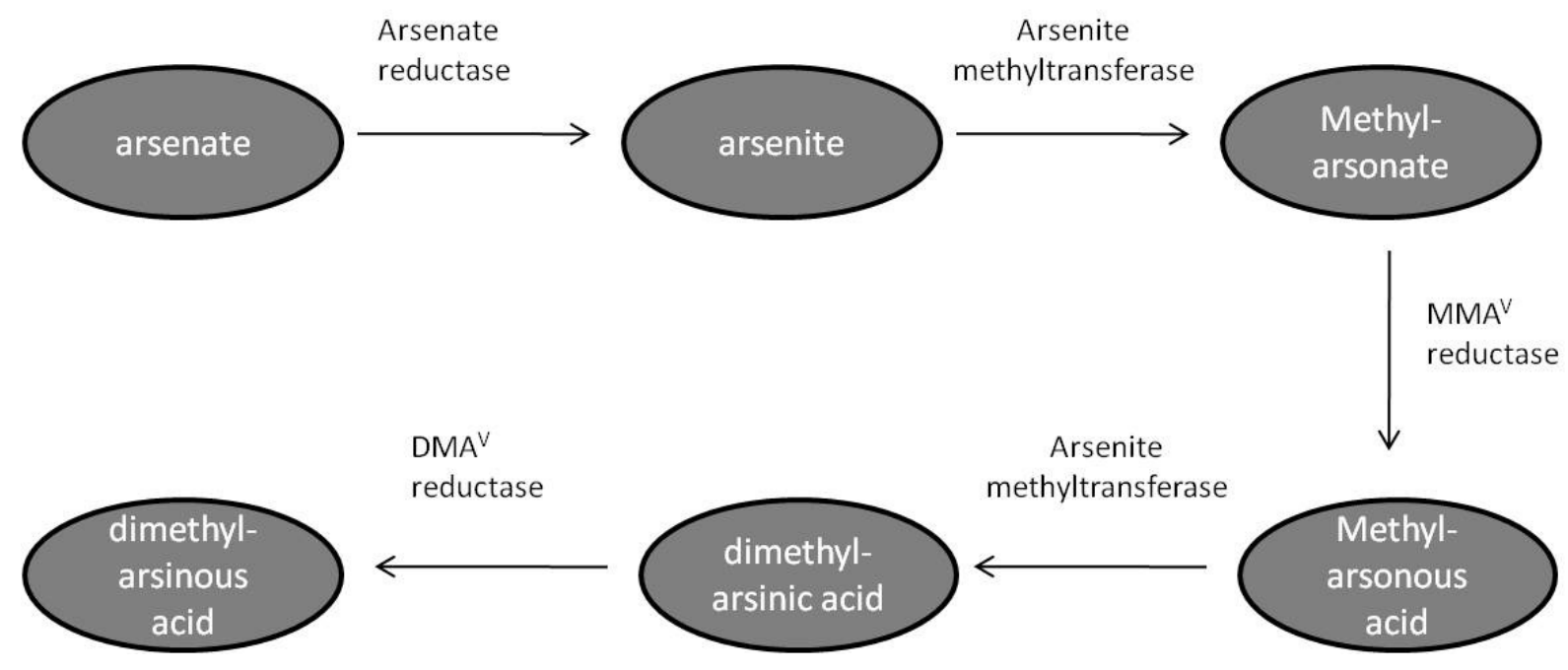

Fig. 1. Biotransformation of inorganic arsenic within mammalian cells. 


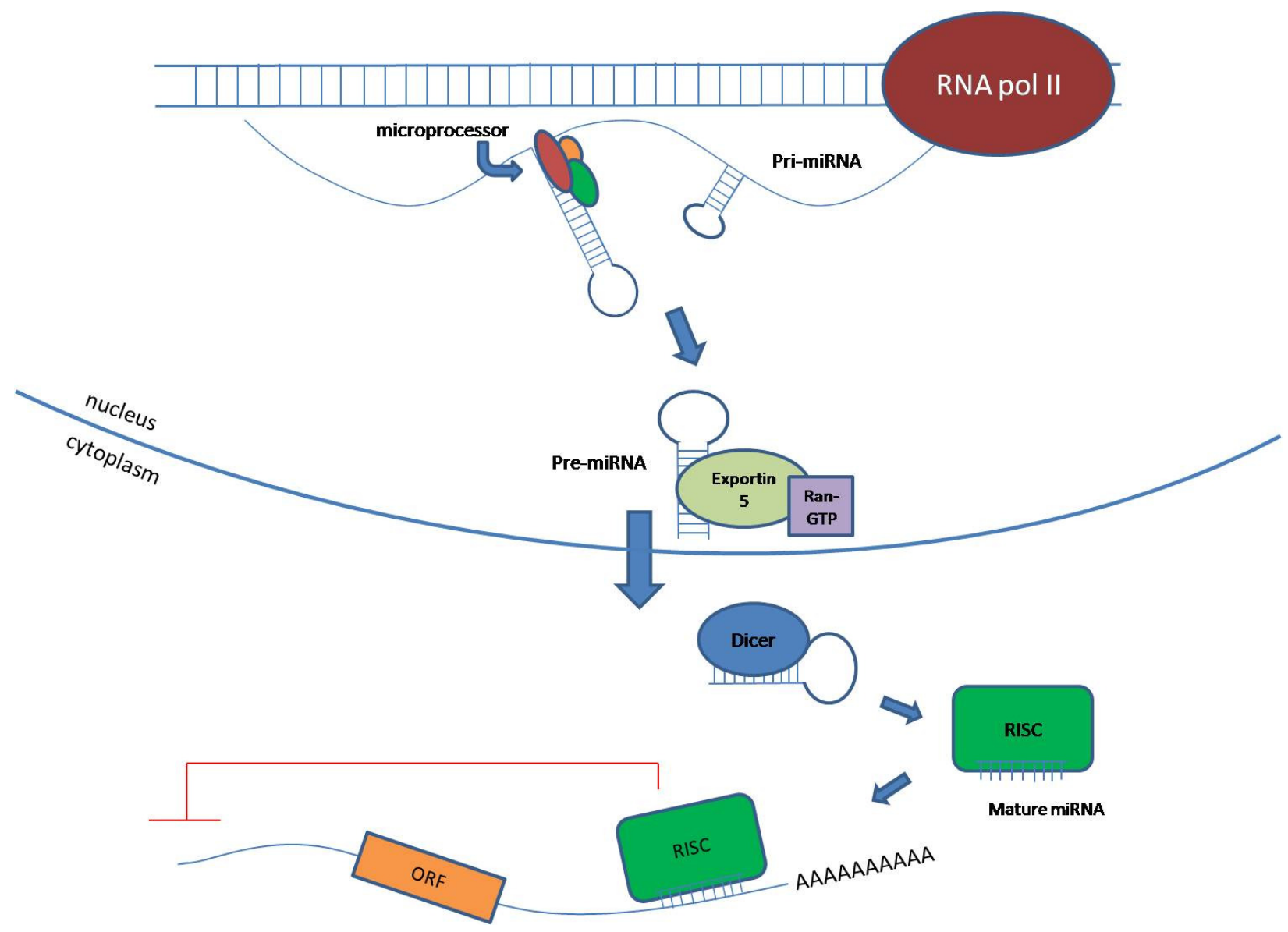

Fig. 2. Schematic representation of miRNA biogenesis and function. Adapted from Beezhold, K. et al. Molecular Cancer 9, 134 [59] 


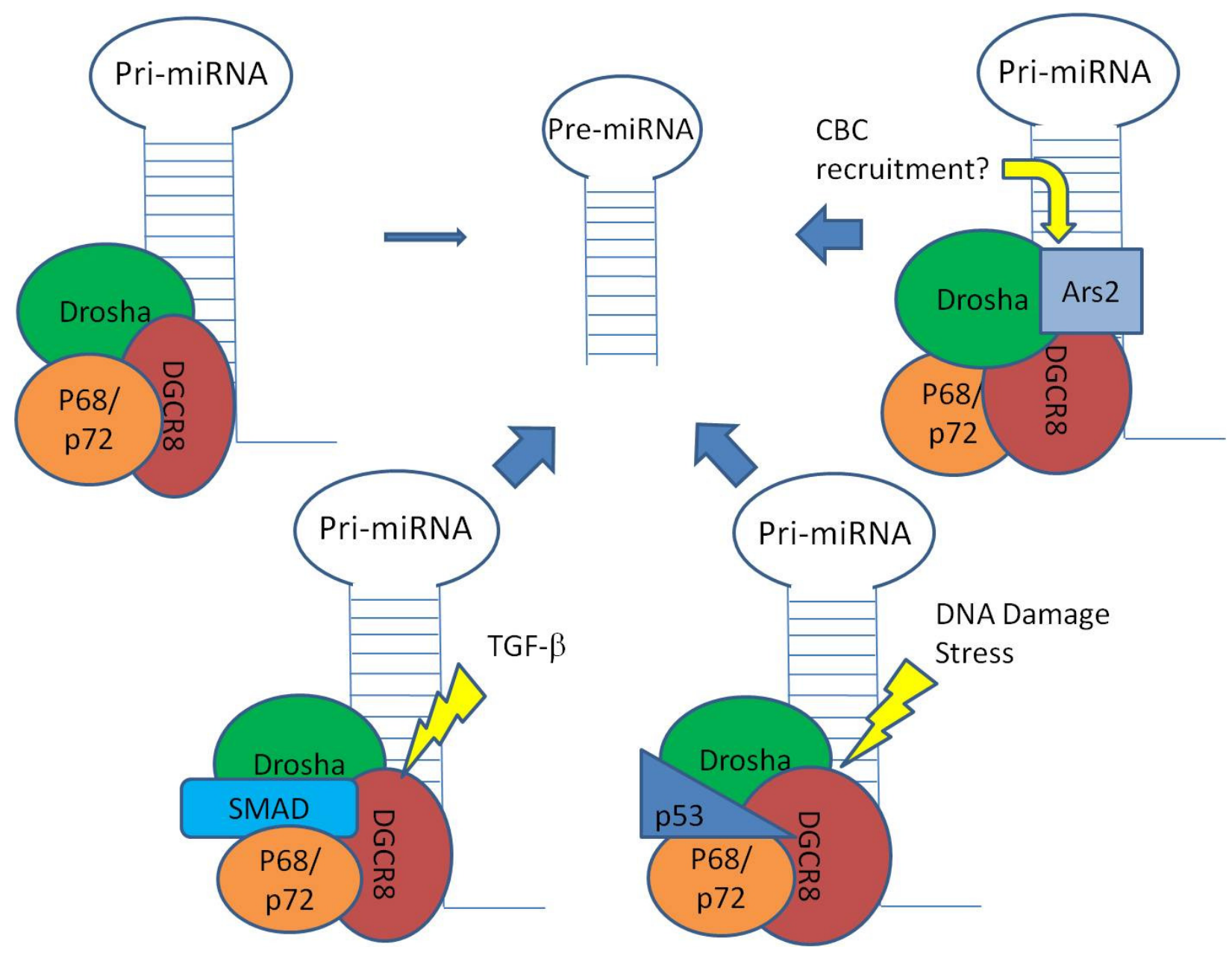

Fig. 3. Modulation of microprocessor function. Adapted from Beezhold, K. et al. Molecular Cancer 9, 134 [59]

* Figures 2 and 3 are used with permission from Molecular Cancer. 


\title{
CHAPTER 2
}

\section{miR-190-mediated downregulation of PHLPP contributes to arsenic-induced Akt activation and carcinogenesis}

\author{
Adapted from published manuscript:
}

\section{miR-190-mediated downregulation of PHLPP contributes to arsenic-induced Akt} activation and carcinogenesis

Kevin Beezhold,*’ $†$ Jia Liu,* ’ $\neq$ Hong Kan,* Terry Meighan,* Vince Castranova,* Xianglin Shi, $§$ and Fei Chen*'†' $\neq$

*The Health Effects Laboratory Division, National Institute for Occupational Safety and Health, 1095 Willowdale Road, Morgantown, WV 26505, USA; †Cancer Cell Biology Program, School of Medicine, West Virginia University, Morgantown, WV 26506, USA; ¥Department of Pharmaceutical Sciences, Eugene Applebaum College of Pharmacy and Health Sciences, Wayne State University, 259 Mack Avenue, Detroit, MI 48201, USA; §Graduate Center for Toxicology, University of Kentucky, Lexington, UK, USA.

Address correspondence to: Fei Chen, Ph.D., Department of Pharmaceutical Sciences, Wayne State University, 259 Mack Avenue, Detroit, MI 48201,Email: fchen@wayne.edu

Toxicol. Sci (2011) first published online July 12, 2011.

* Section researching response of miR-155 to arsenic (fig 1 and 2) was added for this dissertation and is not in the original manuscript 


\begin{abstract}
:
The role of trivalent arsenic $\left(\mathrm{As}^{3+}\right)$ on the regulation of the recently identified noncoding small RNAs, mainly, microRNAs (miRNAs), has not been explored so far. In the present study we provide evidence showing that $\mathrm{As}^{3+}$ is a potent inducer for the expression of miR-190 in human bronchial epithelial cells. The induction of miR-190 by $\mathrm{As}^{3+}$ is concentration-dependent and associated with the expression of the host gene of miR-190, talin 2, a gene encoding a highmolecular-weight cytoskeletal protein. The elevated level of miR-190 induced by $\mathrm{As}^{3+}$ is capable of down-regulating the translation of the $\mathrm{PH}$ domain leucin-rich repeat protein phosphatase (PHLPP), a negative regulator of Akt signaling. Such a down-regulation is occurred through direct interaction of the miR-190 with the 3'-UTR region of the PHLPP mRNA, leading to a diminished PHLPP protein expression and consequently, an enhanced Akt activation and expression of vascular endothelial growth factor (VEGF), an Akt-regulated protein. Overexpression of miR-190 itself is able to enhance proliferation and malignant transformation of the cells as determined by anchorage-independent growth of the cells in soft agar. Accordingly, the data presented suggest that induction of miR-190 is one of the key mechanisms in $\mathrm{As}^{3+}$-induced carcinogenesis.
\end{abstract}

Key Words: Arsenite, MicroRNA, Akt, Carcinogenesis. 


\section{Introduction:}

Environmental or occupational exposure to arsenic, especially the trivalent inorganic arsenic $\left(\mathrm{As}^{3+}\right)$, is continually a major public health concern in a number of countries worldwide, including the United States of America (USA) [1]. In the south-western region of the USA, As ${ }^{3+}$ levels in the groundwater of some areas ranged from 680 to $1880 \mu \mathrm{g} / \mathrm{L}$ ( $\sim 9$ to $25 \mu \mathrm{M})[2]$. Several population based case-control studies suggested a strong association of $\mathrm{As}^{3+}$ exposure with small and non-small cell lung cancers [1], and other cancers [3]. It is particularly important to note that not only high levels of $\mathrm{As}^{3+}$ exposure but also low to moderate levels of $\mathrm{As}^{3+}$ exposure in certain regions of the world have been linked to an increased risk of lung cancer. International Agency for Research on Cancer (IARC, 2004) has classified $\mathrm{As}^{3+}$ as a group I carcinogen for lung cancer. In addition, several ecological and cohort studies also confirmed $\mathrm{As}^{3+}$ contribution to human lung cancers [4-6]. Thus, there is an urgent need to understand how lower dose and sustained $\mathrm{As}^{3+}$ exposure causes malignant transformation of the lung cells.

Previous studies by our group and others have shown that $\mathrm{As}^{3+}$ activated several kinases upstream of transcription factors, thereby, regulating the expression of genes important for cell cycle transition and cell proliferation [7-9]. Recently, a group of genes that encode small noncoding RNA, including microRNA (miRNA), small nuclear RNA (snRNA), small nucleolar RNA (snoRNA), and piwiRNA, have been identified. In this study, we explored the effect of $\mathrm{As}^{3+}$ on the expression of miRNAs.

Human miRNA genes are either located in intergenic areas or in introns of known genes. Under the regulation of RNA polymerase II, primary miRNA (pri-miRNA) is transcribed and then subjected to processing by the RNase enzyme Drosha in the nucleus to form precursor 
miRNA (pre-miRNA) with hairpin loops about 70 nucleotides in length. The pre-miRNA is then exported to the cytoplasm by the nuclear membrane protein Exportin-5 and further processed by the RNase Dicer to generate mature miRNA. Following association with the miRISC protein complex, one strand of the mature miRNA binds to its complementary 3-UTR region of the target mRNA to repress translation or promote degradation of the target mRNA, depending on the degree of complementary binding [10].

Emerging evidence suggests that many miRNAs play a pivotal role in malignant transformation and carcinogenesis of cells. Examples of this include the overexpression of miR155 in pancreatic cancer [11] and lymphomas [12], as well as an increase of miR-221/222 in prostate cancer [13]. Increases in miR-155 expression have been attributed to activation of NF$\kappa \mathrm{B}$ [14] through JNK[15] and AP-1 transcription factors [16]. Increases in miR-155 expression are linked to repressing apoptosis through Tumor protein 53 induced nuclear protein 1(TP53INP1) [11], enhancing growth and cell plasticity by targeting RhoA [17], and enhancing survival by targeting FOXO3a [18]. Human miRNA-190 is derived from an intron region of the talin 2 gene on chromosome 15 . The proteins of the talin family include talin 1 and talin 2 . They share several highly conserved domains, such as the rod domain and the FERM domain, that are important for interaction with F-actin, integrin, PIP5KI isoforms, and focal adhesion molecules [19, 20]. Earlier data indicate that inhibition of miR-190 decreased growth of HeLa cells without an overall change in the apoptotic caspase activity [21]. An additional study shows that the level of miR-190 was increased in granulocytes from patients with primary myelofibrosis [22]. These results suggest a role for miR-190 in regulating cell cycle or proliferation rate. 
In the present report, we demonstrate that $\mathrm{As}^{3+}$ is a potent inducer of human miR-190, correlating with an increased accumulation of its host gene product, talin 2 protein. Through repressing expression of the $\mathrm{PH}$ domain leucin-rich repeat protein phosphatase (PHLPP), its target gene encoding a negative regulator of Akt signaling, increased level of miR-190 is able to enhance the activation of Akt, leading to an increased expression of vascular endothelial growth factor (VEGF). Overexpression of miR-190 itself is able to enhance proliferation and anchorage-independent growth of the cells in soft-agar. Induction of miR-190, therefore, may provide a new mechanistic insight into the carcinogenicity of environmental or occupational exposure to $\mathrm{As}^{3+}$.

\section{Experimental Procedures}

Cell culture and reagents:

BEAS-2B cells were purchased from ATCC (Manassas, VA) and seeded in 6-well plates at a density of $5 \times 10^{5}$ cells per well. Cells were cultured in DMEM medium supplemented with $5 \%$ FBS for approximately 48 hours before treatment with arsenic chloride $\left(\mathrm{As}^{3+}\right)$ (Sigma, MO) for 6-12 hours (unless otherwise specified). Cells were lysed with TRIzol reagent (Invitrogen, CA) according to manufacturer's instructions for total RNA isolation and real-time RT-PCR

experiments. Antibodies against talin 2, $\beta$-catenin, PHLPP, TP53INP1, phospho-Akt, and nonphospho-Akt were purchased from Santa Cruz Biotechnology, Inc. (Santa Cruz, CA) or Abcam, (Cambridge, MA). ELISA kit for the detection of VEGF was purchased from Thermo Scientific (Rockford, IL). Dual-luciferase assay reagents were purchased from Promega (Madison, WI).

Cloning and analysis of miR-155/BIC promoter: 
The full-length promoter for miR-155/BIC from -2000 to +127 was cloned from commercially purchased human genomic DNA. The promoter region was amplified using upstream primer 5' -gatcgctagcacgttcagattccacagct-3' and downstream primer 5'CTGAAAGCTTGGCGTCCCTGCCACGTTCAA-3'. The product of approximately $2130 \mathrm{bp}$ was excised from an agarose gel and purified using the QIAquick gel extraction kit following the manufacturer's instructions. The PCR product was inserted into the TOPO XL PCR product cloning vector from Invitrogen and large scale isolation of the vector was done following the manufacturer's protocol. The vector with PCR product insert was sequenced to check for proper cloning. The cloning vector plasmid and a PGL3 basic luciferase vector were double digested with NHE1 and HindIII restriction enzymes to insert the promoter region into the luciferase vector using T4 ligase. This ligated vector was then used to transform bacteria for amplification and isolation followed by double digestion to check for proper product insertion.

\section{Western blotting:}

Total cellular proteins were prepared with NuPage LDS sample buffer (Invitrogen, Carlsbad, CA) containing $50 \mu \mathrm{M}$ DTT. The cell lysates were run on 6\% SDS-PAGE gels and then transferred to PVDF membranes (Invitrogen, CA). Membranes were first probed with the primary antibodies at a dilution of 1:2000. The secondary antibody with AP tag was then applied at a dilution of 1:5000. Densitometry analysis of the Western blotting data was performed using a Molecular Biosystems scanner (San Diego CA).

\section{Real-Time RT-PCR:}

The microRNA array was performed using the Cancer MicroRNA qPCR Array with QuantiMir $^{\mathrm{TM}}$ from System Biosciences (Mountain View CA) according to the manufacturer's 
instruction. RNA was isolated from untreated cells as well as cells treated with $20 \mu \mathrm{M}$ As ${ }^{3+}$ for 6 hours using either TRIzol reagent or a MirVana kit from Ambion (Austin TX). The real-time PCR primers and probes for the detection of talin 2 mRNA were designed using Roche online ProbeFinder program (http://www.universalprobelibrary.com) by selecting Automatically Select an intron spanning assay and G6PD as the preferred reference gene. The designated amplicon will be specific for talin 2 mRNA only without contamination of the genomic DNA sequences. The primer sequences are: left primer, 5'-TGGTCAAATCGGCCTCAG-3'; right primer: 5' GACCACTGTCCGTCGTCTG-3'. Probe \#49 was used for the talin 2 real-time PCR. Expression of some individual miRNAs was also analyzed using TaqMan MicroRNA Assays from Applied Biosystems (Foster City, CA). Reverse transcription and real-time steps were performed according to the manufacturer's specifications from total RNA isolates. Either miR30c or snoRNA U47 was used as the endogenous control for all real-time PCR experiments of miRNAs.

Transfection of the cells with miRNA mimic:

To validate the role of miR-190 on its target mRNAs, BEAS-2B cells $\left(1 \times 10^{5} / \mathrm{ml}\right)$ were seeded in 6-well tissue culture plates and transfected with $50 \mathrm{nM}$ pre-miR negative control (mock), miR-190 mimic or $100 \mathrm{nM}$ anti-miR-190 (miR-190In) in triplicates using a reverse transfection procedures as suggested by the manufacturer. The Pre-miR ${ }^{\mathrm{TM}}$ miRNA Starter Kit that contains chemically modified pre-miR negative control, pre-miR-190 mimic and pre-miR190In were purchased from Ambion (Austin, TX). The pre-miR negative control used in mock transfection is a pre-miRNA molecule with random sequence that does not target any known mRNA in the human cells. The transfected cells were first cultured in serum-free medium at $37^{\circ} \mathrm{C}$ for $24 \mathrm{~h}$ and then cultured with 5\% FBS for an additional $24 \mathrm{~h}$. Various concentrations of 
$\mathrm{As}^{3+}$ were added $12 \mathrm{~h}$ before the end of the culture. Protein levels of potential miR-190 targets were determined by Western blotting as described above.

\section{Reporter vector construction:}

To construct a luciferase reporter vector for the talin 2 promoter, the genomic DNA encompassing the 1095 base pairs human talin 2 promoter region were amplified with PCR primers: left primer, 5'-ATCGGCTAGCCACCATGCCAGGCTAATTTT-3', Right primer, 5'CAGTCTCGAGACTCGACACGCATCGTACAC-3'. The left and right primers designed to amplify the region from genomic DNA had the restriction enzyme sites for NheI and XhoI included, respectively, to aid insertion of the cloned region into the vector. The talin 2 promoter fragment was then cloned into the pGL3-basic vector from Promega (Madison, WI).

For the construction of the PHLPP 3'-UTR miRNA-targeting reporter vector, the genomic DNA containing a 911 base pairs region of the human PHLPP 3'-UTR was amplified with left primer, 5'-GATCGAGCTCCAAGAGTCTCCCAGGCTCAC-3', and right primer, 5'GCTAAAGCTTTCCATTTGTGCATTCTGCTT-3'. For the purpose of deleting the miR-190binding site in the 3'-UTR region of the PHLPP mRNA, an additional left primer with sequence 5'-GTCAGAGCTCATGTAAAGACAAAGAACAAAAGGTTTA-3' was introduced in a separate PCR reaction, which generates a deleted 3'-UTR by removing the sequence containing the binding site of miR-190. The amplified fragments were cloned into the pMIR-REPORT vector (Ambion, Austin, TX) utilizing the SacI and HindIII restriction enzyme sites. Chemically competent E. coli (Invitrogen, Carlsbad, CA) were transformed with the vectors following the manufacturers recommendations. DNA sequencing was performed on the purified vectors to confirm proper insertion of the fragments. 


\section{Reporter gene activity assay:}

The indicated reporter vectors were transfected along with a pRL-TK Renilla luciferase vector for normalization into BEAS-2B cells in 24 well tissue culture plates using Lipofectamine 2000 (Invitrogen, Carlsbad, CA), at concentrations of 200 and $10 \mathrm{ng} /$ well, respectively, and 1.56 $\mu 1$ of the transfection reagent in a total volume of $500 \mu \mathrm{l}$. After 12 hours $500 \mu \mathrm{l}$ of DMEM supplemented with 5\% FBS was added and the cells were incubated for an additional 12 hours. Following appropriate treatments or additional co-transfections with miR-190 oligos, a Dual Luciferase Reporter assay (Promega, Madison, WI) was performed according to the manufacturer's specifications.

\section{Generation of stable cell lines:}

Stable cell lines overexpressing either miR-190 or a control oligo were generated by transfecting miRNASelect pEP-hsa-miR-190 and pEP-miR null expression vectors (Cell Biolabs, San Diego CA) into BEAS-2B cells using the same general protocol as the luciferase reporter gene assay. The transfected cells were subjected to selection by puromycin at $1 \mu \mathrm{g} / \mathrm{ml}$ for 3 days.

\section{Cell proliferation and carcinogenic transformation assays:}

Control and miR-190 stably expressing cells were seeded into a 96 -well plate at $5 \times 10^{3}$ cells/well, cultured for 16 hours followed by serum starvation for 12 hours. An assay for proliferation was then performed using Cell Titer 96 AQueous One Solution Cell Proliferation Assay (Promega, Madison WI) according to the manufacturer's specifications. The plate was then read at $490 \mathrm{~nm}$ at 1,2,3, and 4 hour time points. Carcinogenic transformation of the cells was determined by seeding the cells in soft-agar. Briefly, the stably transfected cells were suspended in a $0.33 \%$ agar solution above a $0.5 \%$ agar layer containing 2 - mercaptoethanol, and 
penicillin/streptomycin in wells of 6-well plates. The plates were incubated at $37{ }^{\circ} \mathrm{C}$ and $5 \%$ $\mathrm{CO}_{2}$ in a humidified incubator without feeding for 21 days. The colonies were counted and imaged on days 14 and 21.

Enzyme-linked immunosorbant assay (ELISA):

The protein concentrations of VEGF in supernatants from BEAS-2B cells receiving various treatments were determined using a DuoSet ELISA development system (R\&D systems, Minneapolis MN). The cells were transfected with the pre-miR-190 or pre-miR-190In oligos as described earlier. The supernatants were collected and the ELISA was performed according to the manufacturer's specifications. The supernatants were either diluted 1:1 or not diluted before incubation with the ELISA plate. Visualization was achieved using appropriate volumes of solution A and solution B from the Substrate Reagent Pack (R\&D systems, Minneapolis MN). The reaction was quenched with sulfuric acid and then read on a plate reader with a wave length of $450 \mathrm{~nm}$.

Statistics:

Both SigmaPlot 9.0 and Microsoft Excel were used in statistical analyses for the quantitative data. The data were expressed as mean \pm standard deviation (SD).

\section{Results:}

Effects of arsenite on miR-155 expression:

Environmental or occupational exposure to $\mathrm{As}^{3+}$ poses a great risk of developing multiple types of cancer including cancers of the lung, skin, liver, and bladder. Little is known about the effect of $\mathrm{As}^{3+}$ on the expression of miRNAs. One possible mechanism for cancer development 
induced by $\mathrm{As}^{3+}$ is the deregulation of miRNA, especially those oncogenic miRNAs. Changes in miR-155 expression are related to tumorigenesis in epithelial cells, and its expression is controlled by transcription factors known to be induced by arsenic. We hypothesized that miR155 may play a role in arsenite-induced carcinogenesis and began to characterize the effect that $\mathrm{As}^{3+}$ might have on either transcription or biogenesis of miR-155. To test this hypothesis, we cloned the promoter region for $\mathrm{BIC} / \mathrm{miR}-155$ and constructed a reporter vector by inserting the cloned promoter region into the upstream of the firefly luciferase gene. During the course of cloning and construction of reporter vectors, a study was published, which indicates that a role for AP-1 but not NF- $\mathrm{kB}$ in the activation of miR-155 transcription and expression (16). Thus, we obtained these reporter vectors which were subject to deletion or mutation of the NF- $\mathrm{KB}$ and AP-1 sites in the promoter region (Fig. 1A). The promoter activity was determined by transfection of these vectors into the BEAS-2B cells followed by treatment of the transfected cells with $\mathrm{As}^{3+}$. The results from these experiment showed that deletion of the region from 2000 to -1494 that contains 3 NF- $\mathrm{kB}$ binding sites enhanced the arsenic-induced luciferase activity (Short), indicating that these 3 NF- $\mathrm{kB}$ sites are dispensible for the miR-155 promoter activity in response to $\mathrm{As}^{3+}$. An additional possibility is that this region might contain inhibitory elements that negatively regulate the promoter activity. Site-directed mutation of the down-stream NF- $\mathrm{KB}$ site at position -1221 to -1211 also had no effect on the $\mathrm{As}^{3+}$-induced promoter activity (comparing Short to delta $\mathrm{kB}$ Short). In contrast, deletion of the AP-1 site at position -107 to -100 completely abolished the promoter activity (Fig. 1C), which is in agreement with the report suggesting that AP-1 site is an essential element for miR-155 transcription. 
To further determine whether $\mathrm{As}^{3+}$ induces increase of the mature miR-155 in the BEAS2B cells, we next measured the levels of miR-155 by real-time PCR using RNAs from the cells treated with or without $\mathrm{As}^{3+}$. Intriguingly, several experiments failed to detect changes of miR155 in the cells treated with $\mathrm{As}^{3+}$ (Fig.2), which possibly indicates that $\mathrm{As}^{3+}$ might negatively regulate the processing of mature miR-155.

\section{Microarray of miRNA expression:}

We revealed that $\mathrm{As}^{3+}$ induces miR-155 promoter activity but failed to induce mature miR-155 (Figs. $1 \& 2$ ). To determine whether $\mathrm{As}^{3+}$ is able to regulate other miRNAs, we next profiled miRNA expression using Cancer MicroRNA qPCR Array that contains 95 different miRNAs. Total RNA used in this analysis was isolated from the bronchial epithelial cell line, BEAS-2B, exposed to $20 \mu \mathrm{M} \mathrm{As}{ }^{3+}$ for 6 hours. The array showed an up-regulation of 67 miRNAs as well as a down-regulation of 28 other miRNAs (Fig 3A). Among the up-regulated miRNAs by $\mathrm{As}^{3+}$, the highest miRNAs induced are the miR-1-1 and miR-190. A 4-6 fold induction of miR-1-1 and miR-190 by $\mathrm{As}^{3+}$ was noted (Supplement Table 1). The capability of $\mathrm{As}^{3+}$ on the induction of miRNAs in this array was additionally supported by the parallel upregulation of miRNAs within miRNA clusters that share the same transcriptional unit, such as the miR-106-363 cluster (miR-92, miR-106a and miR-19a, indicated by arrows in Fig. 3) and the miR-17-92 cluster (miR-17-3p, miR-17-5p and miR-20a, indicated by arrow heads in Fig. 3). Of the upregulated miRNAs, miR-190 was an attractive candidate for follow-up study because of its involvement in cell growth and proliferation [21].

To validate the array data, we next performed real-time RT-PCR using total RNA isolated from BEAS-2B cells treated with increasing concentrations of $\mathrm{As}^{3+}$ for 12 hours. A 
concentration-dependant increase of miR-190 was seen in the cells treated with As ${ }^{3+}$ (Fig. 3B). $\mathrm{As}^{3+}$ at concentrations of 10,15 and $20 \mu \mathrm{M}$ induced a 2-, 3- and 7-fold increase of miR-190 expression in the BEAS-2B cells, respectively. Moreover, in addition to BEAS-2B cells, we also observed induction of miR-190 by $\mathrm{As}^{3+}$ in other two different cell lines, A549 lung cancer cell line (Fig. 3C) and SAEC, the primary human small airway epithelial cell line (Supplement Fig. S1). A 3 fold induction of miR-190 was noted in SAEC cells treated with lower concentrations of $\mathrm{As}^{3+}, 2.5-5 \mu \mathrm{M}$, for 48 hours.

$A s^{3+}$ induces miR-190 through activating talin 2 gene.

Noncoding RNAs, including miRNAs, are transcribed either from intergenic loci or intronic DNA of genes. A database search for the genomic context surrounding the miR-190 using the online Ensemble genome information system [23] revealed that miR-190 is located on chromosome 15 within intron 52 of the talin 2 gene (Fig. 4A). The talin family proteins, including talin 1 and talin 2, are important molecules for the spreading and mobility of the cells by regulating the function of integrins and the assembly of the stress fibers [24]. To determine whether or not an increase in expression of miR-190 correlates with expression of the talin 2 mRNA and protein, real-time RT-PCR and Western blotting were performed (Figs. 4B and 4C). In agreement with the data for miR-190 expression, $\mathrm{As}^{3+}$ induced talin 2 mRNA accumulation in a concentration-dependent manner (Fig. 4B), which correlated with an increased levels of the talin 2 protein (Fig. 4C). The peak induction of the talin 2 mRNA occurred in the cells treated with $20 \mu \mathrm{M} \mathrm{As}{ }^{3+}$ for $12 \mathrm{~h}$ (Fig. 4B). Semi-quantification of the Western blotting data by densitometry scanning showed that $\mathrm{As}^{3+}$ at concentrations of 10 and $20 \mu \mathrm{M}$ induced a 1.5 - to 2fold increase of the talin 2 protein (Fig. 4C, the numbers at the bottom). 
To further assess the capability of $\mathrm{As}^{3+}$ on the induction of the talin 2 gene, a luciferase reporter gene activity assay was conducted by using a reporter vector containing the proximal 1 $\mathrm{kb}$ region of the talin 2 promoter. Transfection of BEAS-2B cells with the talin 2 reporter gene and followed by exposure to $\mathrm{As}^{3+}$ showed a concentration dependant induction of talin 2 promoter activity (Fig. 4D). All of these data clearly indicate that the expression of miR-190 in response to $\mathrm{As}^{3+}$ is associated with the expression of its host gene. These results also suggest that regulation of miR-190 by $\mathrm{As}^{3+}$ is very likely at the level of transcription.

miR-190 targets PHLPP:

$\mathrm{As}^{3+}$ is an established human carcinogen and some miRNAs have been previously demonstrated as oncogenic miRNAs that can suppress expression of the tumor suppressors or activate cell growth signaling [25]. The information available on the role of miR-190 in human carcinogenesis is currently very limited. We postulate that miR-190 may be partially responsible for the carcinogenicity of $\mathrm{As}^{3+}$ by affecting certain oncogenic signals. In order to identify potential targets of miR-190 we adopted a computational approach by using several of the available prediction algorithms based on evolutionary conservation of target sites across species, including miRDB [26, 27], PicTar [28] and Targetscan [29]. One limitation of this approach is that each of these algorithms predicts hundreds of possible targets for miR-190 or other miRNAs. To circumvent this problem, we focused on the targets important for cell proliferative or pre-survival signals that were predicted by all of these programs. Among the predicted candidate targets, 3'-UTRs of human PH domain and leucine-rich repeat protein phosphatase (PHLPP) and tumor protein 53-induced nuclear protein 1 (TP53INP1) contained regions that matched the seed sequences of miR-190. The predicted miR-190 binding sites are found $223 \mathrm{nt}$ and 217 nt downstream of the stop code for PHLPP (Fig. 5A) and TP53INP1 (supplement Fig. 
S2A) mRNAs, respectively. The binding site of miR-190 is well conserved among PHLPP mRNAs from other species, including monkey, rat, mouse, horse and chicken, which is indicative for the importance of miR-190 on the regulation of PHLPP (Fig. 5A). PHLPP is known to target phosphorylated serine 473 specifically for dephosphorylation and inactivation of Akt kinase, leading to an increased apoptotic potential, and thereby causing tumor suppression [30]. We had previously demonstrated that $\mathrm{As}^{3+}$ is able to activate Akt in BEAS-2B cells [31]. Accordingly, it is very likely that $\mathrm{As}^{3+}$-induced Akt activation is achieved through the downregulation of PHLPP by miR-190, leading to a sustained Akt activation and an increase in cell growth and proliferation, resulting in cell transformation. Western blotting examining the level of the PHLPP protein in the cells treated with $\mathrm{As}^{3+}$ clearly indicated a concentrationdependent repression of the PHLPP protein (Fig. 5B), suggesting a potential link between $\mathrm{As}^{3+}{ }_{-}$ induced miR-190 and Akt activation.

Transfection of the cells with miR-190 precursor suppresses PHLPP expression:

To verify above observation indicating that $\mathrm{As}^{3+}$-induced expression of miR-190 can repress the translation of the PHLPP protein, the cells were directly transfected with a mock transfection, miR-190, and miR-190In, respectively. As depicted in Fig. 3C, PHLPP protein levels were reduced in the cells transfected with the miR-190 by $60-70 \%$ relative to the mocktransfected cells (Fig. 5C, lanes $1 \&$ 2). No inhibitory effect of the miR-190In on PHLPP was observed (Fig. 5C, lane 3). Again, treatment of the cells with $\mathrm{As}^{3+}$ decreased expression of the PHLPP protein (Fig. 5C, lane 4).

To confirm that miR-190-mediated repression of PHLPP expression is achieved through interacting with the potential miR-190 binding site in the PHLPP 3'-UTR region, the entire 3'- 
UTR of PHLPP mRNA was cloned downstream of a luciferase gene in the pMIR-REPORT vector. The BEAS-2B cells were co-transfected with this reporter vector, pRL-TK Renilla luciferase vector, and miR-190 or miR-190In. We observed that the co-transfection of the miR190 suppressed the luciferase activity of the vector with the PHLPP 3'-UTR by about 40\% (Fig. 5D). In contrast, the miR-190In did not show inhibition on the PHLPP 3'-UTR reporter activity. Moreover, deletion of the miR-190 binding site within the PHLPP 3'-UTR abrogated the repressive ability of the miR-190 on the reporter gene activity (Fig. 5E), demonstrating specificity of the target sequence for PHLPP. Thus, these data provide strong evidence suggesting that $\mathrm{As}^{3+}$-induced miR-190 is crucial for the downregulation of the PHLPP protein.

\section{Expression of miR-190 enhances Akt phosphorylation and VEGF production:}

Having found that miR-190 represses expression of PHLPP, a negative regulator of Akt kinase by dephosphorylation of the serine 473 (Ser473)-phosphorylated, but not threonine 308 (Thr308)-phosphorylated, Akt [30], we investigated Ser473 phosphorylation of Akt in the cells treated with $20 \mu \mathrm{M} \mathrm{As}^{3+}$ in the presence or absence of overexpressed miR-190 or miR-190In. Western blotting assays using antibody specific for Ser473 phosphorylation of Akt was performed followed by a densitometry quantification of Akt phosphorylation. As indicated in Fig. $6 \mathrm{~A}, 10 \mu \mathrm{M} \mathrm{As}{ }^{3+}$ activated Akt in a time-dependent manner with a peak occurring at $8 \mathrm{~h}$, as judged by the Ser473 phosphorylation of Akt. Although decreased after As ${ }^{3+}$ treatment for 12 and $20 \mathrm{~h}$, the activation of Akt at these time points is still evident (compare lanes $4 \& 5$ to lane 1 , Fig. 6A). In an additional experiment using cells treated with $\mathrm{As}^{3+}$ for $12 \mathrm{~h}$ in the absence or presence of miR-190, both $\mathrm{As}^{3+}$ and miR-190 induced Akt phosphorylation notably (Fig. 6B, comparing lanes 2 and 5 to lane 1). Akt activation by $\mathrm{As}^{3+}$ was substantially enhanced in the 
cells overexpressing miR-190 (Fig. 6, lane 6). In contrast, this effect was not seen in the cells transfected with the miR-190In (Fig. 6B, lanes 3 and 4).

To determine if the effect of miR-190 on Akt phosphorylation has any downstream effects, an ELISA experiment for the expression of VEGF, a protein whose expression is known to be induced by the activation of Akt [32], was performed. Results from the ELISA show that both $\mathrm{As}^{3+}$ and miR-190 are able to induce expression of VEGF. Combination of $\mathrm{As}^{3+}$ and miR190 further enhanced VEGF induction (Fig. 6B, lane 6, the bottom panel). Enforced expression of miR-190In, has very marginal effect on the basal VEGF expression (Fig. 6B, bottom panel, lane 3). Furthermore, miR-190In appears to be unable to potentiate $\mathrm{As}^{3+}$-induced VEGF expression (lane 4). These results indicate that miR-190 is indeed able to stimulate Akt activation and VEGF expression induced by $\mathrm{As}^{3+}$.

miR-190 enhances cell proliferation and carcinogenic transformation:

The observations that miR-190 induced by $\mathrm{As}^{3+}$ represses PHLPP and consequently activates Akt imply that this miRNA is an important regulator of critical cellular events associated with carcinogenesis, such as proliferation and transformation. To determine if over expression of miR-190 leads to substantial changes in cell proliferation, colony formation and/or other properties associated with malignant transformation and carcinogenesis, stably transfected BEAS-2B cell lines were generated by expressing miR-190 or a control vector. The stable miR190 overexpressing cells exhibited an approximate nine-fold increase of miR-190 expression compared to control transfected cells (Fig. 7A). A substantial enhancement of Akt activation in the cells stably expressing miR-190 was observed (Fig. 7B). To determine how miR-190 expression affects cells, we next measured cell growth by a MTS-based cell proliferation assay. 
As depicted in Fig. 7C, cells stably expressing miR-190 showed a significant increase in proliferation either in the absence or presence of different concentrations of $\mathrm{As}^{3+}$. In agreement with the results from transient transfection, VEGF expression was increased in the stable miR190 expression cells (Fig. 7D). To directly determine whether overexpression of miR-190 enhances malignant transformation of the cells, we next performed anchorage-independent cell growth assay by seeding the cells in soft agar. Colony formation by the cells stably expressing miR-190 was substantially enhanced. The number of colonies was increased more than 50\% when compared to cells stably expressing the control miRNA (Fig. 7E). Remarkably, cells stably expressing miR-190 formed large colonies (pointed by white arrows, Fig. 7F), whereas cells stably expressing the control-miRNA formed only small aggregates of the cells (Fig. 7F). These results suggest that miR-190 is an oncogenic miRNA.

\section{Discussion}

$\mathrm{As}^{3+}$ is tumorigenic as demonstrated in both experimental animal and epidemiological studies of human populations in some specific environmental or occupational settings. The detailed mechanism of $\mathrm{As}^{3+}$-induced malignant transformation of the cells, however, remains to be fully established. A number of intracellular signaling pathways can be perturbed in response to $\mathrm{As}^{3+}$ exposure, including redox balancing, kinase activation, transcription factor activity, DNA damage repair, and cell cycle. All of these pathways are either directly or indirectly linked to cell growth, apoptosis and transformation. The regulatory role of $\mathrm{As}^{3+}$ on the expression and function of miRNA has not been explored yet. The discovery in this report that $\mathrm{As}^{3+}$ induces miR-190 expression, therefore, may provide an additional mechanistic insight into $\mathrm{As}^{3+}$ exposure and human cancer. 
Unlike other well-studied miRNAs, such as let-7, miR-155 and miR-21, the function of miR-190 is largely unsubstantiated. In HeLa cells, inhibition of miR-190 by anti-sense RNA compromised cell growth without effect on cell apoptosis [21]. The level of miR-190 was significantly increased in the granulocytes isolated from patients with primary myelofibrosis (PMF) relative to granulocytes from normal subjects [22]. PMF is the rarest and most severe form of the $\mathrm{Ph}^{-}$myeloproliferative disorders (MPDs), including PMF, polycythemia vera (PV) and essential thrombocythemia (ET). Since PMF is characterized by aberrant proliferation of the megakaryocytes in the bone marrow, it is believed that such a disorder is very likely due to deregulation of the stem-cell niche or deficiency in stem-cell differentiation. Indeed, a recent study using human embryonic stem cells and differentiated embryoid bodies indicated a significant up-regulation of miR-190 expression in embryoid bodies and embryonic stem cells relative to the adult cells [33]. Furthermore, an association of miR-190 overexpression with clonal malignant transformation has been observed in hematopoietic stem cells [34], suggesting potential linkage of miR-190, cancer stem cells and cancer development.

Additional evidence suggesting the role of miR-190 played in cancer development has recently been provided by miRNA profiling in pancreatic cancer tissue samples and pancreatic cancer cell lines [35]. Real-time PCR data indicate that miR-190 was one of the eight most highly expressed miRNAs in pancreatic cancer, whereas its expression in normal pancreatic tissues was hardly detectable. An average of 21-fold increase of miR-190 was noted in 17 pancreatic cancer tissues relative to the case-matched normal pancreatic tissues. Similarly, miR190 had been previously implicated as a signature miRNA in B cell chronic lymphocytic leukeminas (CLL) [36]. As compared to the normal $\mathrm{CD5}^{+} \mathrm{B}$ cells, the level of miR-190 in CLL 
was substantially increased. It was believed that this increase in miR-190 expression in CLL is possibly a result of genomic rearrangement because the host gene of miR-190, talin 2 , is located in the common fragile sites that are prone to breakage and rearrangement in cancers. Increased expression of miR-190 has most recently been demonstrated in several other types of tumors, including bladder cancer [37], breast cancer [38], lung cancer [39], a subset of HBV positive hepatocellular carcinoma [40], and colorectal cancer [41]. Intriguingly, a miR-190 homolog has also been identified in the Bombyx mori (silkworm) genome, and its expression has been implicated as an important process for the normal development of Bombyx mori [42]. All of these observations clearly indicate that miR-190 is a cell growth-regulating miRNA. Overexpression of miR-190, thus, is oncogenic.

miR-190 is an intronic miRNA whose gene is located in the $52^{\text {nd }}$ intron of the talin 2 gene. The observed association of miR-190 expression with its host gene, talin 2 , in the present study was complementarily supported by observations indicating coordination between talin 2 gene transcription and miR-190 biogenesis in neuron [43]. In mouse or rat hippocampal neurons, activation of the $\mu$-opioid receptor by its agonist, fentanyl, reduced both talin 2 gene transcription and miR-190 expression in a manner of extracellular signal-regulated kinase (ERK)-mediated phosphorylation of YY1. Phosphorylation of YY1, a transcription factor, resulted in an impairment of YY1 association with and activation on the talin 2 promoter, leading to a decreased transcription of talin 2 gene and consequently, reduced biogenesis of miR-190. It is still unclear how intronic miRNAs are transcribed and processed. Several lines of evidence implicated interdependency of pre-mRNA splicing and Drosha-dependent pri-miRNA processing [44], whereas other studies revealed a possible mutual competition between pre-mRNA splicing and pri-miRNA processing [45]. 
Emerging evidence shows that oncogenic miRNAs contribute to the initiation and progression of cancer largely through regulating the expression of genes involved in the control of cell lineage development, cell proliferation, cell apoptosis, and kinase activation in the cells. For example, both miR-17 and miR-20a are able to negatively regulate expression of the E2F1 transcription factor to alter the dynamics of cell cycle progression [46]. The potential targets of miR-190 identified in the present report, PHLPP and TP53INP1, have been previously demonstrated as important regulators for protein kinase Akt signaling and cell apoptosis, respectively [30, 47]. PHLPP is a PH domain-containing serine phosphatase, which specifically dephosphorylates phosphorylated Ser473 of Akt and inactivates Akt, leading to cell apoptosis [30]. It has been well-established that full activation of Akt requires both Thr308 phosphorylation by PDK1 and Ser473 phosphorylation by mTORC 2 or DNA-PK. Accordingly, loss of PHLPP expression will prolong the Ser473 phosphorylation and activation of Akt. Indeed, in some breast and colon cancers, it was believed that loss of PHLPP expression is responsible for the sustained Akt activation, tumorigenesis and metastasis [48, 49]. Thus, induction of miR-190 by $\mathrm{As}^{3+}$ and the consequent PHLPP downregulation by miR-190 can provide the cells with a self-sustaining growth signal due to loss of a negative regulator of the Akt kinases. This may also partially explain observations indicating that $\mathrm{As}^{3+}$ is a potent inducer of Akt activation in bronchial epithelial cells and fibroblast cells as reported by ourselves and others $[31,50]$. Downregulation of TP53INP1 by As ${ }^{3+}$-induced miR-190, on the other hand, would cause the cells to be insensitive to pro-apoptotic signals. All of these effects of miR-190 induced by $\mathrm{As}^{3+}$, therefore, may be causatively important in malignant transformation and tumorigenesis of the cells. 
In summary, we have provided the first evidence showing that $\mathrm{As}^{3+}$ is capable of inducing miR-190 expression associated with an appreciable protein accumulation of its host gene, talin 2. Elevated miR-190 in response to $\mathrm{As}^{3+}$ is responsible for the downregulation of PHLPP and TP53INP1, two important tumor suppressors. Reduced PHLPP expression will consequently cause a prolonged or potentiated Akt activation and expression of its downstream targets, such as VEGF, leading to either a malignant transformation of the normal cells or tumorigenesis of the transformed cells. We believe that these discoveries may shed new light on the carcinogenic mechanism of environmental and occupational $\mathrm{As}^{3+}$ exposure. Further experiments are in progress to determine additional authentic targets of the miR-190 and how miR-190 or its host gene, talin 2, is transcriptionally regulated by $\mathrm{As}^{3+}$.

\section{Supplementary Data}

To further support the hypothesis that arsenite is capable of inducing the expression of miR-190, small airway epithelial cells (SAEC) were exposed to increasing concentrations of arsenite for 48 hours (Fig. S1). An increase in expression of miR-190 was observed indicating that this effect is not limited to transformed cell lines, giving support for the hypothesis.

TP53INP1 is a p53 inducible protein which takes part in the induction and regulation of p53-mediated apoptosis [47]. A decrease in the expression of TP53INP1 in tumor tissue has been documented [51, 52]. Re-expression of TP53INP1 is known to be tumor suppressive [11]. TP53INP1 is indicated to be a potential target of miR-190 by in silico analysis. An appreciable concentration-dependent inhibition of the TP53INP1 in the cells by $\mathrm{As}^{3+}$ was noted (Supplement Fig. S2). Accordingly, induction of miR-190 by $\mathrm{As}^{3+}$ will repress the expression TP53INP1, which will consequently weaken the tumor suppression potential and enhance carcinogenesis. 
As an additional control for testing the effect of miR-190 on the pmiR-REPORT-PHLPP vector, we experimented on the effect of miR-190 on the cells transfected with pMIR-REPORT empty vector. No inhibitory effect of miR-190 on this empty reporter vector was observed (Supplement Fig. S3).

\section{References}

1. Heck JE, Andrew AS, Onega T, Rigas JR, Jackson BP, Karagas MR, Duell EJ: Lung cancer in a U.S. population with low to moderate arsenic exposure. Environ Health Perspect 2009, 117:1718-1723.

2. Camacho LM, Gutierrez M, Alarcon-Herrera MT, Villalba Mde L, Deng S: Occurrence and treatment of arsenic in groundwater and soil in northern Mexico and southwestern USA. Chemosphere 2011, 83:211-225.

3. Celik I, Gallicchio L, Boyd K, Lam TK, Matanoski G, Tao X, Shiels M, Hammond E, Chen L, Robinson KA, et al: Arsenic in drinking water and lung cancer: a systematic review. Environ Res 2008, 108:48-55.

4. Hopenhayn-Rich C, Biggs ML, Smith AH: Lung and kidney cancer mortality associated with arsenic in drinking water in Cordoba, Argentina. Int J Epidemiol 1998, 27:561-569.

5. Chiu HF, Ho SC, Yang CY: Lung cancer mortality reduction after installation of tapwater supply system in an arseniasis-endemic area in Southwestern Taiwan. Lung Cancer 2004, 46:265-270.

6. Chen CL, Hsu LI, Chiou HY, Hsueh YM, Chen SY, Wu MM, Chen CJ: Ingested arsenic, cigarette smoking, and lung cancer risk: a follow-up study in arseniasisendemic areas in Taiwan. JAMA 2004, 292:2984-2990.

7. Cavigelli M, Li WW, Lin A, Su B, Yoshioka K, Karin M: The tumor promoter arsenite stimulates AP-1 activity by inhibiting a JNK phosphatase. EMBO J 1996, 15:62696279 .

8. Chen F, Castranova V, Li Z, Karin M, Shi X: Inhibitor of nuclear factor kappaB kinase deficiency enhances oxidative stress and prolongs c-Jun NH2-terminal kinase activation induced by arsenic. Cancer Res 2003, 63:7689-7693.

9. Ye J, Li A, Liu Q, Wang X, Zhou J: Inhibition of mitogen-activated protein kinase kinase enhances apoptosis induced by arsenic trioxide in human breast cancer MCF-7 cells. Clin Exp Pharmacol Physiol 2005, 32:1042-1048. 
10. Beezhold KJ, Castranova V, Chen F: Microprocessor of microRNAs: regulation and potential for therapeutic intervention. Mol Cancer 2010, 9:134.

11. Gironella M, Seux M, Xie MJ, Cano C, Tomasini R, Gommeaux J, Garcia S, Nowak J, Yeung ML, Jeang KT, et al: Tumor protein 53-induced nuclear protein 1 expression is repressed by miR-155, and its restoration inhibits pancreatic tumor development. Proc Natl Acad Sci U S A 2007, 104:16170-16175.

12. Eis PS, Tam W, Sun L, Chadburn A, Li Z, Gomez MF, Lund E, Dahlberg JE: Accumulation of miR-155 and BIC RNA in human B cell lymphomas. Proc Natl Acad Sci U S A 2005, 102:3627-3632.

13. Galardi S, Mercatelli N, Giorda E, Massalini S, Frajese GV, Ciafre SA, Farace MG: miR-221 and miR-222 expression affects the proliferation potential of human prostate carcinoma cell lines by targeting p27Kip1. J Biol Chem 2007, 282:2371623724.

14. Taganov KD, Boldin MP, Chang KJ, Baltimore D: NF-kappaB-dependent induction of microRNA miR-146, an inhibitor targeted to signaling proteins of innate immune responses. Proc Natl Acad Sci U S A 2006, 103:12481-12486.

15. O'Connell RM, Taganov KD, Boldin MP, Cheng G, Baltimore D: MicroRNA-155 is induced during the macrophage inflammatory response. Proc Natl Acad Sci U S A 2007, 104:1604-1609.

16. Yin Q, Wang X, McBride J, Fewell C, Flemington E: B-cell receptor activation induces BIC/miR-155 expression through a conserved AP-1 element. J Biol Chem 2008, 283:2654-2662.

17. Kong W, Yang H, He L, Zhao JJ, Coppola D, Dalton WS, Cheng JQ: MicroRNA-155 is regulated by the transforming growth factor beta/Smad pathway and contributes to epithelial cell plasticity by targeting RhoA. Mol Cell Biol 2008, 28:6773-6784.

18. Kong W, He L, Coppola M, Guo J, Esposito NN, Coppola D, Cheng JQ: MicroRNA-155 regulates cell survival, growth, and chemosensitivity by targeting FOXO3a in breast cancer. J Biol Chem 2010, 285:17869-17879.

19. Monkley SJ, Pritchard CA, Critchley DR: Analysis of the mammalian talin2 gene TLN2. Biochem Biophys Res Commun 2001, 286:880-885.

20. Critchley DR, Gingras AR: Talin at a glance. J Cell Sci 2008, 121:1345-1347.

21. Cheng AM, Byrom MW, Shelton J, Ford LP: Antisense inhibition of human miRNAs and indications for an involvement of miRNA in cell growth and apoptosis. Nucleic Acids Res 2005, 33:1290-1297. 
22. Guglielmelli P, Tozzi L, Pancrazzi A, Bogani C, Antonioli E, Ponziani V, Poli G, Zini R, Ferrari S, Manfredini R, et al: MicroRNA expression profile in granulocytes from primary myelofibrosis patients. Exp Hematol 2007, 35:1708-1718.

23. Flicek P, Aken BL, Beal K, Ballester B, Caccamo M, Chen Y, Clarke L, Coates G, Cunningham F, Cutts T, et al: Ensembl 2008. Nucleic Acids Res 2008, 36:D707-714.

24. Zhang X, Jiang G, Cai Y, Monkley SJ, Critchley DR, Sheetz MP: Talin depletion reveals independence of initial cell spreading from integrin activation and traction. Nat Cell Biol 2008.

25. Shi XB, Tepper CG, deVere White RW: Cancerous miRNAs and their regulation. Cell Cycle 2008, 7:1529-1538.

26. Yang H, Kong W, He L, Zhao JJ, O'Donnell JD, Wang J, Wenham RM, Coppola D, Kruk PA, Nicosia SV, Cheng JQ: MicroRNA expression profiling in human ovarian cancer: miR-214 induces cell survival and cisplatin resistance by targeting PTEN. Cancer Res 2008, 68:425-433.

27. Wang X: miRDB: a microRNA target prediction and functional annotation database with a wiki interface. Rna 2008, 14:1012-1017.

28. Krek A, Grun D, Poy MN, Wolf R, Rosenberg L, Epstein EJ, MacMenamin P, da Piedade I, Gunsalus KC, Stoffel M, Rajewsky N: Combinatorial microRNA target predictions. Nat Genet 2005, 37:495-500.

29. Lewis BP, Shih IH, Jones-Rhoades MW, Bartel DP, Burge CB: Prediction of mammalian microRNA targets. Cell 2003, 115:787-798.

30. Gao T, Furnari F, Newton AC: PHLPP: a phosphatase that directly dephosphorylates Akt, promotes apoptosis, and suppresses tumor growth. Mol Cell 2005, 18:13-24.

31. Zhang Y, Bhatia D, Xia H, Castranova V, Shi X, Chen F: Nucleolin links to arsenicinduced stabilization of GADD45alpha mRNA. Nucleic Acids Res 2006, 34:485-495.

32. Jiang BH, Zheng JZ, Aoki M, Vogt PK: Phosphatidylinositol 3-kinase signaling mediates angiogenesis and expression of vascular endothelial growth factor in endothelial cells. Proc Natl Acad Sci U S A 2000, 97:1749-1753.

33. Ren J, Jin P, Wang E, Marincola FM, Stroncek DF: MicroRNA and gene expression patterns in the differentiation of human embryonic stem cells. J Transl Med 2009, 7:20.

34. Lataillade JJ, Pierre-Louis O, Hasselbalch HC, Uzan G, Jasmin C, Martyre MC, Le Bousse-Kerdiles MC: Does primary myelofibrosis involve a defective stem cell niche? From concept to evidence. Blood 2008, 112:3026-3035. 
35. Zhang Y, Li M, Wang H, Fisher WE, Lin PH, Yao Q, Chen C: Profiling of 95 microRNAs in pancreatic cancer cell lines and surgical specimens by real-time PCR analysis. World J Surg 2009, 33:698-709.

36. Calin GA, Liu CG, Sevignani C, Ferracin M, Felli N, Dumitru CD, Shimizu M, Cimmino A, Zupo S, Dono M, et al: MicroRNA profiling reveals distinct signatures in B cell chronic lymphocytic leukemias. Proc Natl Acad Sci U S A 2004, 101:11755-11760.

37. Ichimi T, Enokida H, Okuno Y, Kunimoto R, Chiyomaru T, Kawamoto K, Kawahara K, Toki K, Kawakami K, Nishiyama K, et al: Identification of novel microRNA targets based on microRNA signatures in bladder cancer. Int J Cancer 2009, 125:345-352.

38. Lowery AJ, Miller N, Devaney A, McNeill RE, Davoren PA, Lemetre C, Benes V, Schmidt S, Blake J, Ball G, Kerin MJ: MicroRNA signatures predict estrogen receptor, progesterone receptor and HER2/neu receptor status in breast cancer. Breast Cancer Res 2009, 11:R27.

39. Navon R, Wang H, Steinfeld I, Tsalenko A, Ben-Dor A, Yakhini Z: Novel rank-based statistical methods reveal microRNAs with differential expression in multiple cancer types. PLoS One 2009, 4:e8003.

40. Ura S, Honda M, Yamashita T, Ueda T, Takatori H, Nishino R, Sunakozaka H, Sakai Y, Horimoto K, Kaneko S: Differential microRNA expression between hepatitis B and hepatitis $\mathbf{C}$ leading disease progression to hepatocellular carcinoma. Hepatology 2009, 49:1098-1112.

41. Ng EK, Chong WW, Jin H, Lam EK, Shin VY, Yu J, Poon TC, Ng SS, Sung JJ: Differential expression of microRNAs in plasma of colorectal cancer patients: A potential marker for colorectal cancer screening. Gut 2009.

42. Cao J, Tong $\mathrm{C}, \mathrm{Wu} \mathrm{X}, \mathrm{Lv} \mathrm{J}$, Yang $\mathrm{Z}$, Jin Y: Identification of conserved microRNAs in Bombyx mori (silkworm) and regulation of fibroin $L$ chain production by microRNAs in heterologous system. Insect Biochem Mol Biol 2008, 38:1066-1071.

43. Zheng H, Chu J, Zeng Y, Loh HH, Law PY: Yin Yang 1 phosphorylation contributes to the differential effects of mu-opioid receptor agonists on microRNA-190 expression. J Biol Chem 2010, 285:21994-22002.

44. Shomron N, Levy C: MicroRNA-biogenesis and Pre-mRNA splicing crosstalk. $J$ Biomed Biotechnol 2009, 2009:594678.

45. Kim YK, Kim VN: Processing of intronic microRNAs. EMBO J 2007, 26:775-783.

46. O'Donnell KA, Wentzel EA, Zeller KI, Dang CV, Mendell JT: c-Myc-regulated microRNAs modulate E2F1 expression. Nature 2005, 435:839-843. 
47. Okamura S, Arakawa H, Tanaka T, Nakanishi H, Ng CC, Taya Y, Monden M, Nakamura $\mathrm{Y}$ : p53DINP1, a p53-inducible gene, regulates p53-dependent apoptosis. Mol Cell 2001, 8:85-94.

48. Liu J, Weiss HL, Rychahou P, Jackson LN, Evers BM, Gao T: Loss of PHLPP expression in colon cancer: role in proliferation and tumorigenesis. Oncogene 2009, 28:994-1004.

49. Qiao M, Iglehart JD, Pardee AB: Metastatic potential of 21T human breast cancer cells depends on Akt/protein kinase B activation. Cancer Res 2007, 67:5293-5299.

50. Ouyang W, Li J, Ma Q, Huang C: Essential roles of PI-3K/Akt/IKKbeta/NFkappaB pathway in cyclin D1 induction by arsenite in JB6 C141 cells. Carcinogenesis 2006, 27:864-873.

51. Ito Y, Motoo Y, Yoshida H, Iovanna JL, Takamura Y, Miya A, Kuma K, Miyauchi A: Decreased expression of tumor protein p53-induced nuclear protein 1 (TP53INP1) in breast carcinoma. Anticancer Res 2006, 26:4391-4395.

52. Jiang PH, Motoo Y, Garcia S, Iovanna JL, Pebusque MJ, Sawabu N: Down-expression of tumor protein p53-induced nuclear protein 1 in human gastric cancer. World $J$ Gastroenterol 2006, 12:691-696. 


\section{Figures:}
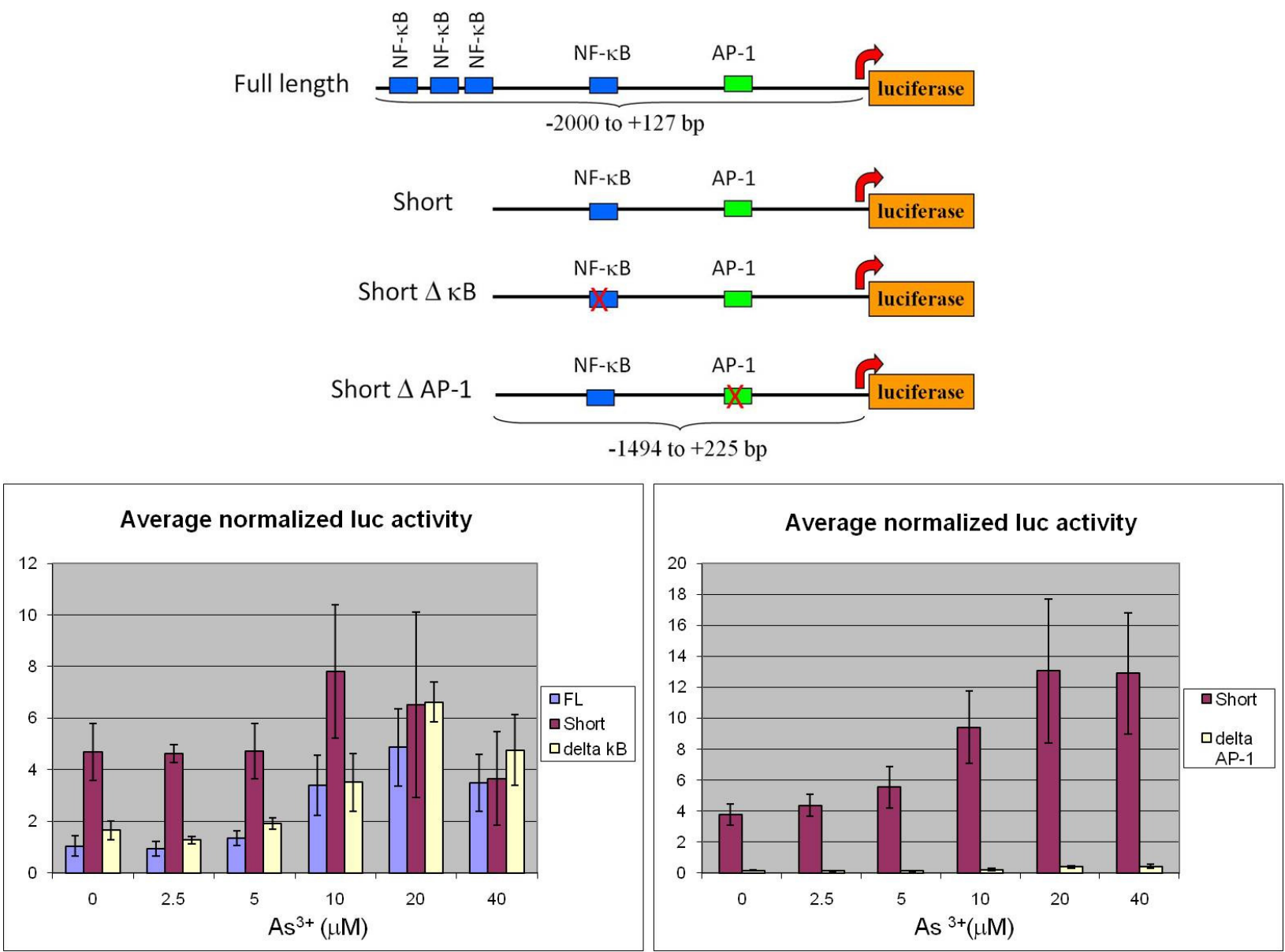

Figure 1: MicroRNA-155/BIC promoter activity. A. A depiction of the four different promoter luciferase reporter vectors used. B. Average normalized luciferase activity expressed in relative luciferase units of the two wild type vectors and the NF-kB knockout vector in response to increasing concentrations of arsenite. C. Average normalized luciferase activity of the short wild type reporter and AP-1 knockout reporter vectors in response to increasing arsenic concentrations. 


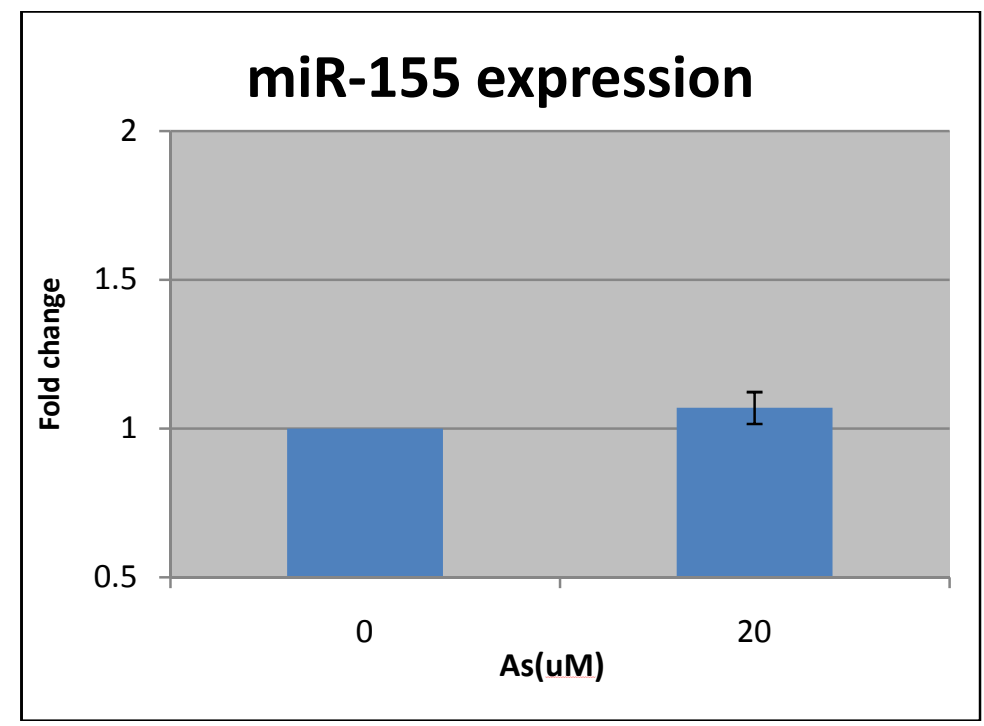

Figure 2: Exposure to arsenite does not alter miR-155 expression in BEAS-2B cells.

The expression level of mature miR-155 was measured by real-time PCR in BEAS-2B cells after exposure to $20 \mathrm{mM}$ arsenite for 12 hours. 
A

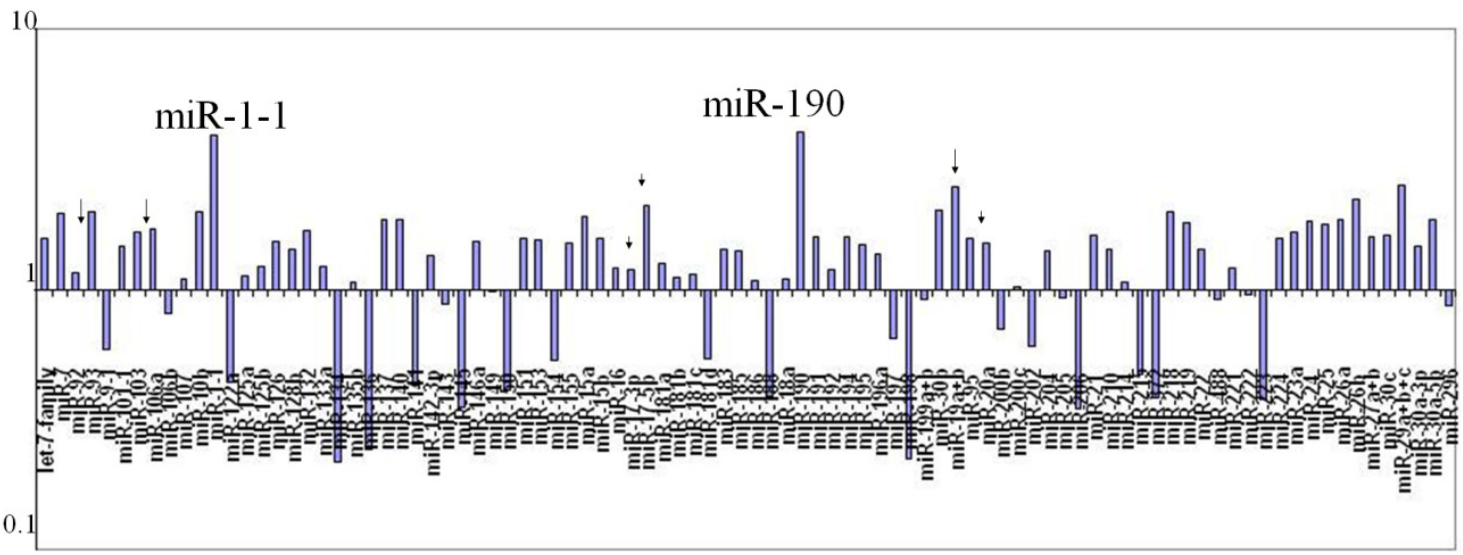

B

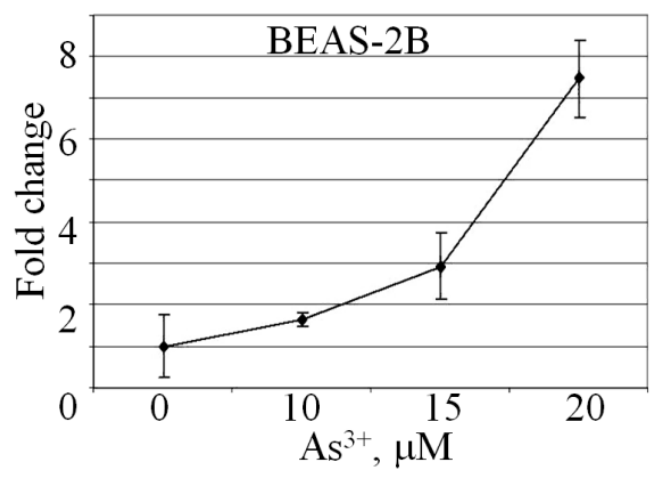

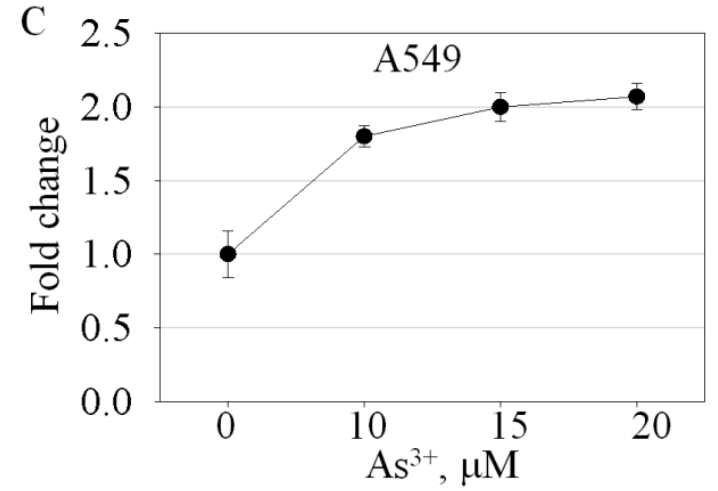

Figure 3: $\mathrm{As}^{3+}$ regulates expression of miRNAs. A. A real-time RT-PCR-based miRNA array using Cancer MiRNA Panel shows expression of miRNAs after $\mathrm{As}^{3+}$ exposure. Arrows indicate miRNAs in the miR-106-363 cluster; arrow heads indicate miRNAs in the miR-17-92 cluster. Data are representative of three experiments. B. $\mathrm{As}^{3+}$ induces expression of miR-190. Realtime RT-PCR was performed using total RNA extracted from the BEAS-2B cells treated with the indicated concentrations of $\mathrm{As}^{3+}$ for $12 \mathrm{~h}$. Data are means \pm SD of five experiments. C. $\mathrm{As}^{3+}$ induces miR-190 in A549 cells. Cells were treated as in B. Data are means \pm SD of three experiments. 


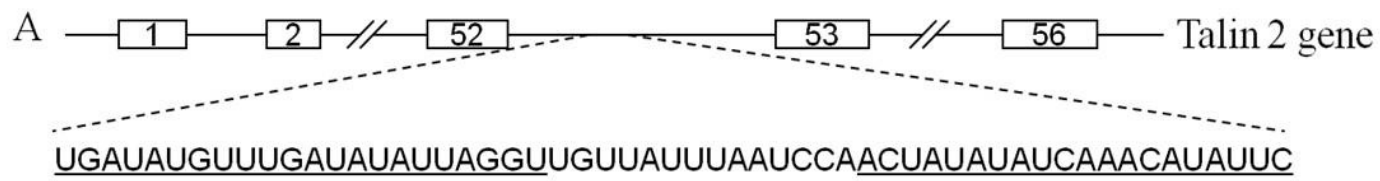

UGAUAUGUUGAUAUAUUGGUUGUUUUUAUCCAACUAUAUAUCAAACAUAUUC
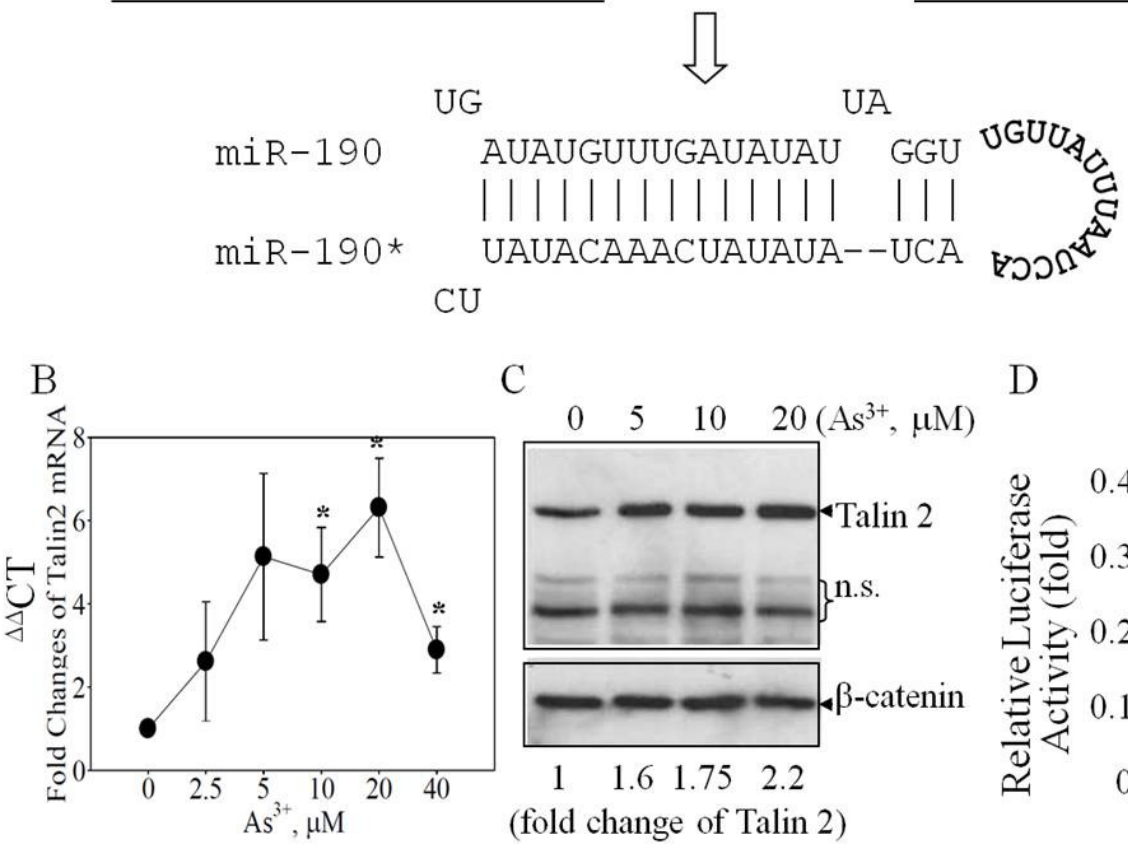

$\mathrm{C}$

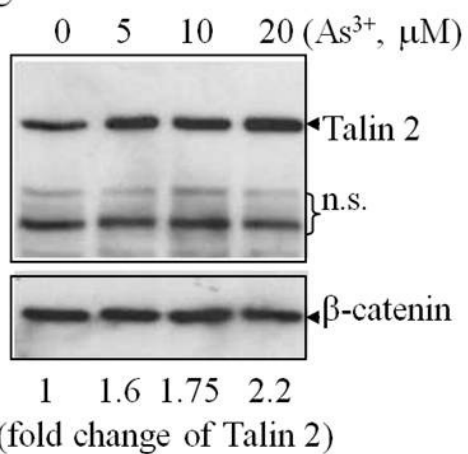

$\mathrm{D}$

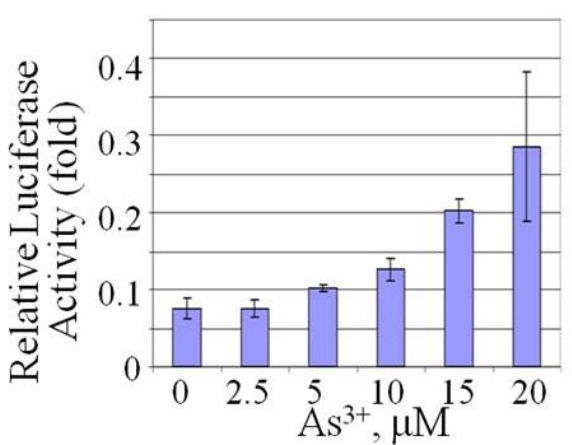

Figure 4: Talin 2 expression in response to $\mathrm{As}^{3+}$. A. Schematic diagram of the talin 2 gene and pre-miR-190 within the intron 52 region of the talin 2 gene. Underlined sequences indicate the sequences that form pre-miR-190 duplex through complementarily association of the inverted repeat region. The asterisk $(*)$ indicates passage strand of the miR-190 duplex. B. Real-time RT-PCR analysis of talin 2 mRNA production in response to $\mathrm{As}^{3+}$. C. Talin 2 protein was induced by a $12 \mathrm{~h}$-exposure of the cells with $\mathrm{As}^{3+}$ at the indicated concentrations. A loading control was made by Western blotting using antibody against $\beta$-catenin. N.s.: non specific bands. The bottom numbers show semi-quantification of the talin 2 protein expression by densitometry. Data are representative of 3 experiments. D. The talin 2 promoter reporter gene activity is activated by $\mathrm{As}^{3+}$ exposure. Data is normalized by calculating the ratio between Firefly luciferase activity vs Renilla luciferase activity. 


\section{A}

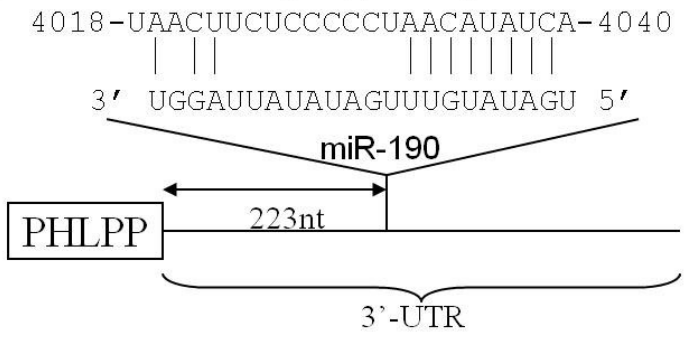

hsa-miR-190 3' uggaunauauagu UUGUAUAG u 5 ,

H. sapiens: AACUUCUCCCCCU AACAUAUC AGAUAUG

M. mulatta: AACUUCUCCCCCU AACAUAUC AGAUAUG

R. norvegicus: AACUUCUUUCCCU AACAUAUC AACUGUG

M. musculus: AACUUCUUUCCCU AACAUAUC AACUGUG

E. caballus: AACUUCUUCCCCU AACAUAUC AGAUGUG

G. gallus: AA- UCUUCCCTU AACAUAUC AA-AUG

D

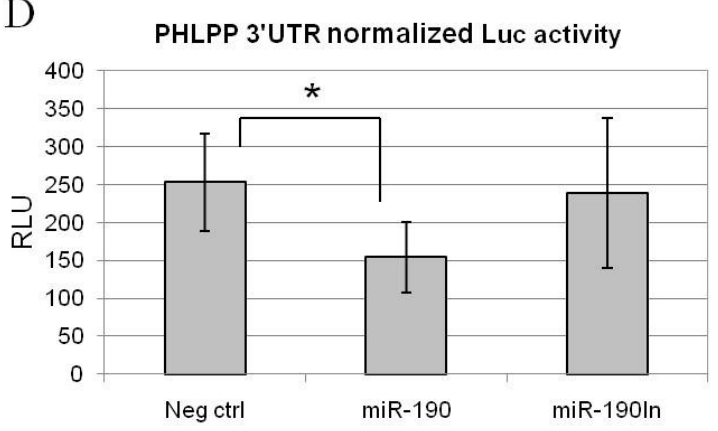

$\mathrm{B}$

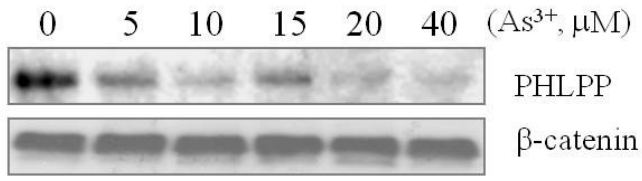

C

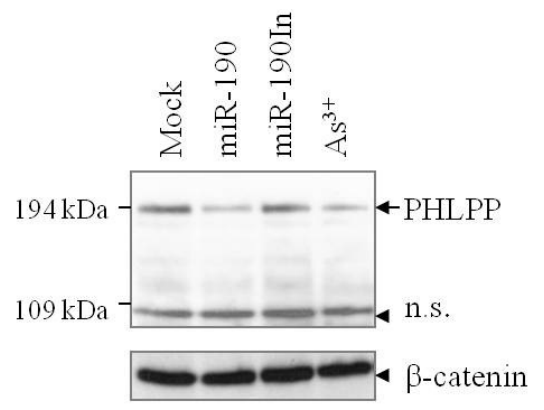

E

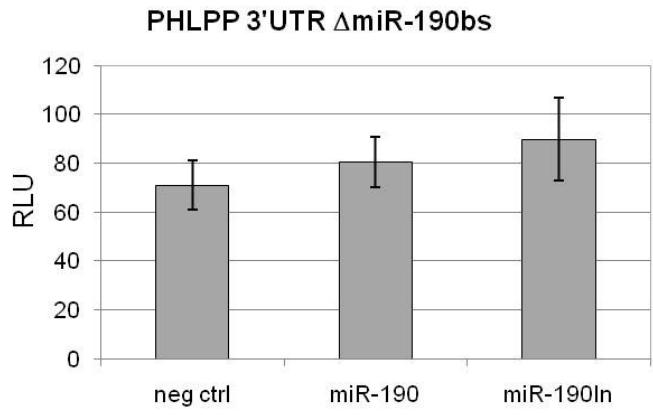

Figure 5: miR-190 targets PHLPP. A. Schematic diagram of the miR-190 binding site at the 3'-UTR of PHLPP mRNA. Lower panel shows alignment of the predicted miR-190 binding sites to 3-UTR of PHLPP from different species (Homo sapiens, Macaca mutatta, Rattus norvegicus, Mus musculus, Eguus caballus, and Gallus gallus). B. Western blotting shows concentration-dependent reduction of the PHLPP protein in the cells treated with $\mathrm{As}^{3+}$. C. Overexpression of miR-190 downregulates PHLPP. The BEAS-2B cells were mock transfected, or transfected with a miR-190, miR-190In, or treated with $20 \mu \mathrm{M}$ of $\mathrm{As}^{3+}$. The protein level of PHLPP was determined by Western blotting. D. Overexpression of miR-190, but not miR-190In, down-regulates the activity of the PHLPP 3'-UTR reporter gene. E. Overexpression of miR-190 has no effect on the PHLPP 3'-UTR reporter without the miR-190 binding site. 
A
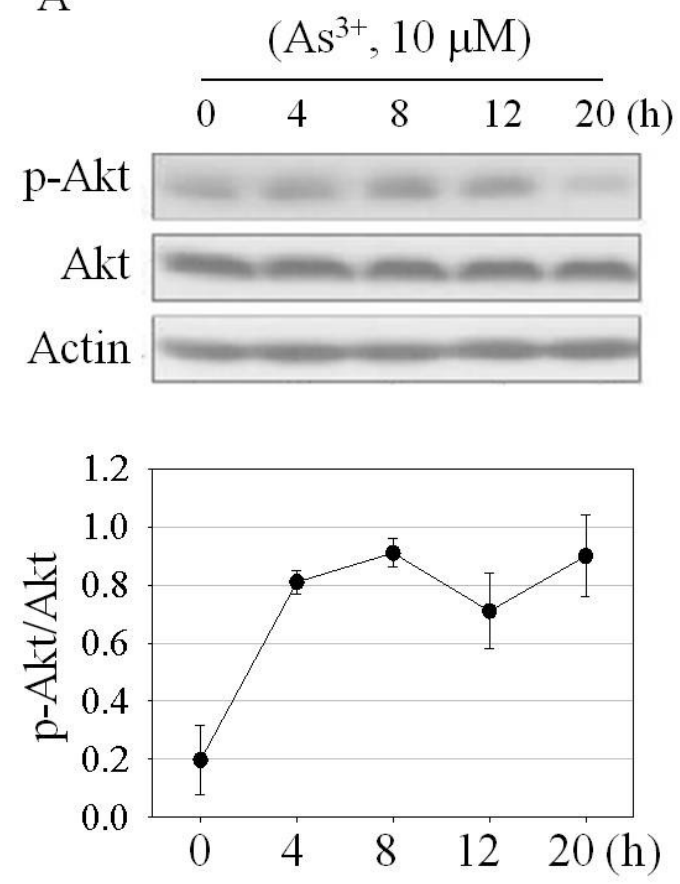

$\mathrm{B}$
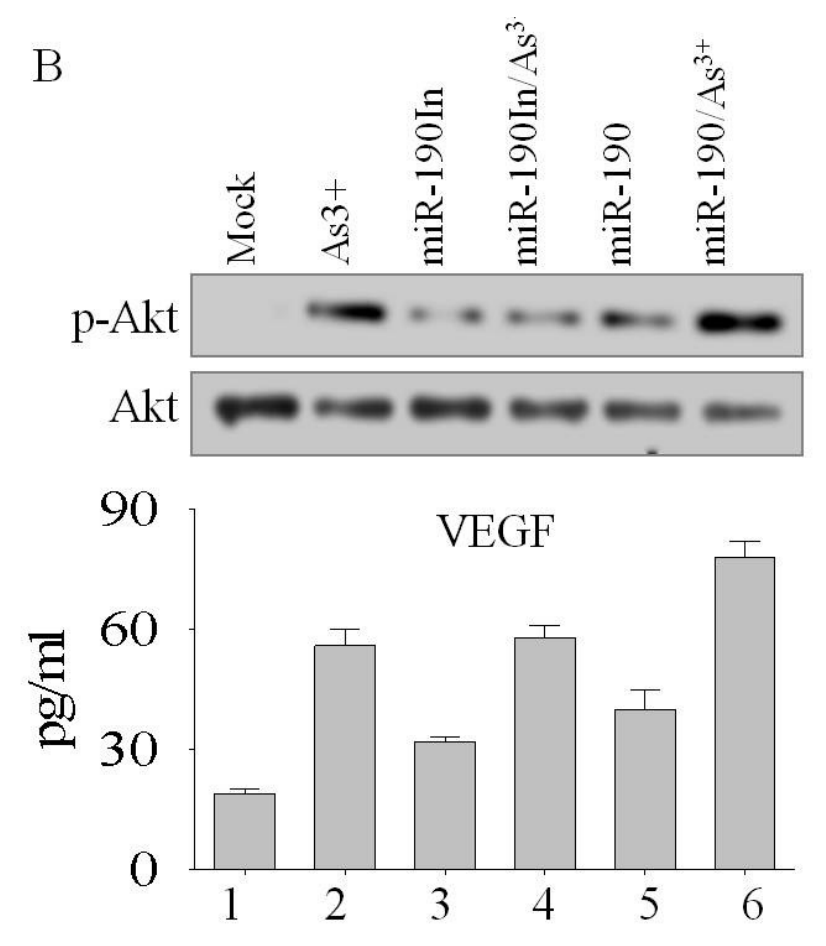

Figure 6: Overexpression of miR-190 enhances $\mathrm{As}^{3+}$-induced Akt phosphorylation and VEGF generation. A. BEAS-2B cells treated with $10 \mu \mathrm{M} \mathrm{As}{ }^{3+}$ for the indicated hours and Akt phosphorylation at Ser473 was determined by Western blotting. The bottom panel shows relative levels of Akt phosphorylation as determined by the ratio of 33hosphor-Akt vs nonphospho-Akt that were determined by densitometry scanning of 3 independent Western blotting experiments. B. BEAS-2B cells were transfected with the miR-190 and miR-190In, respectively. Phosphorylation of Akt at Ser473 was analyzed by Western blot. The bottom panel shows VEGF expression following miRNA transfection and $\mathrm{As}^{3+}$ exposure by ELISA. Data shown is representative of 3 experiments. 

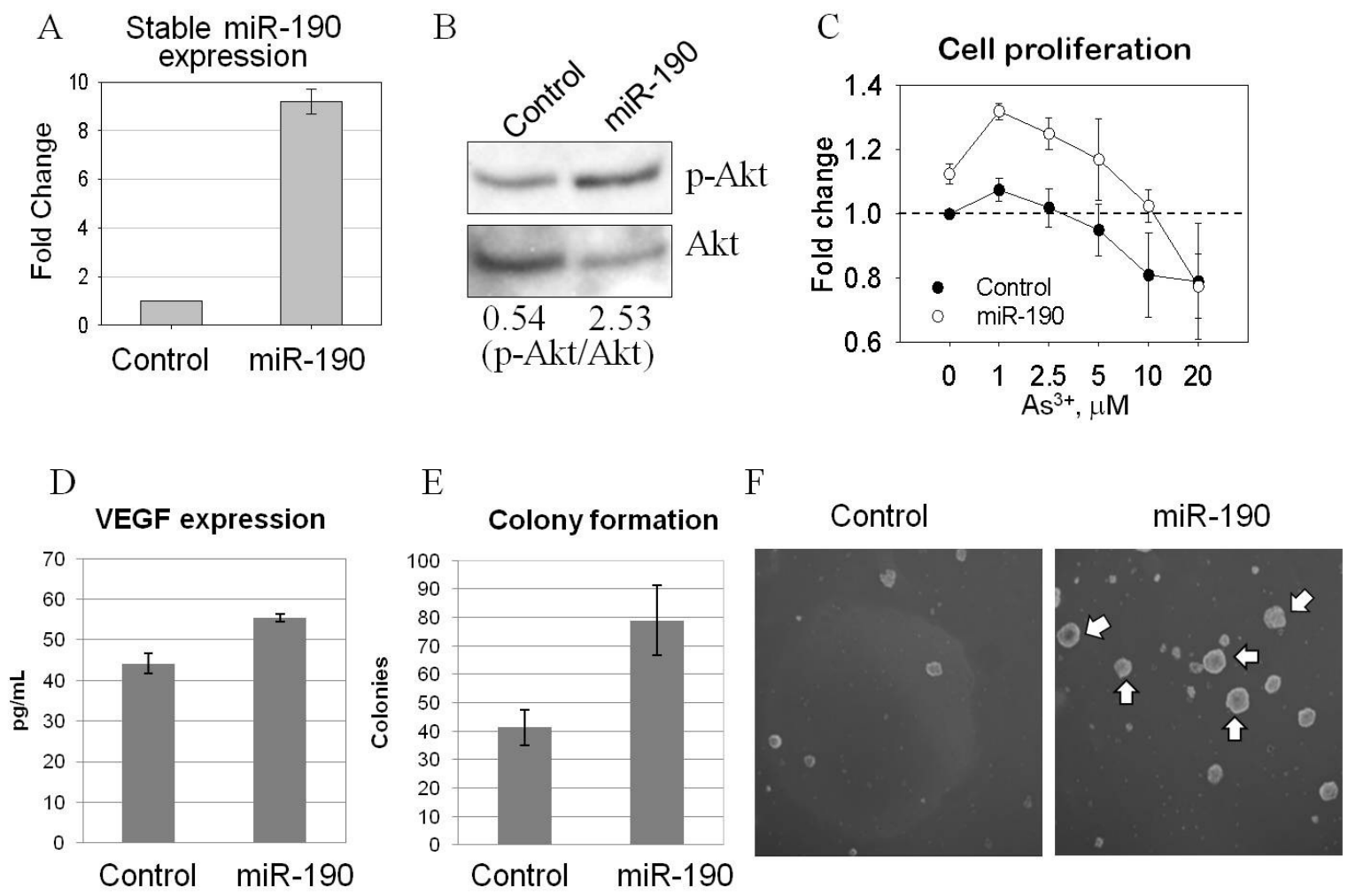

Figure 7: Stable expression of miR-190 enhances cell proliferation and carcinogenic transformation. A. The levels of miR-190 in the cells stably transfected with a control miRNA and miR-190 were determined by real-time PCR. B. Levels of Akt activation in the stably transfected cells were determined by Western blotting using antibody against Ser473phosphorylated Akt (up panel) or the non-phospho-Akt (bottom panel). The numbers at the bottom of the lower panel indicates ratios of Phospho-Akt vs non-phospho-Akt. C. The stably transfected BEAS-2B cells were cultured for $16 \mathrm{~h}$ followed by $\mathrm{As}^{3+}$ treatment with the indicated concentrations for an additional $12 \mathrm{~h}$. Cell proliferation was determined as described in the "Materials and Methods". D. VEGF levels were determined by ELISA in the stably transfected cells. E. Quantification of the colony numbers of the stably transfected cells in soft agar. F. Anchorage-independent growth of the stably transfected cells was determined by the colony 
formation in soft agar. White arrows indicate large colonies formed by the cells stably transfected with miR-190. 
Supplemental Data:

Table S1:

\begin{tabular}{|c|c|c|c|}
\hline upregulated & fold change & Downregulated & $\begin{array}{r}\text { fold } \\
\text { change }\end{array}$ \\
\hline miR-190 & 5.887 & $\mathrm{miR}-134$ & 0.245 \\
\hline $\operatorname{miR}-1-1$ & 4.508 & $\operatorname{miR}-136$ & 0.260 \\
\hline $\operatorname{miR}-19 a+b$ & 2.576 & miR-198 & 0.263 \\
\hline $\operatorname{miR}-29 a+b+c$ & 2.574 & miR-206 & 0.401 \\
\hline miR-93 & 2.308 & miR-223 & 0.402 \\
\hline let-7-family & 2.274 & miR-145 & 0.433 \\
\hline miR-26b & 2.270 & $\operatorname{miR}-141$ & 0.442 \\
\hline miR-17-5p & 2.159 & miR-372 & 0.446 \\
\hline miR-30b & 2.111 & miR-188 & 0.476 \\
\hline miR-218 & 2.083 & miR-215 & 0.488 \\
\hline$m i R-10 b$ & 2.002 & $\mathrm{miR}-150$ & 0.497 \\
\hline $\operatorname{miR}-7$ & 1.982 & miR-154 & 0.559 \\
\hline miR-15a & 1.917 & miR-122a & 0.588 \\
\hline $\mathrm{miR}-25$ & 1.893 & miR-181d & 0.647 \\
\hline miR-30a-5p & 1.876 & miR-197 & 0.658 \\
\hline miR-140 & 1.869 & miR-9-1 & 0.813 \\
\hline miR-26a & 1.867 & miR-202 & 0.825 \\
\hline miR-137 & 1.860 & miR-106b & 0.823 \\
\hline miR-24 & 1.845 & miR-200b & 0.885 \\
\hline miR-219 & 1.820 & miR-488 & 0.923 \\
\hline miR-132 & 1.740 & miR-205 & 0.932 \\
\hline miR-106a & 1.737 & miR-143 & 0.933 \\
\hline miR-153 & 1.718 & miR-222 & 0.956 \\
\hline miR-181a & 1.688 & miR-296 & 0.963 \\
\hline miR-103 & 1.680 & miR-149 & \\
\hline miR-23a & 1.674 & & \\
\hline miR-195 & 1.639 & & \\
\hline miR-21 & 1.635 & & \\
\hline miR-194 & 1.626 & & \\
\hline miR-30c & 1.626 & & \\
\hline miR-151 & 1.621 & & \\
\hline miR-27a+b & 1.620 & & \\
\hline miR-191 & 1.609 & & \\
\hline miR-95 & 1.589 & & \\
\hline miR-224 & 1.574 & & \\
\hline
\end{tabular}




\begin{tabular}{|cc|} 
miR-15b & 1.577 \\
miR-146a & 1.553 \\
miR-20a & 1.530 \\
miR-126 & 1.530 \\
miR-155 & 1.516 \\
miR-101-1 & 1.482 \\
miR-30a-3p & 1.463 \\
miR-22 & 1.458 \\
miR-210 & 1.455 \\
miR-128b & 1.451 \\
miR-183 & 1.428 \\
miR-204 & 1.424 \\
miR-185 & 1.417 \\
miR-142-3p & 1.396 \\
miR-196a & 1.380 \\
miR-133a & 1.249 \\
miR-181c & 1.245 \\
miR-125b & 1.242 \\
miR-214 & 1.231 \\
miR-17-3p & 1.217 \\
miR-16 & 1.216 \\
miR-221 & 1.215 \\
miR-192 & 1.200 \\
miR-92 & 1.161 \\
miR-181b & 1.136 \\
miR-125a & 1.136 \\
miR-18a & 1.113 \\
miR-199a+b & 1.110 \\
miR-107 $-135 b$ & 1.096 \\
\hline
\end{tabular}




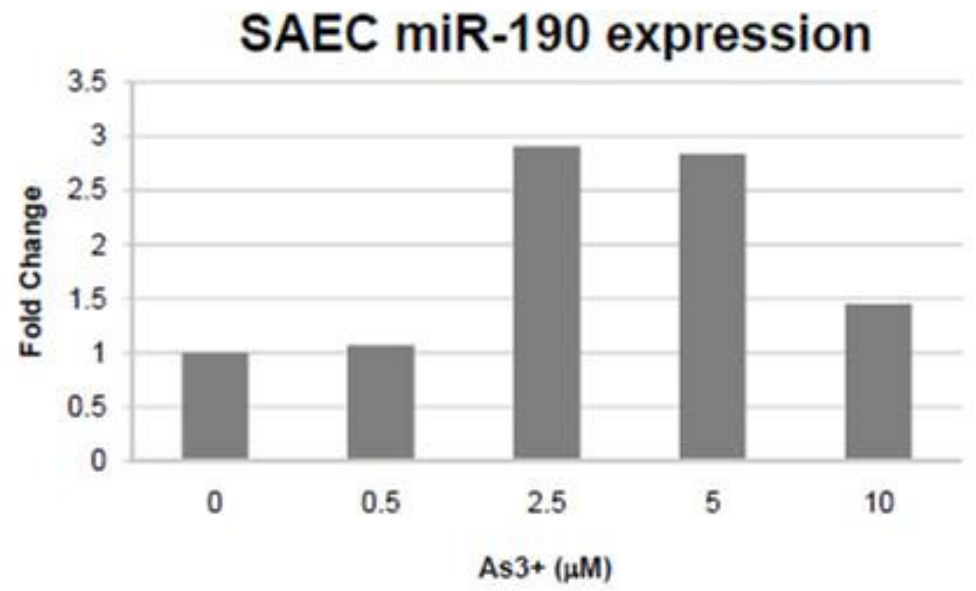

Figure S1: As3+ induces miR-190 expression in human primary SAEC cells. 
A

TP53INP1 (NM_033285)

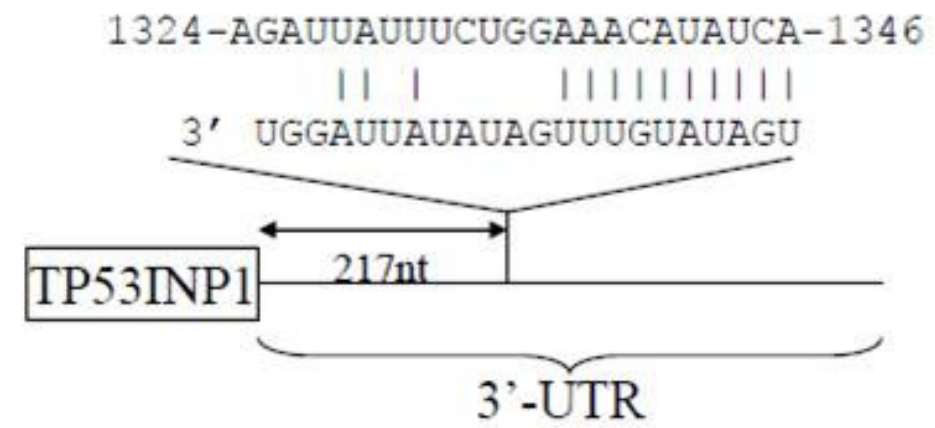

B

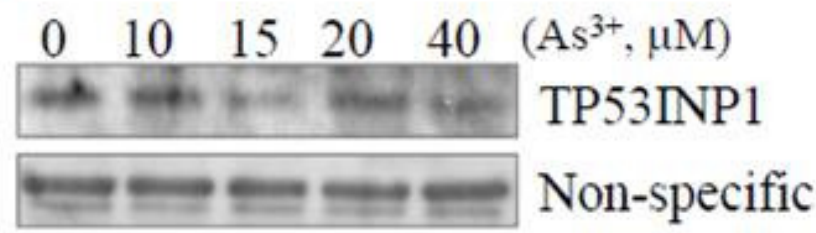

Figure S2. miR-190 targets TP53INP1. A. Schematic diagram shows the miR-190 binding site at the 3'UTR of TP53INP1 mRNA. B. Western blotting shows an As3+ induced decrease in TP53INP1 protein. 


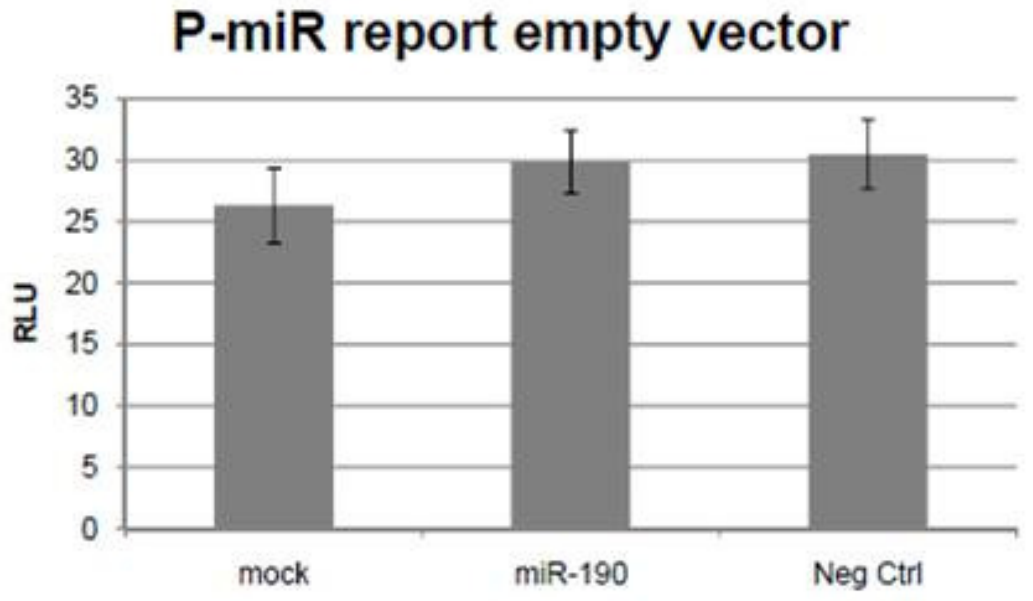

Figure S3: miR-190 has no effect on the control of the p-MIR REPORT vector. 


\title{
CHAPTER 3
}

\section{RT-PCR for miRNA Target Identification:}

\author{
A Preliminary Study
}




\section{Introduction:}

When considering the changes in expression of miRNA in disease states or in response to various stimuli the important next step is to identify downstream targets of the affected miRNA. While knowledge of a change itself is of some interest, uses of this information are limited without understanding of the impact of this change. In order to identify miRNA targets, much bioinformatic work has been done in the way of designing algorithms used to predict potential miRNA:mRNA pairs. These predicted targets must then be verified by various in vitro and in vivo approaches including the use of reporter vectors and site-directed mutagenesis. The usage of these algorithms is a hit-or-miss method of target identification, though the algorithms that have been designed continue to improve. One method is the usage of learning algorithms that verify potential miRNA-target interactions. The calculations might be altered to more accurately reflect proven relationships. While this method is helpful, other approaches should be developed which can more accurately and quickly identify miRNA targets. Such advancement would potentially aid in the quick identification of 'higher value' targets for possible therapeutic intervention.

While thinking about miRNA targeting the 3'UTR of an mRNA target, it is not difficult to view this interaction as similar to primer annealing duing a PCR reaction. In light of this thought, one could conceivably try to identify miRNA targets by using miRNA mimic primers to amplify mRNA targets. This approach is somewhat problematic, and issues arise that lead to multiple approaches for target identification, or a variety of outcomes. One approach might be to try and prime the RT-PCR reaction with the miRNA mimic primer alone. This approach relies on assumption that the mimic primer could bind to an mRNA, synthesizing a long un-ended product during the RT-step. The primer then would have to bind to some other downstream site based 
upon some random priming (Fig.1A). This method would require manipulation of the concentrations of the PCR reaction so that it would require as stringent pairing. This would probably be necessary for any reaction utilizing miRNA mimic primers, as these would contain multiple mismatches with an mRNA target. If by chance a product was obtained by the PCR reaction, several verification steps would be necessary to be sure the miRNA:target interaction was genuine. A variation of this method was published in 2008 which described using endogenously bound miRNAs in cell extracts as reverse transcriptase primers to create a pool of miRNA bound mRNAs [1]. A gene specific primer and a primer against an adapter oligo ligated to the 5' end of the miRNA were then used to identify genes that were targeted by miRNA, the specific miRNA and its binding site within the mRNA. One of the major drawbacks of this technique is that it requires that you first have a gene of interest and then determine its regulatory miRNA(s), instead of having a miRNA of interest and finding the gene(s) it regulates. The major positive for this technique is that it maintains the secondary structure of the mRNA and enhances the specificity of miRNAs for their targets by using cell extracts for the first RT reaction. By utilizing this technique the number of false positives should be cut down dramatically.

A second approach could utilize a specific upstream primer for a predicted mRNA target for a miRNA of interest (Fig. 1A). The usage of target prediction algorithms would still be necessary, and the results would still need to be verified, leaving this approach as not much more than an additional verification for in silico prediction that given current technologies may not be necessary. A third approach that would be significantly more complicated would utilize tagged miRNA mimics for specific miRNA target precipitation followed by PCR verification. This is a method that has already been described in part but is not commonly practiced. The previously described method performs a miRNA 'pull-down' using deoxygenin labeled miRNAs to isolate a 
pool of mRNA targets. This pool is then sub-cloned and sequenced to determine the putative targets for the miRNA [2]. This method was confirmed to be useful in the identification of hand2 as a novel target for miR-1 in zebrafish.

\section{Results:}

In order to determine if miRNAs were capable of priming an RT-PCR reaction on total RNA from cells, multiple mimic primers were used including mimics for miR-21, miR-155, let7a, let-7b, and miR-1. The PCR reactions were set up and run as detailed in the materials and methods section, and the products were run on an agarose gel. Due to the imperfect complementarity of miRNA-target binding, the stringency of the PCR reaction was tweaked to allow for greater mis-pairing of the primers to enhance the number of potential targets by adding magnesium sulfate to the PCR reaction. A trial was run using the let-7a primer for 3 different concentrations of magnesium sulfate including 1.5 (standard), 3 , and $6 \mathrm{mM}$, where the $3 \mathrm{mM}$ concentration yielded the best results. After multiple attempts the miRNA mimic primers were capable of priming PCR products visible on the agarose gel (Fig. 1B). Because miR-21 had the brightest and most easily discernable bands, the 4 brightest bands were cut, purified and cloned into a cloning vector for sequencing, the results from which suggest that bands 1 and 4 (from top to bottom) were amplifying the same gene, and interestingly this happened to be overlapping sequences. A BLAST search for the amplified sequences in the GenBank showed that the PCR products have a near perfect alignment with the MT-CO1 sequence with the exception of the mis-paired sites from the imperfectly complementary miRNA-mimic primer binding sites (fig.

2). The sequenced PCR products (bands1 and 4) also shared an upstream priming site referred to as priming site 1 on the anti-sense strand where the miRNA-mimic primer bound to the region 
encompassing the start codon. The miR-21 mimic primer also bound to two downstream sites on the sense strand creating two products, one $\sim 200$ base pairs in length (priming site 2 ) with the other (priming site 3) 500 base pairs. It is interesting to note that the mimic primer binding site was backward compared to typical miRNA binding sites with the 'seed sequence' located on the 3' end of the miRNA rather than the 5' end. Additionally the miRNA mimic binding sites are located within the coding region of the gene, not in the typically observed 3'UTR or even in more rare cases the 5' UTR. However some precedent does exist for miRNAs binding to the coding region [3].

The gene that was targeted by the miR-21 mimic primers is a mitochondrial protein known as mitochondrial cytochrome c oxidase subunit 1, MT-CO1, or COX1. If this interaction were to be verified, it would be the first time to our knowledge that an endogenous mammalian miRNA was demonstrated to target a gene produced from mitochondrial DNA. An emerging phenomenon within the field of cancer research is that a shift in the major metabolic pathways could be a potent driver of cancer progression [4]. Under normal aerobic conditions a cell uses glycolysis to create energy and pyruvate that then goes to the mitochondria to produce energy and carbon dioxide. It is becoming more evident that cancer cells rely more heavily on glycolysis with the pyruvate being used as an intermediate for other cellular products instead of being used by mitochondria $[5,6]$. Cytochrome $\mathrm{c}$ oxidase is a major component of the electron transport chain that catalyzes the reduction of oxygen to water, and MT-CO1 is part of its catalytic core [7]. A decrease in MT-CO1 expression, as often observed in cancers, by overexpression of miR21, thus, may induce the shift from normal aerobic metabolism to "aerobic glycolysis". Thus, in addition to its known targets such as PTEN and PDCD4 [8, 9], which are tumor suppressors, 
miR-21 may additionally target MT-CO1, enhancing tumorigenesis by altering metabolic pathways together with repressing proteins known to inhibit growth.

Some preliminary work suggests that arsenic is capable of inducing miR-21 expression (Table 1 in chapter 2). As previously discussed, miR-21 is a known oncogenic miRNA. Overexpression of this miRNA is observed in many solid tumors, and an increase in expression in response to arsenic may mediate its carcinogenic effect. If miR-21 could be shown to repress MT-CO1 expression as well as its other known targets in response to arsenic, this could be an additional mechanism by which arsenic induces cancer.

\section{Materials and Methods:}

\section{Reverse-transcriptase PCR for target identification:}

microRNA-mimic primers were purchased from Operon. The sequences are as follows;

Let-7b 5'-UGAGGUAGUAGGUUGUGUGGUU-3', $\quad$ miR-155 UUAAUGCUAAUCGUGUAUAGGGGU-3', $\quad$ miR-1 UGGAAUGUAAAGAAGUAUGUAU-3', miR-21 5'-UAGCUUAUCAGACUGAUGUUGA3'. The Access quick RT-PCR system from Promega was used to run the PCR reactions. The general conditions for the PCR reaction are as follows; $25 \mu \mathrm{l} 2 \mathrm{x}$ master mix, $1 \mu \mathrm{l}$ polyT primer (100 mM), $1 \mu \mathrm{g}$ total RNA from BEAS-2B cells, $3 \mu$ mimic primer, $3 \mu$ additional $\mathrm{MgSO}_{4}(25$ $\mathrm{mM}$ stock; $3 \mathrm{mM}$ final), and water to a total of $50 \mu \mathrm{l}$. The RT-PCR cycling was set up with the RT-step starting at 45 degrees for 45 minutes followed by 95 degrees for 2 minutes. The PCR cycling that followed was 95 degrees for 30 seconds, 50 degrees for 30 seconds, and 70 degrees for 1 minute, cycled 30 times, and followed by a final elongation step of 70 degrees for 5 minutes. 


\section{Potential target cloning:}

The PCR products were visualized on an agarose gel. Those bands chosen for sequencing were excised from the gel and purified using the QIAquick gel extraction kit from Qiagen following the manufacturer's instructions. The purified PCR product was then cloned into the TOPO TA cloning vector purchased from Invitrogen according to the manufacturer protocol. Following successful cloning, the vectors including the inserts were sequenced using the generic M13 forward and reverse primers. 


\section{References:}

1. Andachi Y: A novel biochemical method to identify target genes of individual microRNAs: identification of a new Caenorhabditis elegans let-7 target. RNA 2008, 14:2440-2451.

2. Hsu RJ, Yang HJ, Tsai HJ: Labeled microRNA pull-down assay system: an experimental approach for high-throughput identification of microRNA-target mRNAs. Nucleic Acids Res 2009, 37:e77.

3. Huang S, Wu S, Ding J, Lin J, Wei L, Gu J, He X: MicroRNA-181a modulates gene expression of zinc finger family members by directly targeting their coding regions. Nucleic Acids Res 2010, 38:7211-7218.

4. Hanahan D, Weinberg RA: Hallmarks of cancer: the next generation. Cell, 144:646674.

5. Warburg O: On respiratory impairment in cancer cells. Science 1956, 124:269-270.

6. Vander Heiden MG, Cantley LC, Thompson CB: Understanding the Warburg effect: the metabolic requirements of cell proliferation. Science 2009, 324:1029-1033.

7. Shoubridge EA: Cytochrome c oxidase deficiency. Am J Med Genet 2001, 106:46-52.

8. Meng F, Henson R, Wehbe-Janek H, Ghoshal K, Jacob ST, Patel T: MicroRNA-21 regulates expression of the PTEN tumor suppressor gene in human hepatocellular cancer. Gastroenterology 2007, 133:647-658.

9. Asangani IA, Rasheed SA, Nikolova DA, Leupold JH, Colburn NH, Post S, Allgayer H: MicroRNA-21 (miR-21) post-transcriptionally downregulates tumor suppressor Pdcd 4 and stimulates invasion, intravasation and metastasis in colorectal cancer. Oncogene 2008, 27:2128-2136. 


\section{Figures:}

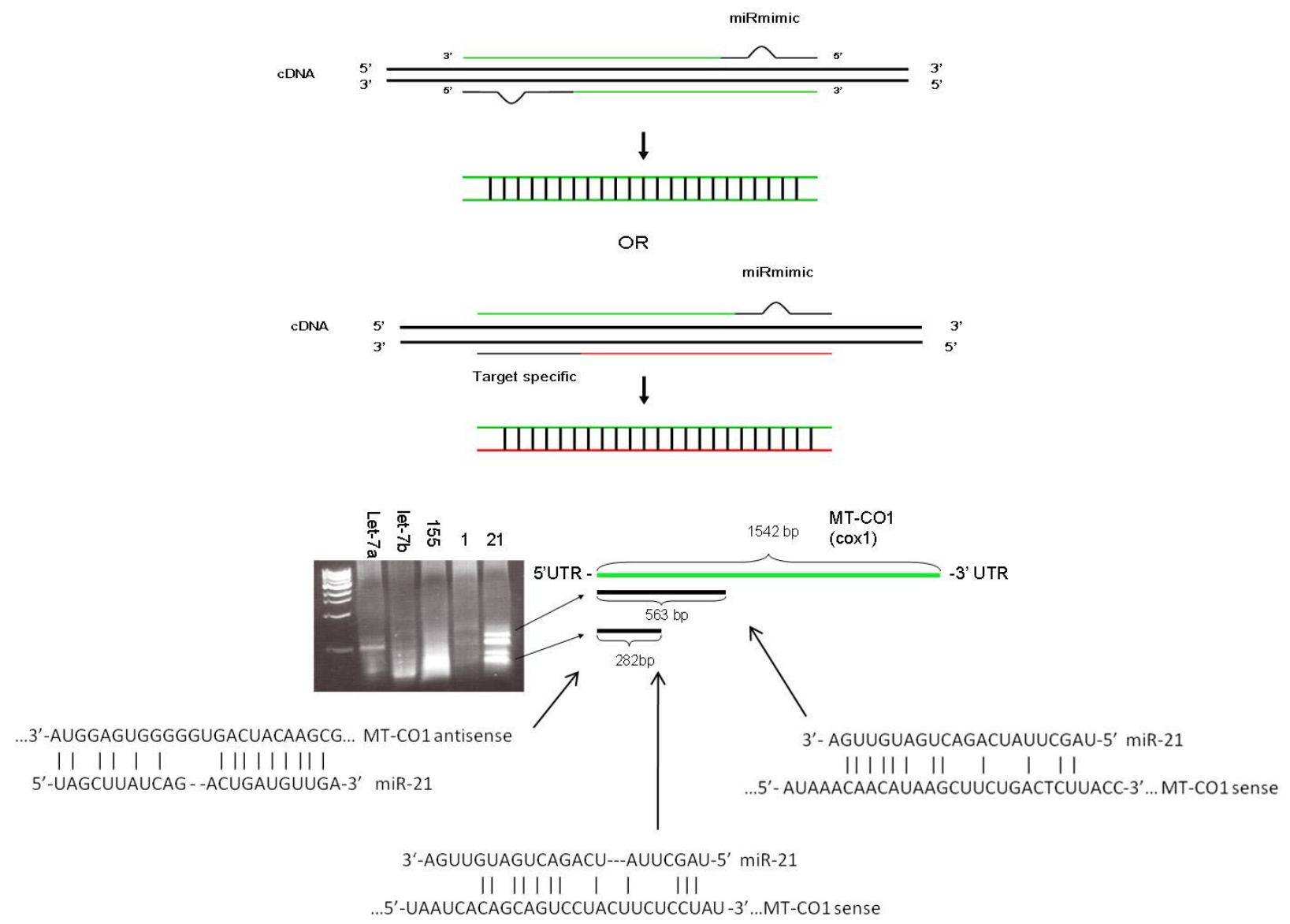

Figure 1. Reverse-transcriptase PCR for miRNA target identification. A. Depicts two of the possible mechanisms for PCR amplification of miRNA targets using miRNA mimic primers. Top, miRNA mimic primer binds to sites on the sense and antisense strand of the resulting cDNA molecule. Bottom, a primer specific for the antisense strand of a potential target is utilized for gene amplification. B. The miRNA mimic primers prime PCR products visible on an agarose gel. The closed arrows from the gel picture indicate which bands represent the amplified sections of the MT-CO1 gene. The open arrows indicate where each priming site is located in the MTCO1 sequence. The sequence and imperfect complementarity for each binding site is provided. 


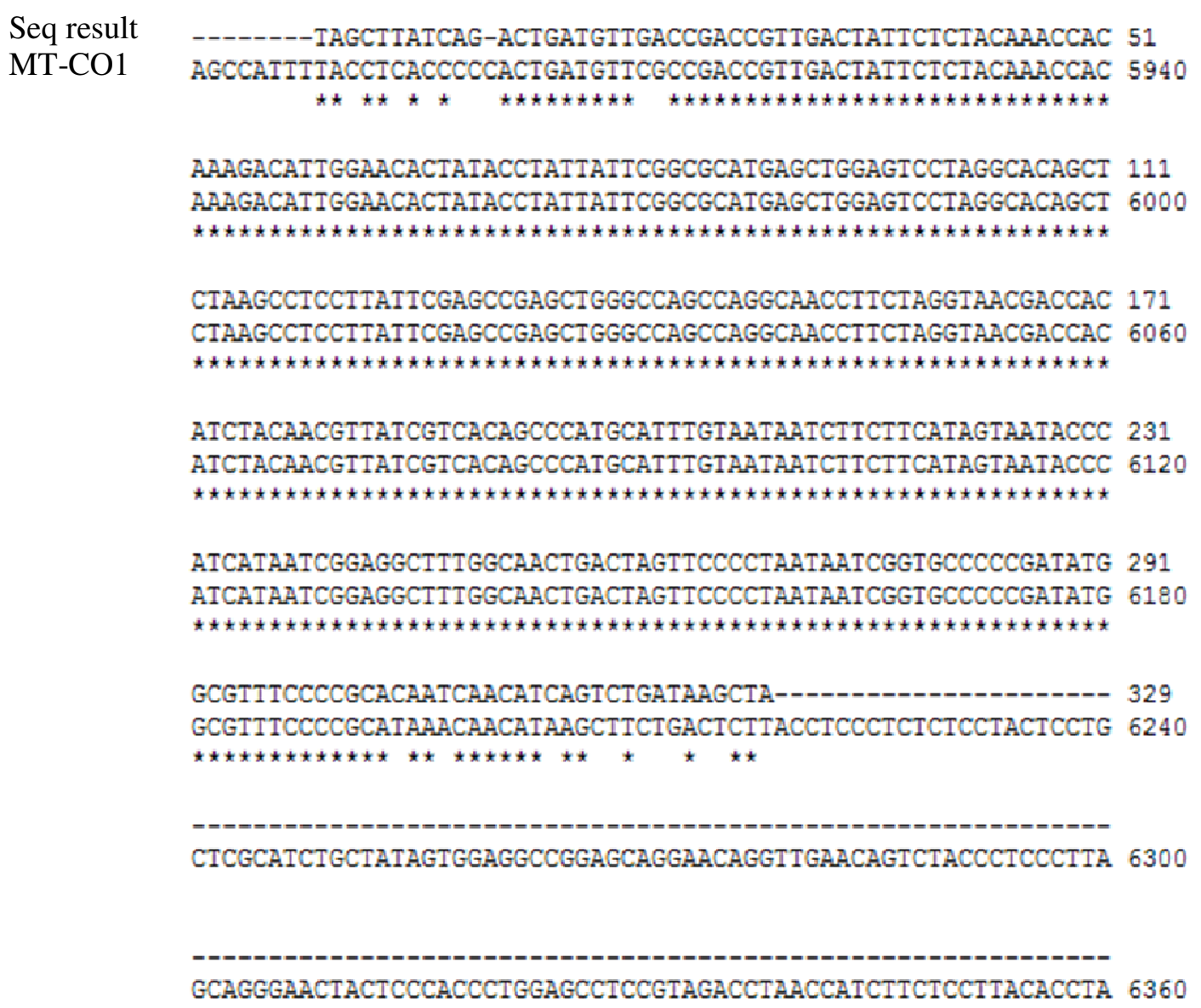

Figure 2. Sequence alignment of the sequencing results for PCR product 4 (priming site 2) with the MT-CO1 mRNA sequence 


\section{CHAPTER 4}

\section{General Discussion}


Environmental or occupational exposure to many naturally and non-naturally occurring chemicals, minerals, industrial products and by-products are known to cause cancer in humans. It is unsurprising that the majority of cancers are carcinomas or cancers of epithelial origin as the epithelial layers represent the primary site of contact for chemical exposure and are thus more susceptible to cancer formation in this regard. Cancers of the lung and bronchus represent the majority of cancers diagnosed yearly within the US, the leading cause of which is exposure to first or second-hand tobacco smoke. An additional cause of lung cancer, more so in developing nations than in the US is exposure to arsenic via contaminated drinking water or exposure by inhalation. The inhalation of arsenic in the form of arsenite is typically an occupational hazard involved in mining or smelting activities. Arsenite is a well-known toxin classified as a class 1 cancer-causing agent by the World Health Organization. Paradoxically arsenic trioxide is used as a treatment for some cancers including promyelocytic leukemia (PML). This brings to light a dynamic where high dose arsenite is toxic to cells, whereas long-term exposure to low dose arsenite is tumorigenic. Due to the nature of long-term exposure, teasing out all of the details of how arsenite causes cancer has been difficult and the mechanisms are not fully understood. The small RNA molecules known as miRNA are now recognized as important regulators of cell function. These molecules play important roles in control over normal cell function, development and disease. Changes in expression of miRNA are easily induced, and are capable of aiding or inducing disease. We aimed with this work to shed further light on the mechanism of arseniteinduced cancer with the hope of identifying a potential oncomiR, which could be used therapeutically. 


\section{Data summary and significance}

Arsenite induces changes in miRNA expression:

The ability of arsenite to induce changes in miRNA expression levels was in some ways a foregone conclusion for this study. Due to the ability of arsenite to alter the activity of transcription factors across varying concentrations and exposure times it stood to reason that miRNA expression levels would change. At the outset of this study only one other report had been completed indicating a role for arsenite, sodium arsenite for this specific study, in the expression of miRNA [1]. This report however reported 'global' increase in miRNA expression, which was partially contrary to our findings. Since this paper, several additional reports have been published showing a role for arsenite in altering miRNA expression. Typically these reports involve arsenic trioxide as a therapeutic for various cancers [2-4]. One study however indicates a role for miR-181b and miR-9 in arsenic induced angiogenesis [5]. Neo-angiogenesis is an important event during carcinogenesis, and this study indicates that miRNA may play an important role in arsenic induced malignancies. For this study the expression of miRNA-155 was studied in response to arsenic due to its potential for transcriptional control by arsenite. While real-time PCR studies for the mature mRNA were unsuccessful at detecting a change, promoter reporter vectors for the miR-155/BIC promoter were. These experiments indicated that arsenite could activate the promoter region. This conflict in results may indicate that in addition to activating transcription, arsenite has some effects downstream which interfere with miRNA processing. Additionally, there could be potential that the BEAS-2B cells contain some attribute which maintains expression of the mature miR-155 at a low level.

The array performed for this study showed that exposure of BEAS-2B cells to arsenite both increased and decreased the expression of several miRNAs. Of these miRNAs one that was 
most interesting was miR-190 due to its potential to alter Akt signaling, a known outcome of arsenic exposure. The induction of expression by arsenite was confirmed using real-time PCR and the expression of miR-190 was correlated with the expression of its host gene, talin 2 (TLN2), which is in agreement with the previous report indicating that miR-190 and Talin 2 are produced from the same transcript [6]. This correlation suggests that the changes in miR-190 abundance are occurring at the transcriptional level.

Arsenic induced miR-190 represses PHLPP expression:

To determine the effect of increased miR-190 expression we utilized multiple algorithms that predict potential miRNA targets. The most compelling target for miR-190 was PHLPP. This phosphatase was recently discovered and is known to target S473 on Akt for dephosphorylation [6]. The 3'UTR region for PHLPP was cloned downstream of a luciferase reporter gene. Transient transfection of a miRNA precursor readily repressed expression of the reporter. Deletion of the miR-190 binding site removed the inhibitive effect of the precursor, indicating that this binding site is the true target for miR-190 within the PHLPP transcript, and that PHLPP is a functional target of miR-190. As a tumor suppressor gene, repression of PHLPP expression in response changes in miR-190 downstream of arsenite presents an interesting scenario for arsenic-mediated carcinogenesis. Arsenite is a known inducer of cell stress, and at higher concentrations, induces cell death. If the concentration is low enough an enhanced activation of Akt could allow cells to escape apoptosis and survive even after cellular damage from the arsenic has occurred.

MiR-190 enhances Akt phosphorylation downstream of arsenite exposure: 
One of the major findings from this study is that arsenite induced Akt phosphorylation and activation is enhanced by miR-190 expression through repression of PHLPP. The enhanced or prolonged Akt signal may be a factor that helps drive cellular survival during cell stress. The enhanced survival allows for the transformative effects of arsenite to occur instead of apoptosis. Akt has a multitude of cellular targets involved in enhancing survival, growth, cell cycle progression, and protein synthesis. Akt enhances cell survival by activating XIAP [7], an inhibitor of apoptosis, as well as MDM2 [8] a p53 inhibitor. Akt inhibits the apoptotic mediators, such as Bim, Bad [9] and Bax [10], potentially allowing cells to survive during various apoptotic stimuli. Akt can enhance cell cycle and growth by inhibiting cell cycle inhibitors such as p27Kip [11], and Myt1, a wee1 family member [12]. Akt also inhibits GSK-3, a Cyclin D1 inhibitor [13]. Akt activates PFK-2 [14] which increases glycolysis, and PIP5K [15] which increases glucose transport. The increased metabolic potential is helpful for cell growth and division. Akt enhances protein synthesis that is necessary for cell cycle progression by activating mTOR and S6. Akt activates mTOR by inhibiting the TSC1/TSC2 inhibitory complex as well as PDCD4, another mTOR inhibitor $[16,17]$.

Active Akt has long been recognized as an important signaling protein involved in enhancing or inducing tumorigenesis. More recent studies continue to support this finding highlighting its importance as a potential therapeutic target. One such study analyzes the role of the Akt isoforms in K-Ras mediated lung tumorigenesis [18]. The results from this study showed that Akt1 but not Akt2 or Akt3 were involved in K-ras induced carcinogenesis. Indeed deletion of Akt1 prevented the formation of tumors, whereas deletion of Akt3 led to increased tumor multiplicity and size. This finding indicates that Akt1 and Akt3 have opposing roles in tumorigenesis suggesting that a specific Akt1 inhibitor would be a better therapeutic option than 
one that targeted all three isoforms like those that are currently used for clinical development [19]. Interestingly the different isoforms of PHLPP target the various Akt isoforms differently. While both PHLPP1 and PHLPP2 target Akt1, only PHLPP2 targets Akt3 for dephosphorylation [20]. PHLPP1 and PHLPP2 are transcribed from different chromosomes and have different 3'UTR regions, and as a result in silico analysis suggests that miR-190 targets only PHLPP1 and not PHLPP2. Inhibition of miR-190 would enhance abundance of PHLPP1 and not PHLPP2 leading to decreased phosphorylation of Akt1 and not Akt3. This indicates that miR-190 may be a useful therapeutic tool in that it may modulate Akt1 but not Akt3 which are suggested to have opposing roles. While modulating miRNA function may be therapeutically less potent than directly targeting Akt1 itself, its potential benefits may still remain.

Activation of Akt is known to induce downstream signaling pathways such as induction of VEGF. The current report indicates that miR-190 enhanced Akt activation by arsenic is also capable of increasing VEGF expression, a known outcome of arsenic exposure [21-23]. Expression of VEGF is strongly linked with tumor vascularization, enhancing tumor invasion and metastasis as well as inducing epithelial cell growth [24]. VEGF is a common target for cancer therapy across a wide range of tumor types [25]. Induction of VEGF expression by arsenic through miR-190, thus, may be able to explain in part the ability of arsenic to induce tumor formation in epithelial cells.

Overexpression of miR-190 enhances colony formation:

The most compelling result from this research is that stable overexpression of miR-190 in BEAS-2B cells led to an increased number of colonies formed as well as an increase in colony size. These data were accompanied by an increase in cellular proliferation as well Akt 
phosphorylation and VEGF expression. The increase in colony formation and size indicates that overexpression of miR-190 enhances the likelihood that cells will continue to proliferate when growing in a context that normally inhibits proliferation. An increase in tumor growth even in the face of anti-proliferative signals (contact inhibition with low serum levels) is the most common indicator of cellular transformation and tumorigenesis. That miR-190 overexpression causes cells to exhibit these characteristics is a strong indication that this miRNA is an oncogenic miRNA.

\section{RT-PCR for target identification:}

Verifying the mRNA targets of miRNAs is crucial to determining the roles of individual miRNAs within cells. Current methods for ascertaining miRNA targets are based upon in silico analysis which is subject to much error, or requires that you start with a protein of interest before moving to a targeting miRNA. In order to design an inexpensive and quick method for identifying potential miRNA targets, a reverse-transcription approach was adopted. We found that miRNA mimic primers could be used to amplify sections of mRNA if the stringency of the PCR reaction was adjusted properly. Upon sequencing the products amplified by miR-21 mimic primer, MT-CO1 was identified as a potential target. This target has yet to be verified by western blotting or other means upon manipulation miR-21 expression, however it may have some meaningful implications as discussed in the previous chapter. Due to the limited number of products observed for each miRNA mimic primer used, this method does not produce a comprehensive look at potential miRNA targets as each miRNA is likely to target many mRNAs. Adjustment of the PCR reaction may be necessary for the individual mimic primer to increase the number of potential targets but also attempt to minimize the number of false positives. 
Although a great potential of errors remain, this method may have some promise as a quick and inexpensive tool for miRNA target identification.

\section{Using miRNAs as therapeutics:}

The utilization of miRNAs as therapeutics has the potential to revolutionize the way diseases are treated. In many cases medicine is only able to treat the symptoms but not the underlying disease. If miRNAs can be successfully manipulated, protein expression that causes the disease phenotype can be changed. In therapeutics, miRNAs are categorized into a class called antisense oligonucleotides or ASOs, which includes other short oligos such as siRNAs. The most significant challenge facing this group of therapeutics is uptake and delivery. Modification of oligos including the addition of 2'-O-methyl ribose sugars and conjugation to cholesterol allows for uptake into cells [26]. Additional modification includes the use of locked nucleic acids or LNAs. These are nucleosides which contain a methylene bridge to keep them in the ideal conformation for Watson-Crick binding. LNA oligos have a higher affinity for target mRNA, and repress their targets more quickly and efficiently [27]. Therapeutic oligos can be delivered directly to the target. This delivery increases bioavailability and minimizes off tissue targeting, but is restricted to tissues like skin, eyes, mucous membranes and solid tumors [26].

Where specific targeting is not possible, ASOs can be packaged into pegylated liposomes or lipid nanoparticles that contain cationic lipids allowing for first uptake and then release of the packaged ASOs once in the cell [28]. Once in the cell the ASO will carry out its intended effect after any requisite processing.

A few therapeutic trials utilizing ASOs have shown success thus far. The most promising ASO undergoing trials thus far is an LNA-antimiR against miR-122. This ASO is capable of 
targeting miR-122 specifically in the liver, reducing replication of Hepatitis C Virus that is dependent on miR-122, as well as reducing total plasma cholesterol [29]. This ASO is currently undergoing phase 2 clinical trials for hepatitis $\mathrm{C}$ infection as wells as cancer and inflammatory diseases [26].

\section{Future studies:}

Future studies proceeding from this work include a number of potential avenues of research. One important area that is currently underway is the determination of what signaling pathways and transcription factors are responsible for the induction of miR-190 expression by arsenite. This information would be useful if modulation of miR-190 expression would prove to have therapeutic potential. Instead of trying to alter miR-190 levels by targeting the molecule itself, modulation of some upstream regulator may achieve the desired effect. Preliminary experiments have shown that ERK kinase may be responsible for the induction of miR-190 expression. Activation of ERK through the MAP kinase cascade leads to the activation of the transcription factor MYC. The miR-190/TLN2 promoter contains multiple MYC binding sites and could potentially be responsive to them. A second transcription factor which may be responsible for activating miR-190 expression is AP-1, a downstream target of JNK. The miR190/TLN2 promoter also contains AP-1 binding sites including conserved 'canonical' sites. Arsenic is known to activate both of these transcription factor signaling pathways and they are critical for mediating the proliferative effects of arsenic.

As mentioned earlier, there are differences in the roles of the varying isoforms of Akt in cellular function as well as differences in how the different PHLPP isoforms regulate Akt phosphorylation. Reports indicate that active Akt3 has effects that counteract the other isoforms, 
and the only PHLPP isoform which targets Akt3 is PHLPP2. It is highly unlikely that miR-190 targets PHLPP2 due to the lack of miR-190 binding site(s) in the 3'-UTR region, therefore it would be of considerable interest to determine whether modulation of the Akt isoforms by manipulation of miR-190 would yield significant results that would be therapeutically useful. A comprehensive study analyzing the effects of miR-190 overexpression or repression on the phosphorylation of the various Akt isoforms paired with a targeted therapeutic model to determine if miR-190 modulation would yield better results than a pan-Akt inhibitor, thus, would shed light on this issue.

An additional area of research of considerable interest would be to tease out exactly the role miR-190 has in arsenite induced cancers and/or other malignancies. In the study of cancer caused by arsenite exposure it appears that miR-190 expression is a transient phenomenon. While in the presence of arsenite, cells produce more miR-190, which will enhance Akt phosphorylation and the subsequent survival signal. This survival signal enhanced by transient miR-190 expression may be enough to overcome cellular death signals and allow for DNA alterations leading to cell transformation. Some preliminary data has shown that BEAS-2B cells transformed by long-term low-dose exposure to arsenite do not exhibit persistent overexpression of miR-190. It would be of interest to generate a miR-190 knockout mouse or cell line to test how readily these animals or cells undergo transformation in response to arsenite or other transformative stimuli. If it could be shown that miR-190 knockout animals are more resistant to carcinogenesis, it could be of significant worth to pursue miR-190 as a therapeutic target.

Further research could also be performed on the ability of miR-190 to enhance expression of VEGF. Increased expression of VEGF has severe consequences for increased angiogenesis for tumor growth. Tumor cells are known to produce high levels of VEGF to enhance the growth of 
new blood vessels and vascularize the solid tumor [30]. Once vascularized, the tumor can increase in size, and is more likely to become metastatic. It would be of significant interest to determine whether miR-190 plays a role in the ability of tumor cells to produce VEGF and recruit endothelial cells to the tumor causing neo-vascularization. Therapeutic targeting of miR190 may be capable of reducing VEGF expression and inhibit tumor growth through a decreased vascularization and ensuing necrosis.

Under the broader study of arsenic-induced miRNA expression, our lab has generated some preliminary data suggesting that arsenite induces the expression of miR-21. Interestingly the expression of this miRNA also has implications for the activation of Akt in response to arsenite, which involves down-regulation of PTEN, a negative regulator of the upstream activating signaling for Akt, by miR-21 [31]. Also involved in the Akt pathway is another known miR-21 target, the PDCD4 tumor suppressor [32]. Akt directly phosphorylates and inhibits PDCD4 [17], and this activity along with miR-21 repression would strongly push cells toward tumorigenesis.

\section{Conclusion:}

Since shortly after the discovery of miRNA, changes in miRNA expression have been linked to disease states, with the hypothesis that the miRNAs are causative rather than being a result of the disease. The expression of miRNA is now established as important regulators of cellular function and they are being targeted for therapeutic intervention. The research in the current study set out to understand if arsenic could regulate the expression of miRNAs, and whether these miRNAs might play a role in arsenic-induced carcinogenesis. The results from this study indicate that arsenite indeed does regulate the expression of miRNAs associated with neoplastic transformation or tumorigenesis. Specifically, the expression of miR-190 in response 
to arsenite and the enhanced Akt activation downstream of PHLPP repression, provide a mechanism by which arsenite could cause diseases. This pathway also presents a potential therapeutic target for arsenic-induced cancer prevention. 


\section{References:}

1. Marsit CJ, Eddy K, Kelsey KT: MicroRNA responses to cellular stress. Cancer Res 2006, 66:10843-10848.

2. Cao Y, Yu SL, Wang Y, Guo GY, Ding Q, An RH: MicroRNA-dependent regulation of PTEN after arsenic trioxide treatment in bladder cancer cell line T24. Tumour Biol 2011, 32:179188.

3. Gao SM, Chen C, Wu J, Tan Y, Yu K, Xing CY, Ye A, Yin L, Jiang L: Synergistic apoptosis induction in leukemic cells by miR-15a/16-1 and arsenic trioxide. Biochem Biophys Res Commun 2010 403:203-208.

4. Meng XZ, Zheng TS, Chen X, Wang JB, Zhang WH, Pan SH, Jiang HC, Liu LX: microRNA expression alteration after arsenic trioxide treatment in HepG-2 cells. $J$ Gastroenterol Hepatol 2011, 26:186-193.

5. Cui Y, Han Z, Yi H, Song G, Hao C, Xia H, Ma X: MicroRNA-181b and microRNA-9 mediate arsenic-induced angiogenesis via NRP1. J Cell Physiol 2011.

6. Gao T, Furnari F, Newton AC: PHLPP: a phosphatase that directly dephosphorylates Akt, promotes apoptosis, and suppresses tumor growth. Mol Cell 2005, 18:13-24.

7. Dan HC, Sun M, Kaneko S, Feldman RI, Nicosia SV, Wang HG, Tsang BK, Cheng JQ: Akt phosphorylation and stabilization of X-linked inhibitor of apoptosis protein (XIAP). $J$ Biol Chem 2004, 279:5405-5412.

8. Feng J, Tamaskovic R, Yang Z, Brazil DP, Merlo A, Hess D, Hemmings BA: Stabilization of Mdm2 via decreased ubiquitination is mediated by protein kinase $B$ /Akt-dependent phosphorylation. J Biol Chem 2004, 279:35510-35517.

9. Rusinol AE, Thewke D, Liu J, Freeman N, Panini SR, Sinensky MS: AKT/protein kinase B regulation of BCL family members during oxysterol-induced apoptosis. Journal of Biological Chemistry 2004, 279:1392-1399.

10. Gardai SJ, Hildeman DA, Frankel SK, Whitlock BB, Frasch SC, Borregaard N, Marrack P, Bratton DL, Henson PM: Phosphorylation of Bax Ser(184) by Akt regulates its activity and apoptosis in neutrophils. Journal of Biological Chemistry 2004, 279:21085-21095.

11. Mirza AM, Kohn AD, Roth RA, McMahon M: Oncogenic transformation of cells by a conditionally active form of the protein kinase Akt/PKB. Cell Growth \& Differentiation 2000, 11:279-292.

12. Okumura E, Fukuhara T, Yoshida H, Hanada S, Kozutsumi R, Mori M, Tachibana K, Kishimoto T: Akt inhibits Myt1 the signalling pathway that leads to meiotic G2/M-phase transitions. Nature Cell Biology 2002, 4:111-116.

13. Piwien-Pilipuk G, Van Mater D, Ross SE, MacDougald OA, Schwartz J: Growth hormone regulates phosphorylation and function of CCAAT/enhancer-binding protein beta by modulating Akt and glycogen synthase kinase-3. Journal of Biological Chemistry 2001, 276:19664-19671. 
14. Deprez J, Vertommen D, Alessi DR, Hue L, Rider MH: Phosphorylation and activation of heart 6-phosphofructo-2-kinase by protein kinase $B$ and other protein kinases of the insulin signaling cascades. Journal of Biological Chemistry 1997, 272:17269-17275.

15. Berwick DC, Dell GC, Welsh GI, Heesom KJ, Hers I, Fletcher LM, Cooke FT, Tavare JM: Protein kinase B phosphorylation of PIKfyve regulates the trafficking of GLUT4 vesicles. $J$ Cell Sci 2004, 117:5985-5993.

16. Inoki $\mathrm{K}$, Li Y, Zhu T, Wu J, Guan KL: TSC2 is phosphorylated and inhibited by Akt and suppresses mTOR signalling. Nat Cell Biol 2002, 4:648-657.

17. Palamarchuk A, Efanov A, Maximov V, Aqeilan RI, Croce CM, Pekarsky Y: Akt phosphorylates and regulates Pded4 tumor suppressor protein. Cancer Res 2005, 65:1128211286.

18. Hollander MC, Maier CR, Hobbs EA, Ashmore AR, Linnoila RI, Dennis PA: Akt1 deletion prevents lung tumorigenesis by mutant K-ras. Oncogene, 30:1812-1821.

19. Gills JJ, Dennis PA: Perifosine: update on a novel Akt inhibitor. Curr Oncol Rep 2009, 11:102-110.

20. Brognard J, Sierecki E, Gao T, Newton AC: PHLPP and a second isoform, PHLPP2, differentially attenuate the amplitude of Akt signaling by regulating distinct Akt isoforms. Mol Cell 2007, 25:917-931.

21. Kao YH, Yu CL, Chang LW, Yu HS: Low concentrations of arsenic induce vascular endothelial growth factor and nitric oxide release and stimulate angiogenesis in vitro. Chem Res Toxicol 2003, 16:460-468.

22. Soucy NV, Mayka D, Klei LR, Nemec AA, Bauer JA, Barchowsky A: Neovascularization and angiogenic gene expression following chronic arsenic exposure in mice. Cardiovasc Toxicol 2005, 5:29-41.

23. Gao N, Shen L, Zhang Z, Leonard SS, He H, Zhang XG, Shi X, Jiang BH: Arsenite induces HIF-1alpha and VEGF through PI3K, Akt and reactive oxygen species in DU145 human prostate carcinoma cells. Mol Cell Biochem 2004, 255:33-45.

24. Brown KR, England KM, Goss KL, Snyder JM, Acarregui MJ: VEGF induces airway epithelial cell proliferation in human fetal lung in vitro. Am J Physiol Lung Cell Mol Physiol 2001, 281:L1001-1010.

25. Delli Carpini J, Karam AK, Montgomery L: Vascular endothelial growth factor and its relationship to the prognosis and treatment of breast, ovarian, and cervical cancer. Angiogenesis 2010, 13:43-58.

26. Broderick JA, Zamore PD: MicroRNA therapeutics. Gene Ther 2011.

27. Braasch DA, Corey DR: Locked nucleic acid (LNA): fine-tuning the recognition of DNA and RNA. Chem Biol 2001, 8:1-7. 
28. Semple SC, Akinc A, Chen J, Sandhu AP, Mui BL, Cho CK, Sah DW, Stebbing D, Crosley EJ, Yaworski E, et al: Rational design of cationic lipids for siRNA delivery. Nat Biotechnol 2010, 28:172-176.

29. Elmen J, Lindow M, Schutz S, Lawrence M, Petri A, Obad S, Lindholm M, Hedtjarn M, Hansen $\mathrm{HF}$, Berger U, et al: LNA-mediated microRNA silencing in non-human primates. Nature 2008, 452:896-899.

30. Fontanini G, Vignati S, Boldrini L, Chine S, Silvestri V, Lucchi M, Mussi A, Angeletti CA, Bevilacqua G: Vascular endothelial growth factor is associated with neovascularization and influences progression of non-small cell lung carcinoma. Clin Cancer Res 1997, 3:861-865.

31. Meng F, Henson R, Wehbe-Janek H, Ghoshal K, Jacob ST, Patel T: MicroRNA-21 regulates expression of the PTEN tumor suppressor gene in human hepatocellular cancer. Gastroenterology 2007, 133:647-658.

32. Asangani IA, Rasheed SA, Nikolova DA, Leupold JH, Colburn NH, Post S, Allgayer H: MicroRNA-21 (miR-21) post-transcriptionally downregulates tumor suppressor Pdcd4 and stimulates invasion, intravasation and metastasis in colorectal cancer. Oncogene 2008, 27:2128-2136. 


\section{Appendix}

Review

\section{Microprocessor of microRNAs: regulation and potential for therapeutic intervention.}

$\underline{\text { Kevin J. Beezhold }^{1,2}, \text { Vince Castranova }^{1} \text {, and Fei Chen }}{ }^{1,2} *$

\footnotetext{
${ }^{1}$ Laboratory of Cancer Signaling and Epigenetics, Health Effects Laboratory Division, Pathology and Physiology Research Branch, National Institute for Occupational Safety and Health, 1095 Willowdale Road, Morgantown, WV 26505, USA; ${ }^{2}$ Cancer Cell Biology Program, West Virginia University, WV 26506, USA.
}

Corresponding should be addressed to:

\section{F. Chen, Ph.D.} $\mathrm{PPRB} / \mathrm{NIOSH}$ 1095 Willowdale Road Morgantown, WV 26505, USA

Email: LFD3@cdc.gov

Phone: 13042856021

Published:

Molecular Cancer (2010) 9: 134 (1 June 2010) 


\begin{abstract}
:
MicroRNAs (miRNAs) are a class of small, noncoding RNAs critically involved in a wide spectrum of normal and pathological processes of cells or tissues by fine-tuning the signals important for stem cell development, cell differentiation, cell cycle regulation, apoptosis, and transformation. Considerable progress has been made in the past few years in understanding the transcription, biogenesis and functional regulation of miRNAs. Numerous studies have implicated altered expression of miRNAs in human cancers, suggesting that aberrant expression of miRNAs is one of the hallmarks for carcinogenesis. In this review, we briefly discuss most recent discoveries on the regulation of miRNAs at the level of microprocessor-mediated biogenesis of miRNAs.
\end{abstract}




\section{Introduction:}

MicroRNAs (miRNAs) are endogenously synthesized small non-coding RNAs that regulate gene expression by interfering with protein translational machinery and/or inducing degradation of target mRNAs [1]. Since the discovery of miRNAs, much effort has been made to understand the mechanisms by which miRNAs are synthesized and involved in cell lineage development and human diseases, especially, cancer. It is imperative that scientists continue to delineate how the biogenesis of these miRNAs is controlled by the cellular processing machinery, so that one may better understand how to modulate their expression or function as it contributes to a unique disease state. Recent research shows the involvement of additional proteins that modulate the function of the miRNA processing machinery, the Drosha processing complex, or microprocessor. This article reviews these new findings and discusses the potential for targeting these regulatory pathways in cancer therapy.

\section{MicroRNA biogenesis:}

It has been well-established that the biogenesis of microRNAs (miRNAs) involves three step-wise processes, including transcription of primary miRNAs (primiRNAs) from the miRNA genes [2], partially processed precursor miRNAs (premiRNAs) in nuclei [3] and the mature miRNAs that were generated in the cytoplasm (Fig. 1). Pri-miRNA is typically a large RNA polymerase pol II-derived transcript whose tertiary structure forms stem loop structures. The stem loop is cleaved off by the microprocessor machinery, Drosha complex, to form 60-100 nucleotide long premiRNA, which is further processed into 22 nucleotide long mature miRNAs by Dicer, a RNase III enzyme, following translocation from the nuclei to cytoplasm [4]. 
After successful cleavage, the pre-miRNA is bound by exportin-5 in a ran-GTP dependant manner and exported from the nucleus [5-7]. Binding of pre-miRNA by exportin-5 is dependent upon the stem of the miRNA, requiring a length of 16-18 base pairs, and alterations in the 3' overhang will affect the efficiency of exportin-5 binding[8]. Interestingly, reduced binding of exportin-5 by reduction of the protein itself or alteration in the miRNA structure causes a reduced expression of the mature miRNA, without buildup of pre-miRNA in the nucleus [5]. This suggests that exportin-5 may play a protective role during miRNA transport to the cytoplasm [8]. Once in the cytoplasm, the pre-miRNA is released from exportin-5 after the hydrolysis of GTP, and is free to be processed further.

In the cytoplasm, pre-miRNA undergoes the next step of processing mediated by Dicer to produce the mature miRNA. The RNase III enzyme, Dicer, was found to cleave RNAs into 22 nucleotide products [9-11]. This cleavage occurs in an ATP independent manner, through which the loop structure and 3' overhang are removed [12]. Recognition and correct cleavage of the pre-miRNA are determined by the different domains of Dicer. Dicer contains a PAZ domain which recognizes the 3' end of the premiRNA, and the rest of the molecule acts as a molecular ruler directing the RNase III domains to cleave the 3 ' overhang and the loop structure to generate the mature miRNA [13]. After cleavage, one strand of the miRNA duplex is preferentially incorporated into the RISC complex. The selection of one strand over the other is based upon thermodynamic properties of the duplex, and the strand with the less thermodynamical stability at the 5' end is usually selected [14]. The mature miRNA bound to RISC then 
associates with an Argonaute protein, most commonly Ago2, and directs binding of the RISC complex to partially complementary sites in the 3'-UTRs of targeting mRNAs [15].

Previous observations suggested that the specificity of miRNA is determined by the sequence complementarity between bases $2-8$ on the $5^{\prime}$ end of the miRNA, termed the seed sequence, and the target mRNAs [16, 17]. A recent study appears to oppose this seed sequence pairing mechanism, and identifies binding and repression of mRNA by several "seedless" miRNA-mRNA duplexes [18]. In a microarray study for proteins down regulated by miR-24 expression, it was observed that multiple genes whose expression was reduced do not have predictable target sequences. Using an algorithm that does not require a seed match, it was further confirmed that the miR-24 targeting sequences are indeed within the 3' UTRs of the repressed genes [18].

There are multiple mechanisms by which miRNAs downregulate gene expression, some of which are still in controversy. These mechanisms have been reviewed in-depth elsewhere [19]. Briefly, mRNAs have been observed to be repressed by three major processes including endonucleolytic cleavage, mRNA degradation by deadenylation, and inhibition of translation initiation. Similar to siRNA-mediated mRNA degradation, the endonucleolytic cleavage of mRNA by miRNA requires perfect or near perfect complementarity between miRNA and the target mRNA. If such a condition is satisfied, proteins within the RISC complex are then able to cleave the mRNA, leading to its degradation and silencing [20]. This gene silencing process has been shown to occur in multiple organisms including mammals. Of note however, this mechanism of gene 
regulation rarely occurs in mammalian cells because nearly all miRNA-mRNA interactions have significant mismatches [17, 21-23].

Inhibition of translation initiation is another widely studied mechanism of miRNA-induced gene silencing. In 2005 Pillai et al. found that a miRNA-targeted reporter mRNA sedimented with small polysomes in HeLa cells, which indicates the repression occurred at translation initiation. In the same publication, they also showed that reporter constructs which are not dependant on the 7-methyl guanosine cap structure did not undergo repression, and suggested that miRNPs are capable of binding to the cap structure [24]. A motif was later found within AGO2 that was indeed capable of binding to the 5' cap structure of mRNA, which could then compete with eIF4E that is necessary for initiation of translation [25].

Cellular localization is another mechanism by which miRNA might mediate repression of mRNA translation. There is evidence suggesting that some miRNP-bound mRNAs localize to p-bodies within the cytoplasm. The p-bodies are cytoplasmic foci that contain mRNAs that are not actively undergoing translation. The p-bodies also contain proteins that are responsible for mRNA degradation [26]. Several observations suggest that mRNAs within the p-bodies are being repressed by miRNA that are colocalized in these foci. However, a detailed mechanism by which the repression occurs has yet to be fully determined. In addition, the deadenylation of mature mRNA has been implicated as a mechanism by which miRNAs are able to repress protein translation within the p-bodies. It was believed that GW182, a protein important for deadenylation of mRNAs, localizes in p-bodies and is able to interact with AGO1. This interaction leads 
to recruitment of decapping complexes and subsequent degradation of the miRNP-bound mRNA [27-29].

\section{Microprocessor and pri-miRNA processing:}

The pri-miRNAs transcribed from miRNA genes usually exhibit a size of several thousands of nucleotides long, whereas the size of mature miRNAs is only about 22 base pairs [30]. As briefly mentioned earlier, the generation of mature miRNA, encoded by either an intron of protein-coding gene or intergenic non-coding transcription unit, requires two sequential endonucleolytic cleavages by RNase III enzymes. A nuclear protein, Drosha, is the first enzyme to catalyze such processing. It is believed that Drosha is able to cleave intronic pri-miRNA without interference with the splicing of the precursor mRNA (pre-mRNA) [31]. There is also evidence indicating that cleavage of pri-miRNA by Drosha can be closely coupled with transcription of the pri-miRNAs from either intronic or intergenic miRNA genes [31].

Accumulating evidence suggests that processing of pri-miRNA by Drosha itself is insufficient and often erroneous, since imprecise cleavage occurred by the recombinant Drosha protein [32]. Inaccuracy of pri-miRNA cleavage will result in production of premiRNAs with altered hairpin secondary structure and identities. To ensure efficient and precise processing of pri-miRNA by Drosha, a number of co-factors are necessarily needed. Indeed, protein fractionation by affinity chromatography revealed that Drosha is present in protein complexes with different sizes in vivo [32, 33]. The study performed by Gregory et al. showed association of Drosha with 2 different complexes, a large complex with $\sim 20$ proteins and a small complex consisting of Drosha and DiGeorge 
syndrome critical region 8 (DGCR8) [32]. The association of Drosha with these proteins forms microprocessors to ensure the fidelity and activity of Drosha cleavage on primiRNA [32]. DGCR8 is a protein found within the DiGeorge syndrome critical region and was revealed to be essential for the processing of pri-miRNA to pre-miRNA by Drosha. At about the same time, Han et al. also identified DGCR8 as a critical player in miRNA processing and demonstrated that the microprocessor complex may be composed of multiple DGCR8 and Drosha molecules, possibly creating a dynamic processing structure [33]. Because most pri-miRNAs have similar structures typified by a terminal loop, a double stranded stem, and single stranded flanking sequences, it was speculated that this common structure may be the determining factor that regulates primiRNA cleavage (Fig. 2). There is evidence indicating that both the terminal loop and single stranded flanking sequences are important for processing efficiency [4, 34, 35]. An in-depth look at the molecular mechanisms controlling the binding of pri-miRNAs by the microprocessor complex suggests that DGCR8 is responsible for the binding of the complex to the pri-miRNA stem-loop. DGCR8 recognizes both the single stranded flanks and the double stranded stem, and then acts as a ruler guiding Drosha to cleave the molecule in the correct place, 11 base pairs up the stem from the ssRNA-dsRNA junction (Fig. 2) [36].

In addition to DGCR8, other well-characterized proteins in the microprocessor which facilitate the activity of Drosha include two DEAD-box RNA helicases p68 and p72 [32, 37]. Both p68 and p72 are originally identified as ATP-dependent RNA helicases important for pre-mRNA and pre-rRNA splicing by association with spliceosome complexes [38]. Genetic disruption of either p68 or p72 in mice is lethal. 
Surveying miRNA expression profiling using embryo fibroblast cells (MEF) suggests about $35 \%$ reduction of pre-miRNA and mature miRNA expression in p68 or p72 gene knockout MEFs relative to the wild type MEFs. Intriguingly, the level of pri-miRNAs is comparable between the knockout MEFs and the wild-type MEFs, indicating contribution of p68 or p72 to the Drosha-mediated pri-miRNA processing [39]. Direct evidence of p68 and p72 in pri-miRNA processing was provided by demonstrating their interaction with the Drosha and DGCR8 proteins in an immunoprecipitation-mass spectromic analysis $[32,37]$.

Regulation of the microprocessor by SMADS:

The first evidence showing additional proteins binding to and modulating the function of the Drosha complex was provided by Davis et al. in 2008 [40]. Through studying which miRNAs might play a role in the phenotypic changes of the vascular smooth muscle cells in response to TGF- $\beta$ signaling, they found that miR-21 and miR199a were induced by BMP4 and TGF- $\beta$ stimulation. Further studies indicate that such an induction occurred at the post-transcriptional level because BMP4 or TGF- $\beta$ rapidly induces pre-miR-21 and mature miR-21 but not pri-miR-21. Indeed, the expression of pri-miR-21 stayed stable following the activation of the TGF- $\beta$ signaling. The induction of pre-miR-21 and miR-21 by BMP4 or TGF- $\beta$ was blocked in the cells when expression of SMAD proteins was repressed by siRNA knock-down. Previous studies suggest that the MH2 domain on the carboxyl-terminus of SMAD proteins is capable of binding to p68, the RNA helicase associated with the Drosha complex [41]. This conclusion was supported by Davis et al. [40] who demonstrated direct interaction of p68 with SMAD1, 3, and 5 in a GST-pull down experiment. The interaction of Drosha with the p68/SMAD 
complex occurred only under conditions where the miRNA transcripts were intact. Furthermore, RNA co-immunoprecipitation confirmed the specific regulation of SMADs on the microprocessors of miR-21 and miR-199a, but not miR-214, in response to BMP4 or TGF- $\beta$ (Fig. 2).

Activation of SMAD proteins by TGF- $\beta$ has long been assumed as a mechanism for inducing epithelial to mesenchymal transition (EMT) and overall cancer cell growth. Adding to this role, the above study demonstrates an additional function of TGF- $\beta$ being able to increase the expression of miRNAs 21 and 199a. MiR-21 is the most commonly over-expressed miRNA in cancers [42]. Over-expression of miR-21 has been reported in more than 15 different malignancies [43]. The oncogenic potential of miR-21 is largely attributed to its involvement in several intracellular signaling pathways, including the activation of AKT [44] and antagonizing the expression of the pro-apoptotic protein PDCD4 [45]. Expression of miR-199a has also been associated with cancers. One study suggests that leukemias with higher expression of miR-199a exhibit a worse prognosis [46]. Several other studies, however, show that a loss in expression of miR-199a, enhanced tumor progression by an enhancement of IKK $\beta$ expression and its induced inflammatory and tumorigenic signals in ovarian cancer [47].

TGF- $\beta$ and SMAD4 have also been recognized as key players in inducing transcription of miR-155 and miR-214, two other oncogenic miRNAs [48]. Elevated miR-155 represses RhoA protein expression, reduces the ability of epithelial cells to form tight junctions, and enhances a tumors' ability of metastasis [48]. In ovarian cancer, miR-214 is overexpressed, leading to a sustained activation of the Akt kinases by down- 
regulation of PTEN, a negative regulator of Akt signaling. Decrease in PTEN expression, thus, causes an aberrant activation of Akt and resistance of the tumor cells to chemotherapy, such as cisplatin treatment [49].

The above reports detailing regulation of Drosha processing by SMADs in response to TGF- $\beta$ signaling are of particular interest. This modulation appears to be specific to a subset of miRNAs, and it will be important to determine what other miRNAs are regulated by this same mechanism and what molecular events govern such regulation. It appears that the binding of SMAD proteins to the Drosha microprocessor stabilizes the formation of the complex on a specific set of pri-miRNAs. Accordingly, it will be important to determine the downstream targets of these miRNAs and whether regulation of miRNA processing is a major mechanism of TGF- $\beta$ in cell transformation and carcinogenesis.

\section{p53 and miRNA processing}

The tumor suppressor p53 is perhaps the most intensively studied protein in cell biology and cancer. As a transcription factor, the tumor suppressor function of p53 is achieved largely by transcriptional up-regulation of a number of pro-apoptotic proteins. A recent study by Suzuki and colleagues demonstrates a novel mechanism of p53 in tumor suppression by regulating miRNA biogenesis at the level of Drosha microprocessor [50]. The interaction of p53 with p68, a protein associated with the Drosha microprocessor, has been previously demonstrated [51]. In the latest study, it was noted that p53 is capable of interacting with p68 and p72, both of which are Drosha-associated RNA helicases (Fig. 2). Using doxorubicin as a DNA damaging agent and p53 inducer in human colon 
cancer cell line HCT116, the expression of a subset of miRNAs was up-regulated. These miRNAs include miR-15a, miR-16-1, miR-23a, miR-26a, miR-103, miR-143, miR-145, miR-203, as well as miR-34a that had previously been determined to be induced by p53 [52]. Upon examination of the expression levels of pri-, pre- and mature miRNAs for each of the miRNAs regulated by doxorubicin, as expected, all species of miR-34a, a transcriptional target of p53, were upregulated. Interestingly, several other miRNAs showed increases of pre- and mature miRNA species, but not the pri-miRNA transcripts, suggesting that the regulation of $\mathrm{p} 53$ for some of these miRNAs is independent of transcription. Furthermore, cancer-associated p53 mutants fail to bind p68 or induce miRNA processing. Overexpression of each of these p53-regulated miRNAs substantially decreased the rate of cell proliferation. Taken together, these data clearly indicate that mutation of p53 in cancers hinders the maturation of several miRNAs important for tumor suppression and leads to an increased tumorigenic potential.

The involvement of p53 in miRNA biogenesis post-transcriptionally provides evidence of a global control mechanism for subsets of miRNAs involved in similar cellular functions. The p53 transcriptional target, miR-34a, was shown to repress tumor progression in multiple cancers [53-55] and has recently been found to target c-met and Notch1/Notch2 in glioblastomas [56]. Interestingly, expression of miR-15a and miR-161 is often reduced in tumors. Both miR-15a and miR-16-1 have been shown to target the anti-apoptotic protein, BCL2 [57, 58]. This cluster of miRNAs is also observed to be able to target additional proteins such as Cyclin D1 and WNT3A, which promote tumorigenesis [59]. Decreased expression of miR-143 and miR-145 has been strongly linked to colon cancer [60-62]. MiR-143 has been shown to target KRAS [63] and DNA 
methyltransferase 3A [62]. In breast cancer, loss of miR-145 resulted in an elevation of rhotekin $(\mathrm{RTKN})$, a scaffolding protein for Rho-GTP that is involved in cell proliferation [64].

The involvement of p53 in miRNA biogenesis was unexpected. The capability of p53 to regulate miRNA expression obviously strengthens its tumor suppressor function further. The questions that remain unanswered are why association of p53 with the Drosha microprocessor only regulates a selected subset of miRNAs but not others and how does p53 alter the recognition and processing dynamics of the Drosha complex toward the pri-miRNA repertoire. Nevertheless, the discovery of p53 regulation on miRNA processing confirms that p53 is a powerful suppressor for cancer formation. Loss of p53 as observed in multiple cancers, therefore, will not only weaken the checkpoint mechanisms of the cells but also impair the generation of those tumor suppressor-like miRNAs.

\section{ARS2 regulation of miRNA processing}

Arsenic Resistance protein 2 (Ars2) is a protein whose expression is strongly linked to the proliferation of cells especially during embryonic development [65]. Recently two studies have been published linking Ars2 expression to miRNA processing. The study by Gruber et al. [66] show that in addition to its role in cell proliferation, depletion of Ars2 in mammalian cells repressed miRNA-mediated silencing of reporter genes. After siRNA knockdown of Ars2, the ability of let-7 to repress the expression of a luciferase reporter construct was significantly reduced. Addition of the let-7 duplex RNA was able to reverse the loss of reporter repression, indicating that Ars2 does not function 
down-stream of Drosha processing. Immunoprecipitation of Drosha proteins was able to pull down Ars2, while the same experiment with Dicer did not. This further indicates that repression of miRNA function occurs at the Drosha processing step (Fig. 2). Previous research performed on SERRATE, a plant homolog of Ars2, indicates that Ars2 was responsible for regulating the appropriate processing of miRNA by Drosha [67]. However, Gruber et al. found that Ars 2 was not required for processing of all miRNAs, but only for a subset containing let-7 and miR-21. After screening for factors important in antiviral defense in Drosophila, Sabin et al. simultaneously observed a similar activity of Ars2 in miRNA processing in Drosophila with viral infection [68]. They identified that Ars2 is critical for intrinsic antiviral defense in Drosophila. Loss of Ars2 leads to a pronounced increase in viral replication of several RNA viruses in both cell culture and adult flies. Using an over-expression strategy, Sabin et al. [68] also demonstrate that Ars2 was capable of binding to Pasha, also known as DGCR8 in mammals, the doublestranded RNA binding partner of Drosha. Additional experiments implied interaction between Ars2 and the nuclear cap-binding complex (CBC) that recognizes and binds to the 5'-cap of pri-miRNA transcripts. Based on all of these observations, two nonexclusive models for the role of Ars 2 in miRNA processing were proposed. The first is the so-called bridging model, in which both Ars2 and CBC bind pri-miRNA transcripts followed by recruitment of the Drosha microprocessor by Ars2. In the second model, Ars2 acts as a cofactor for Drosha's enzymatic activity by enhancing the overall processing activity and fidelity of the microprocessor [68].

The discovery of Ars2 in miRNA processing further emphasizes the point that miRNA biogenesis and activity are highly regulated processes involving multiple 
proteins at various stages. Although Ars2 is a protein which has not been extensively studied, early reports indicating its contributions to cell proliferation and more recent studies showing its role in miRNA processing suggest that Ars2 may be a potential target for therapeutic intervention in various disease states including cancer.

\section{Cell-to-cell contact affects miRNA processing:}

The regulation of microRNA processing has been found to be affected by the confluence of the culture or the intensity of cell-to-cell contacts. Hwang et al. found that as cultures reach confluence, the expression of most of the miRNAs that they studied also increased [69]. They were able to show that this effect occurred across multiple cell lines and was typified by an accumulation of pre- and mature miRNA. This change in miRNA levels appears to be independent of the status of cell proliferation, conditions of the cell culture media, or the density of the cells in culture. This indicates that an increase in cellto-cell contacts was the impetus for the increase in miRNA processing. The authors further determined that the abundance of pri-miRNA transcript was not increased by the status of cell confluence with the interesting exception of miR-34a. Such information along with additional experiments indicated that this regulation was caused by an increase in efficiency of the Drosha microprocessor as well as formation of mature miRISC complexes at the Dicer processing step [69].

In light of the study discussed earlier indicating the role of p53 in Drosha processing, it is very likely that this regulation could be due to p53 activity. Along with the non-transcriptional induction of miR-15a, miR-16, miR-26a, and miR-145, the observation that miR-34a was the only transcriptionally regulated miRNA in both studies 
is the key to linking these two studies together. Furthermore, p53 has been implicated as an important mediator for the density-dependant growth inhibition of cells. One study shows that inhibition of p53 led to the loss of density-dependent growth inhibition, leading to increased cell density and decreased apoptosis. While no increase of p53 expression was observed, basal levels were sufficient to cause growth arrest [70]. The studies by Suzuki et al. and Hwang et al. may, at least in part, be able to explain how p53 can cause density-dependent growth inhibition. While most of the miRNAs observed to be up regulated by Hwang et al. are involved in growth inhibition, some are strongly associated with proliferation and tumorigenesis, like miR-21. This may indicate that additional proteins are involved in the effect of cell confluence- or cell-to-cell interactionmediated miRNA processing. It would be of interest to determine if the effect seen on processing efficiency by Dicer and miRISC formation is also due to p53 activity or to additional modulators of miRNA processing.

\section{Inhibition of miRNA biogenesis by estrogen}

Estrogen hormones are well known regulators for transcription and posttranscriptional events of a number of genes through binding to their specific nuclear estrogen receptors (ERs), ER $\alpha$ or ER $\beta$. Although both receptors exhibit a similar affinity toward estrogen, a distinction in tissue distribution between ER $\alpha$ and $\operatorname{ER} \beta$ has long been recognized. ER $\alpha$ is mainly found in endometrium, breast cancer cells, ovarian stroma cells, and in the hypothalamus, whereas ER $\beta$ appears to be ubiquitously expressed. By using embryos derived from female mice with a genetic deficiency of ER $\alpha$, a recent study by Yamagata et al.[71] reported an upregulation of some miRNAs. Conversely, such an upregulation was reversed by estrogen (E2) treatment, suggesting that estrogen 
and its receptor signaling are negative regulators for certain miRNAs, including miR-16, miR-26a, miR-29a, miR-125a, miR-143, miR-145, miR-195, etc.. Further studies indicate that the negative regulation of $\operatorname{ER} \alpha$ on these miRNAs occurred at the level of pri-miRNA processing, rather than transcription. A direct physical association of the E2bound $\mathrm{ER} \alpha$ with Drosha microprocessor components, p68 and p72, was noted in an immunoprecipitation assay. The regulation of $\mathrm{ER} \alpha$ on miRNA biogenesis was also validated in human cells. Collectively, these data suggest that E2-ER $\alpha$ signaling is antagonistic for miRNA processing, possibly through direct interaction between ER $\alpha$ and p68/p72, leading to dissociation of the Drosha microprocessor from a subset of primiRNAs.

The evidence showing inhibitory roles of $\operatorname{ER} \alpha$ on the biogenesis of a select subset of miRNAs provides a new explanation for the molecular mechanisms of the ER $\alpha$ positive breast cancers. Due to its negative regulation on some of these tumor suppressor-like miRNAs, including miR-16 and miR-26a, ER $\alpha$ can amplify the tumorigenic signals from VEGF [71], EZH2 [72] and some oncogenes that are targeted by miR-16 or miR-26a in breast epithelial cells. Thus, there is strong indication for pursuing an ER $\alpha$-based therapeutic approach. First, suppression of the ER $\alpha$ signaling by selective ER $\alpha$ modulators, such as tamoxifen, can inactivate transcriptional regulation of $\mathrm{ER} \alpha$ on some growth factors important for the transformation of the cells. Second, blocking $\mathrm{ER} \alpha$ signaling will enhance the tumor suppressive potential of the cells by promoting the biogenesis of those tumor suppressor-like miRNAs, which limit the growth and vascularization of the tumors. 


\section{Summary and Conclusions:}

An underlying theme in the regulation of miRNA biogenesis at the Drosha processing step seems to be that regulatory proteins selectively alter the expression of certain subsets of miRNAs. This is not entirely surprising, as the cellular functions of miRNAs are diverse, and global up-regulation or down-regulation of all miRNAs might cause havoc on cellular systems. The miRNA subsets whose expression are altered by the regulatory proteins discussed above seem to be in line with the traditionally accepted roles for those proteins. As more and more regulatory proteins are discovered for all steps of miRNA production and processing, it is most likely that this theme will be extended. The activation of Smad proteins is associated with cell growth and transformation, and the miRNAs that are regulated by Smads are associated with similar effects. On the other hand, expression and activation of p53 is a well known mechanism of cell cycle arrest and apoptosis, and its downstream miRNAs can be effectors of the same pathways. While Ars2 is not a very well-studied protein and its detailed function remains to be fully elucidated, recent research shows that it is involved in cell proliferation. Likewise, the miRNAs that Ars2 has been shown to regulate are involved in similar cellular functions. Additional research should be done to delineate exactly which miRNAs are in each regulated subset. This information would be useful for determining if therapeutic intervention of proteins, such as Ars2, would be a fruitful endeavor.

One exception to the theme is the observed activation of miRNA biogenesis by cell-to-cell contacts. This effect appears to be global (with few exceptions), including the expression of miRNA that have historically opposite effects. Cellular signaling that 
occurs during quiescence is highly complex, and the study by Hwang et al. now places miRNA expression into the mix [69].

As the study of miRNA biogenesis continues, it is apparent that more proteins will be discovered to play regulatory roles at various processing steps. It will be important to determine whether or not these proteins or processing pathways are legitimate targets for therapeutic intervention. It is becoming increasingly clear that subsets of miRNA play important roles in multiple disease states. If there are master regulators of expression of these subsets, they could be potential targets for intervention and may be critical for the alleviation of symptoms or reversal of disease. 


\section{References:}

1. Davis BN, Hata A: Regulation of MicroRNA Biogenesis: A miRiad of mechanisms. Cell Commun Signal 2009, 7:18.

2. Lee Y, Jeon K, Lee JT, Kim S, Kim VN: MicroRNA maturation: stepwise processing and subcellular localization. EMBO J 2002, 21:4663-4670.

3. Hutvagner G, McLachlan J, Pasquinelli AE, Balint E, Tuschl T, Zamore PD: A cellular function for the RNA-interference enzyme Dicer in the maturation of the let-7 small temporal RNA. Science 2001, 293:834-838.

4. Lee Y, Ahn C, Han J, Choi H, Kim J, Yim J, Lee J, Provost P, Radmark O, Kim S, Kim VN: The nuclear RNase III Drosha initiates microRNA processing. Nature 2003, 425:415-419.

5. Yi R, Qin Y, Macara IG, Cullen BR: Exportin-5 mediates the nuclear export of pre-microRNAs and short hairpin RNAs. Genes Dev 2003, 17:3011-3016.

6. Bohnsack MT, Czaplinski K, Gorlich D: Exportin 5 is a RanGTP-dependent dsRNA-binding protein that mediates nuclear export of pre-miRNAs. $R N A$ 2004, 10:185-191.

7. Lund E, Guttinger S, Calado A, Dahlberg JE, Kutay U: Nuclear export of microRNA precursors. Science 2004, 303:95-98.

8. Zeng Y, Cullen BR: Structural requirements for pre-microRNA binding and nuclear export by Exportin 5. Nucleic Acids Res 2004, 32:4776-4785.

9. Bernstein E, Caudy AA, Hammond SM, Hannon GJ: Role for a bidentate ribonuclease in the initiation step of RNA interference. Nature 2001, 409:363366.

10. Ketting RF, Fischer SE, Bernstein E, Sijen T, Hannon GJ, Plasterk RH: Dicer functions in RNA interference and in synthesis of small RNA involved in developmental timing in C. elegans. Genes Dev 2001, 15:2654-2659.

11. Knight SW, Bass BL: A role for the RNase III enzyme DCR-1 in RNA interference and germ line development in Caenorhabditis elegans. Science 2001, 293:2269-2271.

12. Zhang H, Kolb FA, Brondani V, Billy E, Filipowicz W: Human Dicer preferentially cleaves dsRNAs at their termini without a requirement for ATP. EMBO J 2002, 21:5875-5885.

13. MacRae IJ, Zhou K, Doudna JA: Structural determinants of RNA recognition and cleavage by Dicer. Nat Struct Mol Biol 2007, 14:934-940. 
14. Khvorova A, Reynolds A, Jayasena SD: Functional siRNAs and miRNAs exhibit strand bias. Cell 2003, 115:209-216.

15. Gregory RI, Chendrimada TP, Cooch N, Shiekhattar R: Human RISC couples microRNA biogenesis and posttranscriptional gene silencing. Cell 2005, 123:631-640.

16. Pusch O, Boden D, Silbermann R, Lee F, Tucker L, Ramratnam B: Nucleotide sequence homology requirements of HIV-1-specific short hairpin RNA. Nucleic Acids Res 2003, 31:6444-6449.

17. Stark A, Brennecke J, Russell RB, Cohen SM: Identification of Drosophila MicroRNA targets. PLoS Biol 2003, 1:E60.

18. Lal A, Navarro F, Maher CA, Maliszewski LE, Yan N, O'Day E, Chowdhury D, Dykxhoorn DM, Tsai P, Hofmann O, et al: miR-24 Inhibits cell proliferation by targeting E2F2, MYC, and other cell-cycle genes via binding to "seedless" 3'UTR microRNA recognition elements. Mol Cell 2009, 35:610-625.

19. Cannell IG, Kong YW, Bushell M: How do microRNAs regulate gene expression? Biochem Soc Trans 2008, 36:1224-1231.

20. Zamore PD, Tuschl T, Sharp PA, Bartel DP: RNAi: double-stranded RNA directs the ATP-dependent cleavage of mRNA at 21 to 23 nucleotide intervals. Cell 2000, 101:25-33.

21. Moss EG, Lee RC, Ambros V: The cold shock domain protein LIN-28 controls developmental timing in $\mathrm{C}$. elegans and is regulated by the lin-4 RNA. Cell 1997, 88:637-646.

22. Vella MC, Reinert K, Slack FJ: Architecture of a validated microRNA::target interaction. Chem Biol 2004, 11:1619-1623.

23. Wu L, Belasco JG: Let me count the ways: mechanisms of gene regulation by miRNAs and siRNAs. Mol Cell 2008, 29:1-7.

24. Pillai RS, Bhattacharyya SN, Artus CG, Zoller T, Cougot N, Basyuk E, Bertrand E, Filipowicz W: Inhibition of translational initiation by Let-7 MicroRNA in human cells. Science 2005, 309:1573-1576.

25. Kiriakidou M, Tan GS, Lamprinaki S, De Planell-Saguer M, Nelson PT, Mourelatos Z: An mRNA m7G cap binding-like motif within human Ago2 represses translation. Cell 2007, 129:1141-1151.

26. Liu J, Valencia-Sanchez MA, Hannon GJ, Parker R: MicroRNA-dependent localization of targeted mRNAs to mammalian P-bodies. Nat Cell Biol 2005, 7:719-723. 
27. Wu L, Fan J, Belasco JG: MicroRNAs direct rapid deadenylation of mRNA. Proc Natl Acad Sci U S A 2006, 103:4034-4039.

28. Rehwinkel J, Behm-Ansmant I, Gatfield D, Izaurralde E: A crucial role for GW182 and the DCP1:DCP2 decapping complex in miRNA-mediated gene silencing. $R N A$ 2005, 11:1640-1647.

29. Jackson RJ, Standart N: How do microRNAs regulate gene expression? Sci STKE 2007, 2007:re1.

30. Seitz H, Zamore PD: Rethinking the microprocessor. Cell 2006, 125:827-829.

31. Morlando M, Ballarino M, Gromak N, Pagano F, Bozzoni I, Proudfoot NJ: Primary microRNA transcripts are processed co-transcriptionally. Nat Struct Mol Biol 2008, 15:902-909.

32. Gregory RI, Yan KP, Amuthan G, Chendrimada T, Doratotaj B, Cooch N, Shiekhattar R: The Microprocessor complex mediates the genesis of microRNAs. Nature 2004, 432:235-240.

33. Han J, Lee Y, Yeom KH, Kim YK, Jin H, Kim VN: The Drosha-DGCR8 complex in primary microRNA processing. Genes Dev 2004, 18:3016-3027.

34. Zeng Y, Yi R, Cullen BR: Recognition and cleavage of primary microRNA precursors by the nuclear processing enzyme Drosha. EMBO J 2005, 24:138148.

35. Chen CZ, Li L, Lodish HF, Bartel DP: MicroRNAs modulate hematopoietic lineage differentiation. Science 2004, 303:83-86.

36. Han J, Lee Y, Yeom KH, Nam JW, Heo I, Rhee JK, Sohn SY, Cho Y, Zhang BT, Kim VN: Molecular basis for the recognition of primary microRNAs by the Drosha-DGCR8 complex. Cell 2006, 125:887-901.

37. Shiohama A, Sasaki T, Noda S, Minoshima S, Shimizu N: Nucleolar localization of DGCR8 and identification of eleven DGCR8-associated proteins. Exp Cell Res 2007, 313:4196-4207.

38. Fuller-Pace FV: DExD/H box RNA helicases: multifunctional proteins with important roles in transcriptional regulation. Nucleic Acids Res 2006, 34:4206-4215.

39. Fukuda T, Yamagata K, Fujiyama S, Matsumoto T, Koshida I, Yoshimura K, Mihara M, Naitou M, Endoh H, Nakamura T, et al: DEAD-box RNA helicase subunits of the Drosha complex are required for processing of rRNA and a subset of microRNAs. Nat Cell Biol 2007, 9:604-611. 
40. Davis BN, Hilyard AC, Lagna G, Hata A: SMAD proteins control DROSHAmediated microRNA maturation. Nature 2008, 454:56-61.

41. Warner DR, Bhattacherjee V, Yin X, Singh S, Mukhopadhyay P, Pisano MM, Greene RM: Functional interaction between Smad, CREB binding protein, and p68 RNA helicase. Biochem Biophys Res Commun 2004, 324:70-76.

42. Krichevsky AM, Gabriely G: miR-21: a small multi-faceted RNA. J Cell Mol Med 2009, 13:39-53.

43. Selcuklu SD, Donoghue MT, Spillane C: miR-21 as a key regulator of oncogenic processes. Biochem Soc Trans 2009, 37:918-925.

44. Yamanaka Y, Tagawa H, Takahashi N, Watanabe A, Guo YM, Iwamoto K, Yamashita J, Saitoh H, Kameoka Y, Shimizu N, et al: Aberrant overexpression of microRNAs activate AKT signaling via downregulation of tumor suppressors in NK-cell lymphoma/leukemia. Blood 2009.

45. Asangani IA, Rasheed SA, Nikolova DA, Leupold JH, Colburn NH, Post S, Allgayer H: MicroRNA-21 (miR-21) post-transcriptionally downregulates tumor suppressor Pdcd4 and stimulates invasion, intravasation and metastasis in colorectal cancer. Oncogene 2008, 27:2128-2136.

46. Garzon R, Volinia S, Liu CG, Fernandez-Cymering C, Palumbo T, Pichiorri F, Fabbri M, Coombes K, Alder H, Nakamura T, et al: MicroRNA signatures associated with cytogenetics and prognosis in acute myeloid leukemia. Blood 2008, 111:3183-3189.

47. Chen R, Alvero AB, Silasi DA, Kelly MG, Fest S, Visintin I, Leiser A, Schwartz PE, Rutherford T, Mor G: Regulation of IKKbeta by miR-199a affects NFkappaB activity in ovarian cancer cells. Oncogene 2008, 27:4712-4723.

48. Kong W, Yang H, He L, Zhao JJ, Coppola D, Dalton WS, Cheng JQ: MicroRNA-155 is regulated by the transforming growth factor beta/Smad pathway and contributes to epithelial cell plasticity by targeting RhoA. Mol Cell Biol 2008, 28:6773-6784.

49. Yang H, Kong W, He L, Zhao JJ, O'Donnell JD, Wang J, Wenham RM, Coppola D, Kruk PA, Nicosia SV, Cheng JQ: MicroRNA expression profiling in human ovarian cancer: miR-214 induces cell survival and cisplatin resistance by targeting PTEN. Cancer Res 2008, 68:425-433.

50. Suzuki HI, Yamagata K, Sugimoto K, Iwamoto T, Kato S, Miyazono K: Modulation of microRNA processing by p53. Nature 2009, 460:529-533.

51. Bates GJ, Nicol SM, Wilson BJ, Jacobs AM, Bourdon JC, Wardrop J, Gregory DJ, Lane DP, Perkins ND, Fuller-Pace FV: The DEAD box protein p68: a novel 
transcriptional coactivator of the p53 tumour suppressor. EMBO J 2005, 24:543-553.

52. Raver-Shapira N, Marciano E, Meiri E, Spector Y, Rosenfeld N, Moskovits N, Bentwich Z, Oren M: Transcriptional activation of miR-34a contributes to p53-mediated apoptosis. Mol Cell 2007, 26:731-743.

53. Zenz T, Mohr J, Eldering E, Kater AP, Buhler A, Kienle D, Winkler D, Durig J, van Oers $\mathrm{MH}$, Mertens $\mathrm{D}$, et al: miR-34a as part of the resistance network in chronic lymphocytic leukemia. Blood 2009, 113:3801-3808.

54. Fujita Y, Kojima K, Hamada N, Ohhashi R, Akao Y, Nozawa Y, Deguchi T, Ito $\mathrm{M}$ : Effects of miR-34a on cell growth and chemoresistance in prostate cancer PC3 cells. Biochem Biophys Res Commun 2008, 377:114-119.

55. Tazawa H, Tsuchiya N, Izumiya M, Nakagama H: Tumor-suppressive miR-34a induces senescence-like growth arrest through modulation of the E2F pathway in human colon cancer cells. Proc Natl Acad Sci U S A 2007, 104:15472-15477.

56. Li Y, Guessous F, Zhang Y, Dipierro C, Kefas B, Johnson E, Marcinkiewicz L, Jiang J, Yang Y, Schmittgen TD, et al: MicroRNA-34a Inhibits Glioblastoma Growth by Targeting Multiple Oncogenes. Cancer Res 2009.

57. Lerner M, Harada M, Loven J, Castro J, Davis Z, Oscier D, Henriksson M, Sangfelt O, Grander D, Corcoran MM: DLEU2, frequently deleted in malignancy, functions as a critical host gene of the cell cycle inhibitory microRNAs miR-15a and miR-16-1. Exp Cell Res 2009.

58. Cimmino A, Calin GA, Fabbri M, Iorio MV, Ferracin M, Shimizu M, Wojcik SE, Aqeilan RI, Zupo S, Dono M, et al: miR-15 and miR-16 induce apoptosis by targeting BCL2. Proc Natl Acad Sci U S A 2005, 102:13944-13949.

59. Bonci D, Coppola V, Musumeci M, Addario A, Giuffrida R, Memeo L, D'Urso L, Pagliuca A, Biffoni M, Labbaye C, et al: The miR-15a-miR-16-1 cluster controls prostate cancer by targeting multiple oncogenic activities. Nat Med 2008, 14:1271-1277.

60. Slaby O, Svoboda M, Fabian P, Smerdova T, Knoflickova D, Bednarikova M, Nenutil R, Vyzula R: Altered expression of miR-21, miR-31, miR-143 and miR-145 is related to clinicopathologic features of colorectal cancer. Oncology 2007, 72:397-402.

61. Motoyama K, Inoue H, Takatsuno Y, Tanaka F, Mimori K, Uetake H, Sugihara $\mathrm{K}$, Mori M: Over- and under-expressed microRNAs in human colorectal cancer. Int J Oncol 2009, 34:1069-1075. 
62. Ng EK, Tsang WP, Ng SS, Jin HC, Yu J, Li JJ, Rocken C, Ebert MP, Kwok TT, Sung JJ: MicroRNA-143 targets DNA methyltransferases 3A in colorectal cancer. Br J Cancer 2009, 101:699-706.

63. Chen X, Guo X, Zhang H, Xiang Y, Chen J, Yin Y, Cai X, Wang K, Wang G, Ba $\mathrm{Y}$, et al: Role of miR-143 targeting KRAS in colorectal tumorigenesis. Oncogene 2009, 28:1385-1392.

64. Wang S, Bian C, Yang Z, Bo Y, Li J, Zeng L, Zhou H, Zhao RC: miR-145 inhibits breast cancer cell growth through RTKN. Int J Oncol 2009, 34:14611466.

65. Wilson MD, Wang D, Wagner R, Breyssens H, Gertsenstein M, Lobe C, Lu X, Nagy A, Burke RD, Koop BF, Howard PL: ARS2 is a conserved eukaryotic gene essential for early mammalian development. Mol Cell Biol 2008, 28:1503-1514.

66. Gruber JJ, Zatechka DS, Sabin LR, Yong J, Lum JJ, Kong M, Zong WX, Zhang $\mathrm{Z}$, Lau CK, Rawlings J, et al: Ars2 links the nuclear cap-binding complex to RNA interference and cell proliferation. Cell 2009, 138:328-339.

67. Dong Z, Han MH, Fedoroff N: The RNA-binding proteins HYL1 and SE promote accurate in vitro processing of pri-miRNA by DCL1. Proc Natl Acad Sci U S A 2008, 105:9970-9975.

68. Sabin LR, Zhou R, Gruber JJ, Lukinova N, Bambina S, Berman A, Lau CK, Thompson CB, Cherry S: Ars2 regulates both miRNA- and siRNA- dependent silencing and suppresses RNA virus infection in Drosophila. Cell 2009, 138:340-351.

69. Hwang HW, Wentzel EA, Mendell JT: Cell-cell contact globally activates microRNA biogenesis. Proc Natl Acad Sci U S A 2009, 106:7016-7021.

70. Meerson A, Milyavsky M, Rotter V: p53 mediates density-dependent growth arrest. FEBS Lett 2004, 559:152-158.

71. Yamagata KF, S. Ito, S. Ueda, T. Murata, T. Naitou, M. Takeyama, K. Minami, Y. O'Malley, BW. Kato, S. : Maturation of MicroRNA Is Hormonally Regulated by a Nuclear Receptor. Mol Cell 2009, 36:340-347.

72. Wong CF, Tellam RL: MicroRNA-26a targets the histone methyltransferase Enhancer of Zeste homolog 2 during myogenesis. J Biol Chem 2008, 283:9836-9843. 


\section{Figures:}

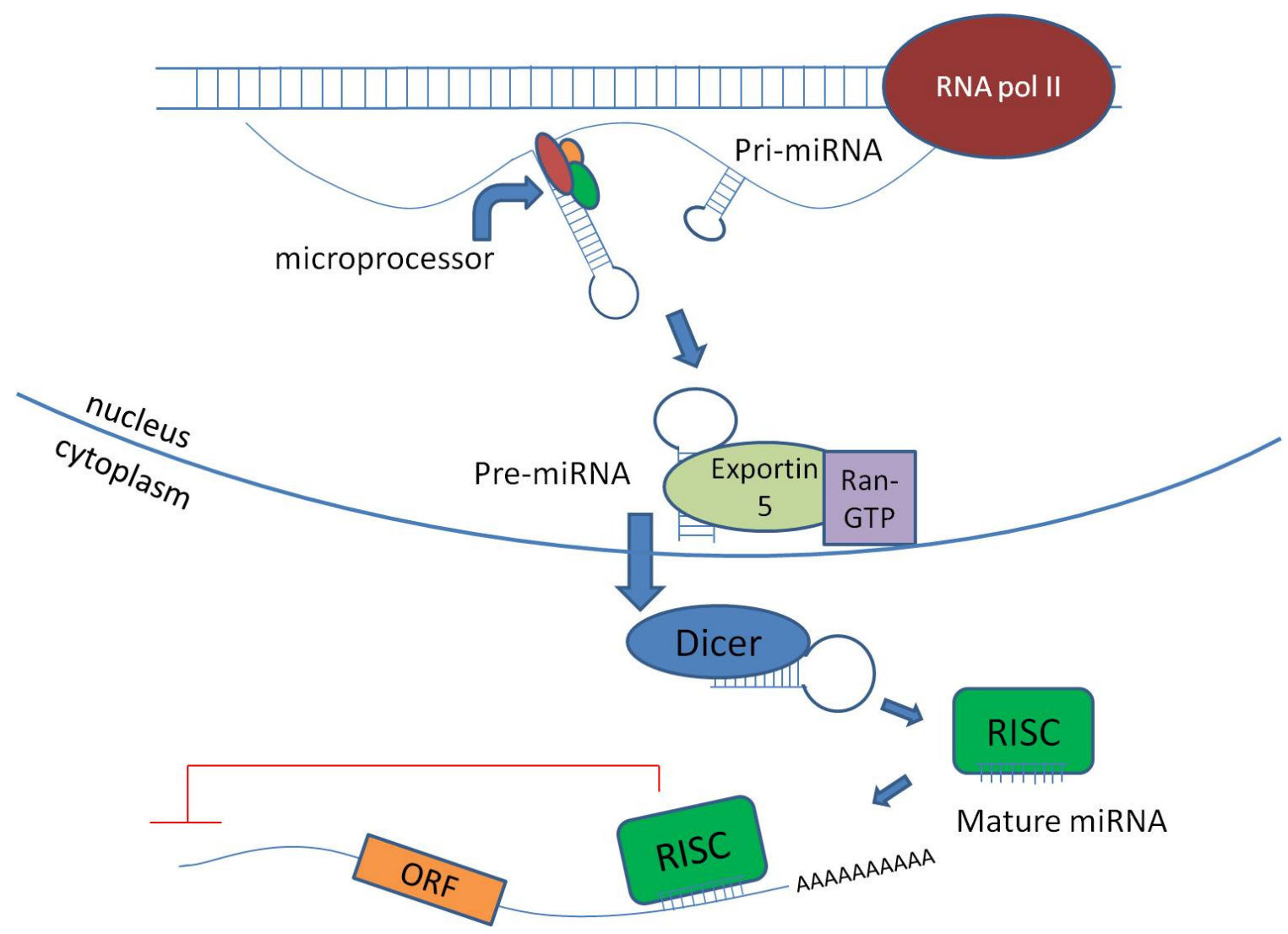

Figure 1. MicroRNA (miRNA) production and processing. The pri-miRNA transcript is transcribed by RNA polymerase II. The stem loop structure is cleaved off by the microprocessor to generate pre-miRNA. The pre-miRNA is exported to the cytoplasm by exportin5 in a ran-GTP dependent manner. Once in the cytoplasm, the pre-miRNA is processed by Dicer creating a single stranded mature miRNA. This mature miRNA is bound by the RISC complex, guiding it to the 3'UTR of target mRNAs, leading to repression of protein expression. 


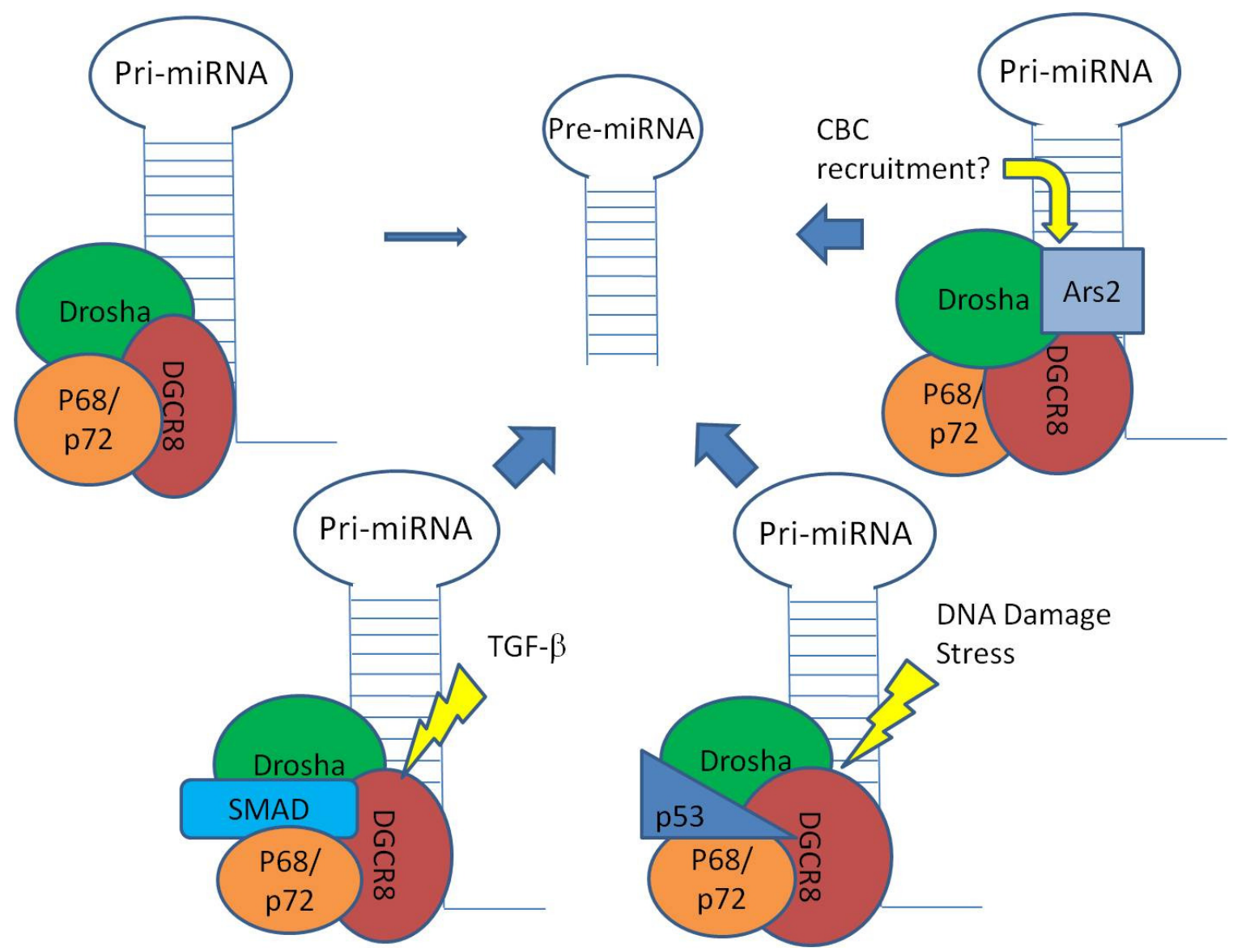

Figure 2. Modulation of microprocessor function by SMAD, p53 and Ars2 in response to TGF- $\beta$, p53 and stress signaling, respectively. 


\title{
CURRICULUM VITAE
}

\section{Kevin J Beezhold}

PhD Candidate, (expected Fall 2011)

Department of Cancer Cell Biology

West Virginia University

Work Address:

\author{
National Institute for Occupational Safety and Health \\ Health Effects Laboratory Division \\ Pathology and Physiology Research Branch \\ 1095 Willowdale Road \\ Morgantown, WV 26505-2888 \\ (304)285-5767 \\ E-Mail: $\underline{\text { PZZ8@cdc.gov }}$
}

\section{Education}

2002-2006

BA in Biology from Trinity Christian College

2007-Present Cancer Cell Biology from West Virginia University

\section{Work Experience}

2007-present Regular Fellow, NIOSH, Morgantown

\section{Internship}

- Research Assistant (Volunteer), NIOSH, Morgantown June-August (2004) 


\section{Presentations/Conferences}

- 39th Annual ACCA Student Symposium (2006)

- WVU Van Liere Convocation and Research Day (2008)

- WVU Van Liere Convocation and Research Day (2009)

- Allegeny-Erie Society of Toxicology Spring meeting (2010)

- WVU Van Liere Convocation and Research Day (2010)

- $49^{\text {th }}$ Annual Society of Toxicology meeting (poster) (2010)

- $6^{\text {th }}$ Conference on Molecular Mechanisms of Metal Toxicity and Carcinogenesis (poster) 2010)

- Allegeny-Erie Society of Toxicology Spring meeting (2011)

\section{Awards}

- 2009 Allegheny-Erie Society of Toxicology student research award (9/24/09)

\section{Journal Article}

\section{Publications}

1. Beezhold K, Liu J, Kan H, Meighan T, Castranova V, Shi X, Chen F [2011]. miR-190mediated downregulation of PHLPP contributes to arsenic-induced Akt activation and carcinogenesis. Toxicol Sci Published online July12, 2011

2. Beezhold K, Castranova V, Chen F [2010]. Microprocessor of miRNAs: regulation and potential for therapeutic intervention. Mol Cancer 9:134

3. Chen F, Beezhold K, Castranova V [2009]. JNK1, a potential therapeutic target for hepatocellular carcinoma. Biochim Biophys Acta 1796(2) 242-251

4. Chang Q, Chen J, Beezhold K, Castranova V, Shi X, Chen F [2009]. JNK1 activation predicts the prognostic outcome of the human hepatocellular carcinoma. Mol Cancer $8(64): 1-14$.

5. Lu Y, Chang Q, Zhang Y, Beezhold K, Rojanasakul Y, Zhao H, Castranova V, Shi X, Chen F [2009]. Lung cancer-associated JmjC domain protein mdig suppresses formation of tri-methyl lysine 9 of histone H3. Cell Cycle 8(13):2101-2109. 
6. Zhang Y, Beezhold K, Castranova V, Shi X, Chen F [2009]. Characterization of an alternatively spliced GADD45 $\alpha$, GADD45 $\xi 1$ isoform by arsenic-treated epithelial cells. Mol Carcinog 48(5):454-464.

7. Chang Q, Zhang Y, Beezhold K, Bhatia D, Zhao H, Chen J, Castranova V, Shi X, Chen F [2009]. Sustained JNK1 activation is associated with altered histone H3 methylations in human liver cancer. J Hepatol 50(2):323-333.

8. Chen F, Beezhold K, Castranova V [2008]. Tumor promoting or tumor suppressing of NF-kB, a matter of cell context dependency. Int Rev Immunol 27(4):183-204.

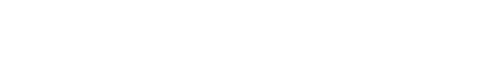 Virginia University Libraries,
ou=Acquisitions Department

